\title{
II. Auffächerungen in den drei Wissenschaftstraditionen
}

\section{Noch einmal zum Beweisen: Die Rolle der Mathematisierung}

»Alles was Gegenstand des wissenschaftlichen Denkens überhaupt sein kann, verfällt, sobald es zur Bildung einer Theorie reif ist, der axiomatischen Methode und damit unmittelbar der Mathematik. ${ }^{1}$

- das lesen wir bei David Hilbert, einem der führenden Vertreter der modernen Mathematik zu Beginn des 20. Jahrhunderts. Dass Wissenschaft idealerweise exakte Wissenschaft sein soll, und Exaktheit sich in mathematischen Verfahren ausdrückt, ist aber auch hundert Jahre später verbreitete Meinung. Doch was hat es mit dieser Meinung auf sich? Worin begründet sie sich? Und was ist das Kernmotiv dieser Auffassung?

Auch hier wird uns eine historische Perspektive, ein Blick auf die Genese dieser Denkfigur helfen. Die axiomatische Methode, von der Hilbert spricht, hat eine ihrer wichtigsten Quellen - wie könnte es anders sein - in der Zweiten Analytik des Aristoteles. Allerdings geht es dort, wie wir gesehen haben, nicht um eine im engeren Sinne mathematische, sondern um eine allgemeine Beweislehre. Beispiele aus der Geometrie und aus der Arithmetik stehen hier neben Beispielen aus der Astronomie und der Politik. Im Kontext seiner allgemeinen Beweislehre gibt Aristoteles dem Begriff axioma in der Zweiten Analytik eine spezifische Bedeutung, nämlich den eines Ausgangspunktes und einer Voraussetzung von erschließbarem Wissen. ${ }^{2}$

1 David Hilbert: Axiomatisches Denken (1918). In: David Hilbert: Hilbertiana. FünfAufsätze von David Hilbert, Darmstadt 1964, S. 1-11, hier S. 11.

2 Wie grundsätzlich diese Voraussetzungen zu verstehen sind, darüber streitet die Aristoteles-Forschung. Sind damit die jeweiligen Prinzipien gemeint, wie, in den Beispielen oben, 


\section{BASISWISSEN 4: Axiome - Grundlagen von Schlussfolgerungen}

Bei Aristoteles hieß axioma zunächst schlicht: der im Disput eingesetzte Satz, für den Zustimmung eingefordert wird - im Sinne von >Wir können doch davon ausgehen, dass .... (vgl. Topik 155b) In den Analytiken wird der Begriff nun zugespitzt auf dasjenige, woraus bewiesen wird. (vgl. 76b 14) Es geht dabei um die allgemeinen und prinzipiellen Voraussetzungen, die einem beweiskräftigen Syllogismus zugrunde liegen. In der Zweiten Analytik wird der Begriff Axiom so eingeführt: Ein Axiom sei ein im logischen Schließen (Syllogismos) eingesetztes Prinzip, das zum Wissenserwerb notwendig ist. (vgl. 72a 15ff.) Dabei werde das Wissen im Modus des Beweisens durch dreierlei bestimmt:

1. das Gesetzte (die vorausgesetzten Gegenstände, um deren Eigenschaften es geht);

2. die Axiome, aus denen bewiesen wird, und

3. die Eigenschaften, die das Bezeichnete annimmt. (Vgl. 76bi3ff.)

Hören wir uns - im Originalton Aristoteles - an, wie sich die drei Dinge in der Erkenntnis durch ein logisches Beweisverfahren wiederfinden. Frage ist (es geht um den Perserkrieg) (vgl.94a 36f.)

»Was war die Ursache, dass die Athener mit Krieg überzogen wurden? Weil sie mit denen aus Eritrea die Stadt Sardis angriffen. Denn das gab

dass Lichter nur in der Ferne funkeln oder dass beleuchtete Gegenstände Schatten werfen, oder nur Voraussetzungen allgemeinster Art wie der Satz vom Widerspruch, oder, dass ein Abzug des Cleichen vom Gleichen wiederum Gleiches ergibt? Jedenfalls geht es um Wahrheiten, die - gleichsam - für sich selbst sprechen und als Crundlage einer logischen Schlussfolgerung (Syllogismos) dienen - sei es im Disput, sei es in einem Beweisverfahren. Umstritten ist auch, ob der Begriff des Axioms aus der Mathematik in die Philosophie oder aus der Philosophie in die Mathematik gelangte. Die Geschichte der wechselseitigen Übernahmen ist schon in der Antike ziemlich verwickelt. Vgl. Árpád Szabo: Anfänge der griechischen Mathematik, Wien 1969, S. 302-416; Aristoteles-Handbuch. Leben-Werk-Wirkung, hrsg. v. Christof Rapp u. Klaus Corcilius, Stuttgart 2011, insbes. S. 47-52. 
den ersten Anstoß. Krieg soll A sein, zuerst angreifen B, Athener das C. Es kommt also B dem C zu, zuerst angreifen den Athenern, $A$ aber dem B; denn man führt gegen diejenigen Krieg, die zuerst eine Unbilde zugefügt haben. Mithin kommt dem B das A zu, daß man gegen die, die zuerst angefangen haben, Krieg führt, dieses $B$ aber den Athenern, weil sie zuerst angefangen haben.«(94a,b übers. Rolfes)

Legt man diesen Syllogimos in die drei genannten Elemente aus, dann stellt sich das folgendermaßen dar:

1. Die Gegenstände sind: Krieg A; Zuerst angreifen B, Athener C.

2. Das Axiom (axioma) ist: Wer zuerst angreift und Unrecht tut, wird mit Krieg überzogen

3. Zukommende Eigenschaften: den Athenern kommt die Eigenschaft $\mathrm{zu}$, mit dem Krieg begonnen zu haben.

So bilden die drei genannten Elemente gleichsam die Spielaufstellung. Nun muss nur noch gespielt werden. Dabei ist (3.) schon der erste Zug, aus dem sich das Folgende notwendig ergibt: Denn setzt man die Athener als Kriegsbeginner ein, so ergibt sich unter dem allgemeinen Prinzip, dass, wer Wind sät, Sturm erntet (um eine sprichwörtlich gewordene Version des Grundsatzes einzusetzen), dass die Athener Kriegsgewalt erleiden - und zwar notwendig.

Die bereits in der Antike nicht ganz einfach zu entwirrenden Verwicklungen um den Begriff Axiom traten in eine neue Phase, als im 12. Jahrhundert nicht nur die Zweite Analytik wieder auftauchte, sondern zeitgleich auch die Elemente des Euklids, das einflussreichste Lehrbuch der antiken Geometrie, vollständig übersetzt und zugänglich wurde. ${ }^{3}$

3 Vgl. Mechthild Dreyer: More Mathematicorum. Rezeption und Transformation der antiken Gestalten wissenschaftlichen Wissens im 12. Jahrhundert, Münster 1996, S. 82-91. 
Robert Grosseteste (1168-1253), der in Oxford einen der frühesten Kommentare zur Zweiten Analytik verfasste, gilt - gemäß einer einflussreichen Studie aus den 1950er Jahren- als einer der Begründer der modernen, experimentellen Wissenschaften. ${ }^{4}$ Diese enthusiastische Einschätzung ist zwar inzwischen einem nüchternen Blick gewichen, ${ }^{5}$ aber an einem Punkt bricht Grosseteste tatsächlich mit dem aristotelischen Denken - und dies ist der Punkt der Rolle der Mathematik. Waren für Aristoteles die Beispiele aus der Geometrie Beispiele unter anderen für das übergreifende Verfahren der apodeixis, so wird bei Grosseteste das geometrische Demonstrieren zur Idealform der Wissensgenese. Im Rahmen der umfassenden aristotelischen Wissenschaftslehre, wie sie im 12. und 13. Jahrhundert aufgefasst wurde, rückt nun die Geometrie an die Stelle einer sprachlichen Syllogistik. ${ }^{6}$ Nach der Weise der Geometrie - »more geometrico « zu verfahren, wird jetzt zu einem Slogan. Hinter diesem zunächst kaum merklichen Paradigmenwechsel steht eine Zusammenführung mit der Euklidischen Geometrie: »Grosseteste is not simply giving a reading of Aristotle's Posterior Analytics alone. Indeed, it is a reading of Aristotle-Euclid together «. ${ }^{7}$

Doch was hat es mit Euklid und dem geometrischen Verfahren auf sich?

Euklid, wohl etwas jünger als Aristoteles, hatte das mathematische Wissen seiner Zeit in einer systematischen Darstellung integriert. Zwar taucht in diesem Text das Wort Axiom nicht auf, doch hatten sich die historischen Verwicklungen in systematische Parallelen niedergeschlagen, die dann in der

4 A. C. Crombie: Robert Grosseteste And the Origins of Experimental Science. 1100-1700, Oxford 1953.

5 Vgl. Andreas Speer: Scientia demonstrativa et universaliter ars faciens scire. Zur methodischen Grundlegung einer Wissenschaft von der Natur durch Robert Grosseste. In. Erfahrung und Beweis. Experience and Demonstration, hrsg. v. Alexander Fidora u. Matthias Lutz-Bachmann, Berlin 2007, S. 25-40.

6 Allerdings ist ebenfalls festzustellen, dass sich Grossetestes Ausführungen zum experimentum durchaus im Rahmen des aristotelischen Erfahrungsbegriffs bewegen. Vgl. Jürgen Sarnowsky: »Expertus - experientia - experimentum. Neue Wege der wissenschaftlichen Erkenntnis im Spätmittelalter«, Das Mittelalter 17, 2: 47-59, doi: https:// doi.org/10.1524/mial.2012.0021.

7 Jeremiah Hackett: Robert Grosseteste and Roger Bacon on the Posterior Analytics. In: Pia Antolic-Piper/Alexander Fidora/Matthias Lutz-Bachmann (Hrsg.): Erkenntnis und Wissenschaft/Knowledge and Science: Probleme der Epistemologie in der Philosophie des Mittelalters/ Problems of Epistemology in Medieval Philosophy, Berlin 2004, S. 161-212, hier S. 166. 
Neuzeit für den Prozess der Mathematisierung von scientia entscheidend werden sollten.

Schauen wir uns die beiden Beispiele - das politische und das geometrische - im Vergleich an, dann fällt das neue Moment, das in der Mathematisierung liegt, sofort ins Auge: Das angegebene Verfahren der Konstruktion lässt sich als Beweis der Aussage verwenden, dass dieses Dreieck gleichseitig ist (»Also ist das Dreieck ABC gleichseitig.»). Der Beweis ist aber zugleich eine präskriptive Anleitung, ein Rezept: durch das vorgeführte Verfahren lassen sich gleichseitige Dreiecke herstellen. Und dass sie sich herstellen lassen, hat einen einfachen Grund: die Längen-, Lagen- und Formverhältnisse sind allesamt reine Produkte von Regelverhältnissen aus den verwendeten Definitionen, Postulaten und Denkvoraussetzungen. Man spricht hier häufig davon, dass die Mathematik mit idealisierten Entitäten arbeite, aber der Kern der Sache ist nicht einmal, dass es auf die reale (immer imperfekte) Zeichnung gar nicht ankommt, sondern dass sie mit Elementen arbeitet, die selbst vollkommen durch Regeln bestimmt sind, sich also in durchgängigen Regelverhältnissen bewegt. So schließt sich der mathematische Beweis gegenüber der Wirklichkeit, während sich der logische Beweis zur Wirklichkeit hin öffnet, indem er eine Regelform des Wirklichen auszudrücken sucht.

\section{$\checkmark$ VERTIEFEND Mathematik versus Logik}

Die Frage nach dem Verhältnis von Mathematik und Logik ist ein Problem, das die Philosophie seit langem beunruhigt. Spätestens seit dem frühen 17. Jahrhundert, seit Descartes und Galilei, hatte sich ein Zweig der Philosophie mit dem Prozedere des mathematischen Operierens eng verbunden. In deren Folgeketten schien die Notwendigkeit der Ableitungen gewährleistet, dadurch sicheres Wissen ermöglicht. Dass die Folgerichtigkeit des mathematischen Vorgehens und die Folgerichtigkeit des logischen Denkens einer weltbezogenen Sprache sich unterscheiden, kam dabei aber kaum in den Blick. Das 20. Jahrhundert war beherrscht von philosophischen Schulen, die mit einem logischen Aufbau der Sprache das leisten und absichern wollten, was mathematische Verfahren in den Wissenschaften leisten. Tatsächlich ist der Unterschied zwischen den mathematischen Verfahren und dem logischen Denken nicht leicht zu fassen. Ein Aspekt dieses Unterschieds lässt sich beleuchten, wenn wir die Rolle des Präskriptiven - also des Rezepthaften - weiter ausleuchten. Beweise zeigen Folgeketten. Sie zeigen aber nicht, was de facto woraus folgte, sondern: 


\section{BASISWISSEN 5: Beweise - Zum Verhältnis von Logik und Mathematik}

Schauen wir uns dieses Verhältnis unter der Lupe an: Die drei Elemente der Ausgangsstellung, wie sie in der Zweiten Analytik kombiniert wird, führen notwendig zu bestimmten Schlüssen. Wie sieht die Ausgangsstellung in der Geometrie, in den euklidischen Elementen aus? Auch hier finden wir eine Dreiteilung der Voraussetzungen:

1. horoi (Definitionen): z.B.: Eine Linie hat eine Länge, aber keine Breite.

2. aitemata (Postulate):z.B.:Eine gerade Strecke ist beliebigverlängerbar.

3. koinai ennoiai (gemeinsame Denkvoraussetzungen): z.B.: Gleichem das Gleiche hinzugefügt ergibt Gleiches.

Die beiden griechischen Wörter axioma und aitemata sind in ihren Ursprüngen fast gleichbedeutend: es sind allgemeine Prinzipien, deren $\mathrm{Zu}$ stimmungsfähigkeit vorausgesetzt wird. Der dritte Punkt bei Euklid entspricht den grundsätzlichsten solcher Prinzipien, die von vielen Interpreten als Axiome im aristotelischen Sinne verstanden werden. Ob das Wort Axiom bei Aristoteles nun aber die jeweiligen oder aber die grundsätzlichsten Prinzipien meint - jedenfalls finden sich bei Euklid zwei andere sprachliche Ausdrücke, die in der Überlieferung beide als Reformulierung für Axiom aufgefasst wurden. So viel zu den begriffsgeschichtlichen Verwicklungen. Von der Sache her zeigt sich nun aber etwas, das von weit größerer Tragweite ist, wenn wir uns nun einem Euklidischen Beispiel zuwenden, und zwar sogleich dem ersten Beweis in den Elementen:

»Der Beweis zeigt uns, was herauskommen soll«. So formuliert es der Philosoph, der sich sicherlich am tiefgründigsten mit Beweisen auseinandergesetzt hat, Ludwig Wittgenstein, in seinen Bemerkungen über die Grundlagen der Mathematik. Und er erklärt: »da jede Reproduktion des Beweises das Nämliche demonstrieren muss, so muss sie einerseits also das Resultat automatisch reproduzieren, anderseits aber auch den Zwang, es zu erhalten. ${ }^{8}$ Das

8 Ludwig Wittgenstein: Bemerkungen über die Grundlagen der Mathematik, Werkausgabe Bd. 6, Frankfurt a.M. 1984, S. 187. 
»\$ 1 (A. 1) Über einer gegebenen Strecke ein gleichseitiges Dreieck [zu] errichten.

Die gegebene Strecke sei $A B$. Man soll über der Strecke $A B$ ein gleichseitiges Dreieck errichten.

Mit A als Mittelpunkt und $\mathrm{AB}$ als Abstand zeichne man den Kreis B C D , ebenso mit B als Mittelpunkt und B A als Abstand den Kreis A C E; ferner ziehe man vom Punkte $C$, in dem die Kreise einander schneiden, nach den Punkten A, B die Strecken C A, C B (Post. 1)

Da Punkt A Mittelpunkt des Kreises C D B ist, ist A C =A B (I, Def. 15); ebenso ist, da Punkt B Mittelpunkt des Kreises C A E ist, B C = B A. Wie oben bewiesen, ist auch $C A=A B$; also sind $C A$ und $C B$ beide $=A B$. Was aber demselben gleich ist, ist auch einander gleich (Ax. 1); also ist auch $\mathrm{C} \mathrm{A}=\mathrm{C}$ B; also sind C A, A B, B C alle drei einander gleich.

Also ist das Dreieck A B C gleichseitig (I, Def. 20); und es ist über der gegebenen Strecke A B errichtet - dies hatte man ausführen sollen.«

Euklid: Die Elemente. Buch I-VIII. Nach Heibergs Text aus dem Griechischen übersetzt und herausgegeben von Clemens Thaer, Darmstadt 1973, S. 3-4., Abb.1.

Zwingende im Beweisen kommt aber auf unterschiedliche Weise zustande, im mathematischen Beweisen anders als im logischen. Das zeigt sich, wenn wir die Analogie zu Rezepten ausbuchstabieren:

In einem sehr lockeren Sinne ist jedes Rezept, nach dem etwas hergestellt wird, ein Beweis. Denn wenn jemand nach einem Rezept, das heißt nach Vorgaben zu Zutaten und Angaben zum Vorgehen, etwa eine SacherTorte backt, ist zugleich bewiesen, dass eben diese Zutaten und Prozesse folglich das Ergebnis einer Sacher-Torte herbeiführen, sollte diese gelingen. Das Besondere des mathematischen Beweises liegt nun in folgendem Unter- 
schied: Im Fall des Kochens und Backens wird etwas NACH Rezept, nach einer Vorschrift hergestellt: auf der einen Seite steht das Rezeptbuch, auf der anderen die Zutaten und Instrumente (dazwischen eine mehr oder weniger ausgeprägte Geschicklichkeit). In der mathematischen Konstruktion ist es anders: dabei wird nicht NACH einem Regelwerk gekocht, gebacken etc., hier wird IM Regelwerk selbst konstruiert; es ist, als würde man im Rezept selbst backen; als würde man nicht Eier, Zucker, Mehl handhaben, sondern die Buchstaben, Worte und Sätze der Rezeptur zusammenstellen, umformen, erweitern - bis eine andere Gestalt entsteht, deren Eigenschaften sich schlüssig aus den Eigenschaften der eingesetzten Elemente ergibt: z.B. Gleichseitigkeit eines Dreiecks aus der gleichen Länge der eingesetzten Strecken. Die Mathematik ist Regelwerk - in seiner Anwendung auf sich selbst. Weil Mathematik stets im eigenen Medium operiert, ist jede Konstruktion zugleich ein Beweis: es lässt sich nämlich durch zeichenhafte Operationen schlüssig eine infrage stehende Struktureigenschaft auf bekannte Struktureigenschaften zurückführen, indem aus den bekannten die infrage stehende durch Konstruktion hergestellt wird.

Im Backen dagegen liegt das Gelingen des Kuchens noch an etwas ganz anderem als im Einhalten der Regeln des Rezepts: nämlich an den Eigenschaften und dem Verhalten der eingesetzten Zutaten und Hilfsmittel - und wer je gebacken hat, weiß, wieviel dabei auf oft recht undurchschaubare Weise misslingen kann. Dies ist kein gradueller, sondern - praktisch betrachtet - ein kategorialer Unterschied: das Eine ist ein Operieren in einem Regelsystem, das Andere die Anwendung des Regelsystems auf eine andere Sphäre, auf einen Realitätsbereich eigener Art, mit allen Schwierigkeiten, die das Anwenden mit sich bringen kann.

Genau in diesem Sinne unterscheidet sich nun der syllogistische, aristotelische Beweis vom mathematischen. Denn das Wissen um die Kriegsentstehung ist ein realitätsbezogenes Wissen. Die logische Form zeigt Regelzusammenhänge auf, doch diese Regelzusammenhänge stehen in einem Verhältnis zu einer äußeren Realität, an der sie sich bewähren müssen. Man kann hier fragen: trifft es überhaupt zu, dass ..., unter welchen Bedingungen trifft zu, dass ... etc. Die aristotelische apodeixis weist logische Implikationen auf, die wahr sind unter der Bedingung, dass die Prinzipien, aus denen bewiesen wird, wahr sind. Ob diese wahr sind und ob sie als Axiome vorausgesetzt werden können, muss aber unabhängig, durch Erfahrung und Einsicht gewonnen werden und bemisst sich an dieser (siehe unten: Basiswissen Induktion). 
Das ist anders im mathematischen Beweisen: Definitionen, Postulate und allgemeine Regeln bilden hier ein vollständiges und in sich geschlossenes System, das sich von jeder äußeren Realität abzukoppeln vermag. Weil der geometrische Beweis mit abstrakten Eigenschaften operiert, die auf keine Gegenstandssphäre beschränkt sind, kann auch keine Gegenständlichkeit ihre je eigenen Bedingungen und Tendenzen ins Spiel bringen. Genau durch diese Abkopplung kann er zu einem operativen System werden, ${ }^{9}$ in dem aus Elementen und Konstellationen immer weitere Elemente und Konstellationen erschlossen werden können, ohne dass sich dies an etwas anderem bewähren müsste als an innerer Folgerichtigkeit.

Nur in vollständig formalen Zeichensprachen wie den mathematischen lassen sich Systeme von Strukturen und Regeln entfalten, die völlig unabhängig davon sind, was an spezifischen Zusammenhängen in der Wirklichkeit besteht oder nicht. Das bedeutet nicht, dass mathematisches Operieren ein bloßes Spiel ist; denn die abstrakten Größen- und Mengenverhältnisse sind Eigenschaften, die wir der Wirklichkeit entnehmen und die wir teils recht erfolgreich auf Wirklichkeit applizieren können. ${ }^{10}$ Doch innerhalb des mathematischen Operierens spielt dieser Bezug keine Rolle; die Systematizität dieses Operierens resultiert gerade aus der Autonomie, also daraus, dass die Operationen mit Zeichen keiner Wirklichkeit verpflichtet ist, außer ihrer eigenen.

Der hier deutlich werdende Unterschied hat sich - kaum merklich - in unterschiedliche Konzepte von Wissenschaft eingeschlichen. Ein Aspekt der mathematischen Beweislehre als Konstruktionslehre ist, dass sich die mathematische Konstruktion als eine eigene Technik von Strukturherstellung - als ein operativer Symbolismus - im Sinne eines ganzen Arsenals von methodischen Werkzeugen und Verfahren verstehen lässt.

Was dieser Punkt für eine bestimmte Wissenschaftsform bedeutet, hat niemand so prägnant zum Ausdruck gebracht wie der britische Wissenschaftsphilosoph Stephen Toulmin, der in seinem Buch Philosophy of Science

9 Vgl. Sybille Krämer: Symbolische Maschinen. Die Geschichte der Formalisierung im historischen Abriß, Darmstadt 1988.

10 Vgl. Torsten Wilholt: Zahl und Wirklichkeit. Eine philosophische Untersuchung überdie Anwendbarkeit der Mathematik, Paderborn 2004, S. $284 \mathrm{f}$. 
von 1953 am Beispiel des physikalischen Theorems, dass Licht sich geradlinig durch den Raum bewegt, erläutert:

»Entscheidende Entdeckungen in den Naturwissenschaften bestehen im Kern aus der Entdeckung neuer Darstellungsmethoden und Folgerungstechniken, mit deren Hilfe man Schlüsse ziehen kann - und zwar auf eine Weise, die sich den untersuchten Phänomenen anpaßt. « ${ }^{11}$

Diesen Zugang, „die Phänomene auf eine neue Weise zu sehen und neue Darstellungstechniken auf sie anzuwenden«, unterscheidet Toulmin kategorisch vom »Aufstellen empirischer Verallgemeinerungen ${ }^{12}$ Als empirische Verallgemeinerungen sind Prinzipien wie das Geradlinigkeitsprinzip von Licht »einfach falsch «; ${ }^{13}$ sie haben in den Wissenschaften tatsächlich eine ganz andere Funktion:

»wenn man sie akzeptiert, gibt man zu erkennen, dass man sich die Erklärungstechniken der geometrischen Optik zu eigen gemacht hat, nämlich das Modell, nach dem das Licht von der Quelle ausgeht und sich bis zu den beleuchteten Gegenständen durch den Raum bewegt, und die Verwendung geometrischer Diagramme, aus denen man erschließt, welche Phänomene unter gegebenen Umständen zu erwarten sind. $^{14}$

Das Akzeptieren, Einüben und Denken in einer bestimmten symbolischen Darstellungstechnik ist nicht auf die geometrische Optik beschränkt, vielmehr ist sie für Toulmin ein elementarer Charakterzug moderner Wissenschaft. Bezugnehmend auf das abgebildete Diagramm der geometrischen Optik schreibt er: »Natürlich ist es nicht besonders wichtig, ob unser Physiker sein Diagramm genau so zeichnet, wie wir es hier angenommen haben, oder ob er trigonometrische Formeln benutzt. Wesentlich ist nur, daß er bestimmte mathematische Formeln oder eine andere Darstellungstechnik verwendet. ${ }^{15}$

11 Stephen I. Toulmin(im Orig. 1953): Einführung in die Philosophie der Wissenschaft, Göttingen 1969, S. 33.

12 Toulmin, 1969, S. 43.

13 Toulmin, 1969, S. 23.

14 Toulmin, 1969, S. 29.

15 Toulmin, 1969, S. 25. (Herv. im Orig.). 
Abb. 2: Aus Toulmin: Einführung in die Philosophie der Wissenschaft, S. 26.

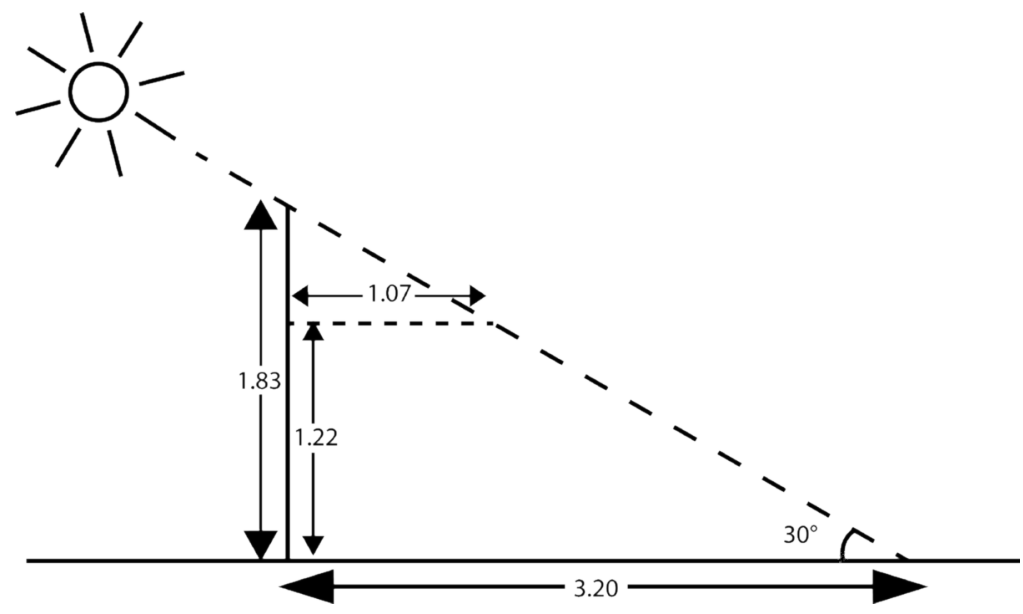

Aus Toulmins Formulierungen lassen sich zwei entscheidende Schlüsse ziehen: Erstens ist es demnach ein charakteristischer Zug zumindest einiger Wissenschaften, dass sie phänomenale Zusammenhänge in symbolischen Formalismen zur Darstellung bringen und zweitens dienen diese Formalismen nicht nur der retrospektiven Darstellung, sondern fungieren außerdem als - wie Toulmin es treffend ausdrückt - »Folgerungstechniken « ${ }^{16}$. Das heißt: Innerhalb des Symbolismus können durch Operationen regelförmiger Art strukturell neue Zusammenhänge erzeugt werden, die erst im Nachhinein mit phänomenalen Zusammenhängen rückvermittelt werden. Toulmins Beschreibung der Wissenschaften vom Typ Physik - er selbst grenzt sie gegen »naturgeschichtliche« Disziplinen $a b^{17}$ - gibt uns also ein Bild davon, welche Rolle mathematische Formalismen in den Wissenschaften spielen können. An der Frage, ob eine solche Entfaltung symbolischer Formalismen ein eigenständiger Zugang zu Erkenntnis ist oder lediglich ein Instrument in der experimentellen Forschung, scheiden sich die Geister - wie wir sogleich sehen werden. Festhalten können wir hier, dass das wirkmächtige Galileische Paradigma der Wissenschaft genau dadurch geprägt ist: das mathematische Schlussfolgern ist in dieser Konzeption der genuine Weg zu

16 Toulmin, 1969, S. 31.

17 Toulmin, 1969, S. 44. 
wahren Erkenntnissen, da nämlich die Natur selbst als eine mathematische Ordnung aufgefasst ist. Genau dies wird sich als Problem erweisen, wenn es nun um das `Schicksal der Induktion geht.

\section{Die Rolle des Experimentierens und das iSchicksal der Induktionı}

Der Status der Mathematik in den Wissenschaften ist ein viel diskutiertes Thema. Aber klar ist: die Mathematik gilt entweder als Idealbild oder als Sonderfall einer Wissenschaft, dem Normalfall entspricht sie jedenfalls nicht. Dazu fehlt ihr jenes Moment der Empirie, der Verbindung mit einem spezifischen Gegenstandsfeld, von dem sie Wissen produzieren könnte. Eine Standardauffassung besagt, dass der empirische Bezug in den Wissenschaften durch Experimente hergestellt wird. Doch die Idee, dass Wissenschaft im Kern durch Experimente gekennzeichnet ist, kommt zunächst ganz ohne Bezug zur Mathematik aus. Eine typische Formulierung lautet:

»Das richtig angestellte und richtig verstandene Experiment bildet zusammen mit der Beobachtung den Grund, von dem wir durch Induktion zur Erkenntnis der Naturgesetze gelangen. Im Altertum und Mittelalter finden wir in der Regel noch keine auf Experimente gegründete Naturerkenntnis, sondern an ihrer Stelle metaphysische Spekulationen. Erst Galilei und besonders Bacon von Verulam [Francis Bacon] schlugen den Weg der Erfahrung ein und begründeten damit eine wissenschaftliche Naturerkenntnis. ${ }^{18}$

Das Zitat stammt aus dem Eintrag »Das Experiment in den Wissenschaften" in einem aktuellen Studienbuch der Wissenschaftstheorie, das wiederum ein Konversationslexikon von 1890 zitiert und folgendermaßen kommentiert:

»Bei der entscheidenden Rolle, die hier dem Experiment bei der Erzeugung von Wissen zugesprochen wird, muss es verwundern, dass sich in dieser Zeit in der Wissenschaftsphilosophie eine deutlich andere Auffassung als die zitierte durchsetzt und insgesamt das Interesse am Experiment stark abge-

18 Michael Heidelberger: Das Experiment und die Wissenschaften. In: Wissenschaftstheorie. Ein Studienbuch, Paderborn 2007, S. 155-176, hier S. 155. 
nommen hat. Mit der Umdeutung des Experiments in der philosophischen Diskussion [...] verlagerte sich der Schwerpunkt auf den Begriff der Theorie und ihre Funktion. ${ }^{19}$

Die Überzeugung, dass wissenschaftliche Erfahrung ein Weg des Experimentierens ist, ist auf eigentümliche Weise zugleich selbstverständlich und alles andere als selbstverständlich. Doch die Ambivalenz, von der hier die Rede ist, ist schon viel älter: sie lässt sich zurückverfolgen bis zu einer Wendung, die über Vorstufen in der Renaissance, etwa bei Leonardo da Vinci, schließlich Galilei und Descartes der Sache gaben - wovon auch der Begriff der Induktion betroffen war.

Wo befinden wir uns? 1620 erschien Francis Bacons Werk Novum Organum - ein großangelegter Versuch, die aristotelische Lehre in eine Experimentaltheorie zu überführen; 1623 Galileo Galileis Il Saggiatore - die Goldwaage, 1632 sein Dialog über die beiden hauptsächlichen Weltsysteme, 1637 Descartes Discours de la méthode und 1644 seine Principia philosophiae. Innerhalb von gut 20 Jahren sind also eine ganze Reihe grundlegender Arbeiten zum Verhältnis von Wissenschaft und Experiment erschienen. Bemerkenswerterweise findet in dieser Reihe aber eine fundamentale Umdeutung statt. Denn während Francis Bacon das Experiment zur eigentlichen Methode wissenschaftlicher Erkenntnis erhebt, degradieren es Galilei und Descartes zu einem Instrument, durch das Erkenntnisse, die auf ganz anderem Wege gewonnen werden, nur noch geprüft werden.

Bacon prägt den lateinischen Begriff experimentum so, dass solche Erfahrungen, die "geschickt und kunstvoll ausgedacht und angewendet werden $«,{ }^{20}$ die einzig geeigneten Mittel sind, allgemeine Prinzipien der Natur nicht nur vorauszusetzen, sondern allererst herzuleiten. Dabei wendet er sich ausdrücklich gegen eine Verkürzung von Wissenschaft auf Beweislehre (»[d]iese Arbeit, Untersuchung und Durchwanderung der Welt kann durch keinen Scharfsinn, kein Nachdenken und keine Beweisführung ersetzt oder ausgeglichen werden ${ }^{21}$ ) und gegen eine Verkürzung auf Naturgeschichte (»die Beobachtung ist nachlässig, unregelmäßig und gleichsam zufällig [...] die Naturgeschichte [...] ist leichtfertig und armselig - alle diese haben den

19 Heidelberger, 2007, S. 155.

20 Francis Bacon: Neues Organon, Hamburg 1999, S. 49.

21 Bacon, 1999, S. 53. 
Geist nur mit dem mangelhaftesten Stoff für die Philosophie und Naturwissenschaft [hier steht im Orig. nur »scientia«] versorgt.«). ${ }^{22}$ Bacon konzipiert dagegen eine wissenschaftliche Methode, die einen Mittelweg zwischen sammelnder Empirie und konstruktiver Rationalität einschlägt. ${ }^{23}$ Das Experimentieren beruht auf der Verknüpfung von beidem: es ist eine Interaktion zwischen Überlegung zur Einrichtung der Erfahrung und der Erfahrung, die sich daraus am Material ergibt.

Ganz anders Galilei und Descartes: Beide sind - in diesem Punkt wesentlich konservativer - dem Ideal der Beweisführung, wie es sich seit dem 12. Jahrhundert ausprägte, verpflichtet, und zwar in seiner mathematisch transformierten Form. Wissenschaft ist für beide zunächst formale Ableitung: Da die »Wahrheit, deren Erkenntnis durch die mathematischen Beweise vermittelt wird, dieselbe ist, welche die göttliche Weisheit erkennt «, ${ }^{24}$ könne, so Galilei, das menschliche Erkennen zwar nicht wie das göttliche auf einen Blick, aber doch »schrittweise von Schluss zu Schluss ${ }^{25}$ voranschreiten und durch »Folgerungen ..., welche streng bewiesen sind ${ }^{26}{ }^{26} \mathrm{zur}$ Wahrheit gelangen. Und auch für Descartes stellen »[j]ene langen Ketten ganz einfacher und leichter Begründungen, die die Geometer zu gebrauchen pflegen, um ihre schwierigsten Beweise durchzuführen« das Ideal wissenschaftlicher Methode dar. Das Experiment dagegen tritt für beide erst auf den Plan, wenn dieser Erkenntnisweg abgeschlossen ist: Galilei bestimmt die Rolle des Experiments als die einer zusätzlichen Bestätigung »in den Wissensgebieten, in welchen auf natürliche Consequenzen mathematische Beweise angewandt werden; so sieht man es bei Allen, die Perspective, Astronomie, Mechanik, Musik und Anderes betreiben; diese alle erhärten ihre Prinzipien durch Experimente «. ${ }^{27}$ Ebenso überlässt Descartes dem Experiment lediglich die Rolle des Entscheiders über verschiedene rational erschlossene Möglichkeiten: In der Schwierigkeit nämlich, dass »der Bereich des von Na-

\footnotetext{
22 Bacon, 1999, S. 53.

23 Vgl. Bacon, 1999, S. 211.

24 Galilei, Galileo: Dialog über die Weltsysteme. In: ders., hrsg. u. eingel. v. Hans Blumenberg: Sidereus Nuncius. Nachricht von neuen Sternen, Frankfurt a.M. 1965, S. 157

25 Galilei, 1965, S. 157.

26 Galilei, 1965, S. 158.

27 Galileo Galilei: Unterredungen und mathematische Demonstrationen über zwei neue Wissenszweige, die Mechanik und die Fallgesetze betreffend, Erster bis sechster Tag, hrsg. von Arthur Oettingen, Darmstadt 1964, S. 162.
} 
tur Möglichen so groß und so weit ist und daß diese Prinzipien so einfach und allgemein sind, daß ich fast keine besondere Wirkung mehr beobachte, von der ich nicht gleich anfangs erkenne, daß sie auf mehrere verschiedene Weisen davon abgeleitet werden kann ${ }^{28}{ }^{28}$ weiß Descartes »keinen anderen Ausweg als wiederum etliche Beobachtungen anzustellen [chercher ... quelques expériences; WK.] und zwar solche, die anders ausfallen, je nachdem die eine oder die andere Erklärungsart richtig ist. $\aleph^{29}$

Damit wurde der Nachwelt eine wenig beachtete, aber umso virulentere Frage übermittelt: Sind Experimente nur der Prüfstein für Erkenntnisse, die durch mathematische Demonstrationen gewonnen werden oder bilden sie das eigentliche Zentrum von Wissenschaft? Diese Frage scheidet in der Folgezeit die Geister. Auf der einen Seite steht die Wissenschaftsphilosophie, die in der Tradition Galileis und Descartes in weiten Teilen eine Standardauffassung zugrunde legt, die so vertraut ist, dass sie als Gemeinplatz erscheint. So liest man etwa in einem populärwissenschaftlichen Magazin Autor ist ein Wissenschaftsphilosoph:

»Im Cegensatz zu seinem antiken Vorgänger ist der moderne Atomismus echte Naturwissenschaft. Er formuliert Cesetze, mit deren Hilfe man das Verhalten der Teilchen berechnen und diese Berechnungen experimentell überprüfen kann. «30 (Herv. WK.)

Ausgangspunkt sind Gesetze - die ideengeschichtlichen Erben der Axiome und Prinzipien ${ }^{31}$-; aus ihnen wird rechnerisch konstruiert und, wenn so ein bestimmtes Verhalten gefolgert wurde, wird im Nachhinein noch experimentell geprüft. Bacons Erkenntnisweg war genau umgekehrt. Aus der Arbeit am Material und der experimentellen Erzeugung bestimmter fraglicher Zustände werden Annahmen sukzessive verfeinert, bis schließlich ein gut fundiertes Verständnis der zugrundeliegenden Prinzipien und Gesetze sich herausschält.

28 René Descartes: Discours de la méthode, Hamburg 1990, S. 105.

29 Descartes, 1990, S. 107.

30 Michael Esfeld: Wissenschaft, Erkenntnis und ihre Grenzen. In: Spektrum der Wissenschaft 8, (2017), S. 12-18, hier S. 14.

31 Michael Hampe: Eine kleine Geschichte des Naturgesetzbegriffs, Frankfurt a.M. 2007, S. 64ff. 


\section{BASISWISSEN 6: Induktion und Empirie - Der Weg der Erfahrung}

Im Kontext der Diskussion um die verschiedenen Rollen des Experimentierens steht auch das >Schicksal der Induktion<. Der Widerstreit zwischen den unterschiedlichen Auffassungen von Erfahrung und Experiment hat nämlich auch diesen Begriff, der so grundlegend in der Wissenschaftstheorie ist, einbezogen und zu Verwirrungen geführt, die wir in groben Umrissen an dieser Stelle klären sollten.

Erstens ist das Wort inductio die lateinische Übersetzung der griechischen Vokabel epagogé. Epagogé ist ein zentraler Begriff der aristotelischen Erkenntnislehre. Er meint die Herausbildung allgemeiner, auf das Ganze (katholou) bezogener Einsichten aus der Flut einzelner Wahrnehmungen, und zwar über die Stationen Erinnerung und Erkennen von Ähnlichkeiten. Diese Kompetenz, in einem Komplex von Fällen relevante Ähnlichkeiten zu sehen, nennt Aristoteles, Erfahrung (empeíria). Epagogé ist daher bei Aristoteles ein im ursprünglichen Sinne sempirischer Erkenntnisweg, auf dem sich Menschen in ihrem Erkenntnisstreben gleichsam naturwüchsig bewegen. Als Weg zu Erfahrenheit und Einsicht (bei Aristoteles: nous), entsteht ein allgemeines Wissen, das schon empirisch gegeben ist, wenn es durch logische Schlussfolgen (syllogismos) und Beweisverfahren (apodeixis) expliziert wird. Epagogé ist deshalb bei Aristoteles Voraussetzung für alle logisch-formalen Erkenntnisprozesse.

Der Grundgedanke einer dem Beweisen vorgeschalteten Erfahrung blieb als Bezugspunkt zum Ideal der scientia im Hochmittelalter und in der frühen Neuzeit stets erhalten. Ausdrücke für diesen Zusammenhang, nämlich«via experientiae und via rationis oder ratio et experimentum (Köhler 129-133) waren stehende Wendungen. Sämtliche die Debatte prägenden Autoren der Zeit wie Robert Grosseteste, Albert Magnus, Thomas von Aquin oder Roger Bacon rezitierten regelmäßig die aristotelischen Formulierungen zur Erfahrungsbildung, die jeder Beweisführung vorausging. Und auch noch das Novum Organum des Francis Bacons kann als Wiederbelebung dieser aristotelischen Konzeptionen gegen die sich allmählich ausbreitende szientifische Überformung, gegen ihre Logifizierung gelesen werden. 
Diese Tendenz der Logifizierung machte nämlich aus der empirischen aristotelischen Induktion ein Schlussverfahren: Im Zuge der Herausbildung eines Wissenschaftsideals, das sich am Begriff der episteme orientierte, konnte es so erscheinen, als müsste das, was ja eigentlich Voraussetzung für die Möglichkeit logischer Beweisführung war, selbst ein auf logischer Zwangsläufigkeit beruhendes Verfahren sein. Die Verwirrungen, die durch diesen in sich widersprüchlichen Begriff einer logischen Induktion entstanden sind, wirkten bis weit ins 20. Jahrhundert nach. Die logisch-empiristische Wissenschaftsphilosophie verstrickte sich immer tiefer in das Dilemma, einerseits Wissenschaft als durchgängig begründeten Gewissheitszusammenhang sehen zu wollen, andererseits der Tatsache nicht entgehen zu können, dass noch so viele Einzelbelege einer These keine allgemeine Behauptung beweisen können. »Allgemeine wissenschaftliche Gesetze gehen immer über die endliche Menge der vorhandenen, sie unterstützenden Beobachtungen hinaus und können daher niemals in dem Sinn bewiesen werden, dass sie sich logisch aus dem Evidenten ableiten lassen.«(39) So hat es der Wissenschaftstheoretiker Alan F. Chalmers ausgedrückt und bringt damit auf den Punkt, »dass wissenschaftliche Erkenntnis nicht aus Tatsachen abgeleitet werden kann, wenn sabgeleitet als >logisch erschlossen interpretiert wird.«(37) Der Induktivismus könne deshalb nicht mit Bezug auf Logik, sondern nur mit Bezug auf Erfahrung gerechtfertigt werden (42f.) - genau dies war bereits die Einsicht, die Aristoteles zur Konzeption einer gegenüber der Syllogistik vorgängigen und radikal eigenständigen epagogé geführt hatte.

Theodor W. Köhler: Sachverhaltsbeobachtung und axiomatische Vorgaben. Zur Struktur wissenschaftlicher Erfassung konkreter Äußerungsweisen des Menschlichen im 13. Jahrhundert. In: Antolic-Piper u.a. (Hrsg.): Erkenntnis und Wissenschaft, Berlin u.a. 2004, S. 125-150. Alan F. Chalmers: Wege der Wissenschaft. Einführung in die Wissenschaftstheorie, Berlin u.a. 2001 (5. überarb. u. erw. Auflage). 
Beide Auffassungen wurden tradiert, seit Mitte des 19. Jahrhundert dominierte allerdings die Cartesianisch-Galileische Auffassung das öffentliche Bewusstsein, bis im 20. Jahrhundert sich, zuerst nur punktuell, dann auf breiter Front, die Baconsche Auffassung wieder Gehör verschaffte. Und zwar geschah dies, indem zuerst einige praktizierende Wissenschaftler ein ganz anderes Bild ihrer Tätigkeit zeichneten als es die Wissenschaftsphilosophie vorsah, ${ }^{32}$ sodann Forschungen in Wissenschaftsgeschichte und -soziologie zeigten, dass wissenschaftliche Erkenntnis in sehr anderer Weise zustande kommen kann, als dies im Galileischen Modell angenommen wurde. Diese Einsicht hat schließlich auch die Wissenschaftsphilosophie erreicht, die im Laufe ihrer Entwicklung im 20. Jahrhundert »einen immer größeren Erfahrungsbezug « ${ }^{33}$ ausbildete, bis sie schließlich ihr kanonisches Werk in Thomas S. Kuhns The Structure of Scientific Revolutions fand. Kuhn selbst hatte zwar das Experiment eher stiefmütterlich behandelt, doch sein Gedanke, dass Wissenschaften in Paradigmen, also in musterhaften Konstellationen, arbeiten, legte auch nahe, diese Muster nicht als Regelwissen, sondern als »wissenschaftliche Betätigung « ${ }^{34}$ aufzufassen (was bereits Kuhn in seinem Postskriptum von 1969 ausdrücklich tut). Aufbauend darauf entwickelte sich eine Strömung, die unter dem Titel New Experimentalism prominent wurde. Für sie ist Wissenschaft "Wissensbildung durch technisch-intervenierendes Handeln ${ }^{35}$ Die technische Seite des Experiments, die Instrumente, die materiellen Versuchsgegenstände, die Labore, die Verfahren und die Fertigkeiten der Experimentatoren wurden zum zentralen Thema. Entsprechend wurde herausgearbeitet, dass diese praktischen Welten der Experimentalsysteme ein Eigenleben ${ }^{36}$ führen, aus dem viele theoretische Fragen erst entstehen. Im Sinne eines Primats des Experimentierens haben eine ganze Reihe von Wissenschaftstheoretiker wie

32 Valer Ambrus: Vom Neopositivismus zur nachanalytischen Philosophie, Frankfurt a.M. 2002, S. 34-40.

33 Ambrus: Vom Neopositivismus zur nachanalytischen Philosophie, 2002, S. 40.

34 Thomas S. Kuhn: Die Struktur wissenschaftlicher Revolutionen, Frankfurt a.M. 1988, S. 203.

35 Michael Heidelberger: Die Erweiterung der Wirklichkeit im Experiment. In: Micheal Heidelberger/Friedrich Steinle (Hrsg.): Experimental Essays = Versuche zum Experiment, Baden Baden 1998, S. 11.

36 Ian Hacking: Do Thought Experiments Have a Life of Their Own? Comments on James Brown, Nancy Nersessian and David Cooding. In: PSA: Proceedings of the Biennal Meeting of the Philosophy of Science Association. Vol. Two: Symposia and Invited Papers, 1992, S. 302-308. 
Ian Hacking, ${ }^{37}$ Holm Tetens, ${ }^{38}$ Bruno Latour, ${ }^{39}$ Andrew Pickering, ${ }^{40}$ Don Ihde, ${ }^{41}$ Hans-Jörg Rheinberger ${ }^{42}$ und Joseph Rouse ${ }^{43}$ die spezifische Praxisform des Experimentierens herausgestrichen und deutlich gemacht, dass es für forschungsförmiges, also auf neue Erkenntnis gerichtetes, Experimentieren charakteristisch ist, einen ergebnisoffenen Prozess auszutragen ${ }^{44}$ - und gerade nicht nur vorgefasste theoretische Möglichkeiten zu prüfen.

37 Ian Hacking (Orig. 1983 (Representing and Intervening)): Einführung in die Philosophie der Naturwissenschaften, Stuttgart 1996.

38 Holm Tetens: Experimentelle Erfahrung, Hamburg 1987.

39 Bruno Latour: Science in Action: How to Follow Scientists and Engineers through Society, Cambridge MA 1987.

40 Andrew Pickering: The Mangle of Practice: Time, Agency, and Science, Chicago 1995.

41 Don Ihde: Instrumental Realism: The Interface between Philosophy of Science and Philosophy of Technology, Bloomington/Indianapolis 1991.

42 Hans-Jörg Rheinberger: Experiment. Differenz. Schrift: Zur Ceschichte epistemischer Dinge, Marburg an der Lahn 1992; Hans-Jörg Rheinberger: Experimentalsysteme und epistemische Dinge. Eine Ceschichte der Proteinsynthese im Reagenzglas, Cöttingen 2001.

43 Joseph Rouse: Engaging Science: How to Understand its Practices Philosophically, Ithaca/ Cornell 1996.

44 Bruno Latour betont in Bezug auf das Experimentieren: »es hat etwas Neues, von der Veranstaltung Unabhängiges herauszukommen, sonst ist die ganze Unternehmung vertan« (Bruno Latour: The force and the reason of experiment. In: H. E. Le Grand (Hrsg.): Experimental Inquieries, Dodrecht 1990, S. 49-80, hier: S. 64. (Übersetzt in Hans Jörg Rheinberger: Experiment. Differenz. Schrift: Zur Geschichte epistemischer Dinge. Marburg an der Lahn 1992, S. 16.); Hans-Jörg Rheinberger schreibt: »Wenn danach gefragt wird, was den Forschungsprozeß treibt, ist es ratsam, mit einer Charakterisierung der Experimentalsysteme, ihrer Struktur und ihrer Dynamik zu beginnen, und nicht von einem ursprünglichen, unhintergehbaren, wie auch immer formulierten Primat der Theorie. [...] Was zur Debatte steht, ist ... eine durch instrumentelle Randbedingungen ausgerichtete Bewegung, in der das Räsonnieren gewißermaßen ins Spiel der materiellen Entitäten gerissen wird." (Rheinberger 1992, S. 22). Die Bestimmung des Wissenschaftsobjekts im experimentellen Prozess beschreibt Rheinberger so: »Man verfehlt seine Spezifik, wenn man diesen Vorgang als den der stheoretischen< Abbildung einer wie immer gearteten ,Wirklichkeit betrachtet. Was praktisch im Forschungsprozess abläuft, ist die Realisierung, also Produktionvon Wissenschaftsobjekten mitHilfevon Dingen, die bereits als hinreichend stabile Materialformen von Wissen betrachtet und gehandhabt werden können. [...] Dieser Prozeß ist keineswegs von vornherein zielgerichtet. Er muß durch jene Vorgänge ertastet werden, die [François] Jacob beschrieben hat als sdie gescheiterten Anläufe, die verfehlten Experimente, die Stottereien, die blödsinnige Probierereien<. Letztlich bleibt der einzige Führer durch diese Landschaft, wie Goethe gesagt haben würde, ১die Verfahrensart selbst.، Sie allein produziert die Hinweise, in welche Richtung man sich zu wenden und wo man 
So zeigen sich auch innerhalb der Experimentaltheorie zwei grundsätzlich verschiedene Auffassungen von Wissenschaft. Was ist Wissenschaft? Ein gedankliches Operieren, eine intellektuelle Tätigkeit, die Kraft logischer Schlussfolgerung und mathematischer Berechnung zu Ergebnissen kommt, die sich in Experimenten prüfen lassen - wie bei Sherlock Holmes die >Theorieく im Geständnis des Delinquenten. Oder ist Wissenschaft das, was sich am deutlichsten in Laboren zeigt, nämlich der Versuch, die Bedingungen von Prozessen in den Griff zu bekommen, sodass sie systematisch variiert und regelhafte Verläufe beobachtet werden können - Experimentalsysteme, bei denen die Tücke stets im Detail liegt und die eine hoch spezialisierte Ausbildung, Erfahrung und Könnerschaft verlangen, um die Versuchsanordnungen so weit zu stabilisieren, dass signifikante und valide Ergebnisse gewonnen werden können?

\section{Laborwissenschaft, Modellierung, Simulation und Realexperimenter}

\section{Was macht die Wissenschaft im Labor?}

Die Antwort lautet: sie operiert mit Modellen an Modellen. Und zwar operiert sie mit physischen Modellen an symbolisch-operativen (häufig mathematischen, aber auch anderen Formelsprachen) und mit symbolisch-operativen an physischen Modellen. Das Verhalten von Wellen, Blitzen, Stadtflüchtigen oder Viren lässt sich auch in der offenen >Natur < beobachten - es ins Labor zu holen, bedeutet vor allem eines: es von der Umwelt abzutrennen, es als Komplex zu isolieren und kontrollierbar, kurz: es zum Modell zu machen. Laborbedingungen einzurichten bedeutet, die physischen Prozesse so zu präparieren, dass einzelne Bedingungen gezielt variiert werden können. Genau dadurch lässt sich das Verhalten der Forschungsgegenstände in Formeln ausdrücken, deren Umformung Prognosen erlaubt: die chemische Reaktionsgleichung zeigt nicht nur, wie sich Substanzen verhalten haben, sondern auch wie sie sich verhalten werden (- unter Laborbedingungen - wenn

umzukehren hat.«(Rheinberger 1992, S. 29f.). Zu erwähnen ist hier auch, dass diese Autoren damit die klassisch moderne Position, die etwa Liebig gegen Bacon vertritt, revidieren und in mancherlei Hinsicht zum Baconschen Ansatz zurückkehren. 
alles funktioniert; dazu später mehr). Umgekehrt werden die Formelsysteme den beobachteten $>$ Naturprozessen $<$ so angepasst und weiterentwickelt, dass sie dem Verhalten der Forschungsgegenstände immer besser entsprechen: der Weg der Formelsprachen und der mathematischen Modellierung.

Das typische Labor ist also ein doppeltes Labor: einerseits arbeitet es im Medium der symbolisch-operativen Sprache, andererseits im physischen Medium des Forschungsgegenstandes. Ein Beispiel: um Zellprozesse zu verstehen, versucht man, elementare Prozesse der lebenden Zelle im Labor zu reproduzieren und zugleich diese Erkenntnisse in ein Computermodell der Zelle zu integrieren - »bis eine gute Übereinstimmung zwischen den experimentellen Daten und den modellierten Vorhersagen erreicht ist. « ${ }^{45}$

An diesem Beispiel lässt sich noch mehr zeigen: die ursprüngliche Formelsprache der Molekularbiologie ist die der Genexpression, also: wie die (in Buchstabenfolgen dargestellten) DNA-Abschnitte in (ebenfalls in Buchstabenfolgen dargestellten) Ketten der Proteine übersetzt werden. Flankiert wurde dieser Grundformelbestand durch einige Regeln der Biochemie. Je weiter aber die Einsicht in die Komplexität zellulärer Prozesse gedieh, desto größer wurden die Ansprüche an die Modellierung der Prozesse; die elementaren Formeln der Genexpression bilden zwar noch immer das theoretische Zentrum, den Kern der molekularbiologischen Forschung, doch lassen sich die Vielzahl der voneinander abhängigen und rückgekoppelten Einflussfaktoren nur noch in ebenfalls sehr komplexen und raffiniert aufgebauten Computermodellierungen reproduzieren. So versucht man, im Medium von Computerberechnungen, also in silico, herzustellen, was in der lebenden Zelle, in vivo, geschieht; ein Geschehen, das nicht unmittelbar beobachtbar ist, sondern aus Effekten in Laborversuchen in vitro (im Reagenzglas) rekonstruiert wird.

45 E. Klipp/R. Herwig/A. Kowald/C. Wierling/H. Lehrach (Hrsg.): Systems Biology in Practice. Concepts, Implementation and Application, Weinheim 2004, S. 4 [Übersetzung der Verfasser]. Das Zitat lautet im Kontext: »Systembiologie beruht auf der Integration von Experiment, Datenverarbeitung und Modellierung. Idealerweise ist dies ein sich wiederholender Prozess. Experimentell gewonnenes Wissen über das untersuchte System führt, gemeinsam mit offenen Fragen, zu einem Ausgangsmodell. Dieses Ausgangsmodell erlaubt Vorhersagen, die in neuen Experimenten verifiziert und falsifiziert werden können. Unstimmigkeiten stimulieren den nächsten Schritt der Modellentwicklung, was wiederum zu experimentell überprüfbaren Vorhersagen führt. Diese Wiederholung wird weiter geführt, bis eine gute Übereinstimmung zwischen den experimentellen Daten und den modellierten Vorhersagen erreicht ist.«. 
Am besten gelingt dieses Forschungsmodell, wo sich unter Laborbedingungen die Komplexität so weit reduzieren lässt, dass sie in symbolsystemischen Modellierungen formelhaft zu reproduzieren ist. Wie weit dies jeweils gelingen kann, ist umstritten, ${ }^{46}$ und stets ist auch die Antwort auf die weitergehende Frage offen, wie sich Ergebnisse aus dem Labor auf Verhältnisse in >freier Wildbahn übertragen lassen.

Modellierungen ohne Labor gehören ebenfalls zu diesem Forschungstyp. Im Falle der Modellierung von Klimaveränderung, Verstädterung oder einer Pandemie lassen sich die >In-vivo-Prozesse nicht oder nur sehr eingeschränkt ins Labor bringen. Die Seite der Forschung im physischen Material wird hier durch beobachtende Datensammlung realisiert - anstelle von experimenteller. Da die Modellierung hier nicht auf die kontrollierte Reproduktion physischer Prozesse zurückgreifen und diese vielmehr nur im Medium des mathematischen Modells darstellen kann, spricht man von Simulation. ${ }^{47}$

Laborwissenschaft, Modellierung und Simulation verknüpfen also experimentelle Praxis mit formaler Folgerungstechnik. Doch wer glaubt, dass diese raffinierte Erfindung eines Forschungstyps sich bruchlos als Synthese aus den älteren Paradigmen der Episteme-Scientia-Tradition ergibt, der verkennt die wissenschaftsphilosophische Sprengkraft, die in diesem Typus liegt. Denn, da Mathematik im Spiel ist, sieht es zwar so aus, als ob hier Beweisverfahren ausgeführt werden - doch tatsächlich haben die Folgerungstechniken hier eine ganz andere Funktion; und da Experimente im Spiel sind, sieht es zwar so aus, als ob Gesetzmäßigkeiten geprüft und bestätigt werden, doch tatsächlich fügt sich das reale Experimentieren ebenso wenig in dieses Bild - wie der letzte Abschnitt schon zeigte.

Die theoretische Sprengkraft dieser Ausprägung des Episteme-ScientiaTypus liegt darin begründet, dass ein Schlüsselbegriff der Wissenschaften davon betroffen ist: Naturgesetze. Naiv stellen wir uns den Zusammenhang

46 Eine Kritik aus Insider-Perspektive ist: ]. D. Sterman: A Skeptic's Guide to Computer Models. In: C. O. Barneyet al. (Hrsg.): Managing a Nation: The Microcomputer Software Catalog. Boulder, CO 1991, S. 209-229.

47 Vgl. Gabriele Gramelsberger: Simulation and Systems Understanding. In: Hanne Andersen/Dennis Dieks/Wenceslao ]. Gonzalez/Thomas Uebel/Gregory Wheeler (Hrsg.): New Challenges to Philosophy of Science, The Philosophy of Science in a European Perspective, Bd. 4, Dordrecht 2013, S. 151-161; Petra Gehring/Michael M. Resch/Andreas Kaminski (Hrsg,): The Science and Art of Simulation. Exploring - Understanding - Knowing, Heidelberg/ New York 2017. 
etwa so vor (ich zitiere hier die prägnante Formulierung der Wissenschaftsphilosophin Sandra Mitchell):

»[Laws] are what science supposedly seeks to discover. They are supposed to be the codifications of knowledge about the world that enable us to explain why what happens, happens, to predict what will happen in the future or in other circumstances and provide us the tools to intervene in the world in order to reach our pragmatic goals. ${ }^{48}$

Was Naturgesetze sind, war allerdings nur innerhalb der klassischen Beweislehre der Episteme-Scientia-Tradition klar. Hier spielen sie die Rolle von universal gültigen Prinzipien, die entdeckt werden können und aus denen sich - durch Folgerungstechnik abgeleitet und durch Experimente bestätigt, Erklärungen und Vorhersagen erstellen lassen. Doch je genauer man auf die Realität der Forschung blickt, desto unklarer wird auch der Begriff des Naturgesetzes. So kommt C. A. Hooker im Eintrag zu »Laws, natural« der Routledge Encyclopedia of Philosophy zu der Konklusion:

»The existence and nature of laws is a complex problem. [...] There is no uncontroversial theory of laws: all face difficulties. As fast as we scientifically unravel nature's mysteries, so fast does the nature of that understanding become mysterious. ${ }^{49}$

Ein knappes Jahrzehnt später hat sich an dieser Sachlage offensichtlich wenig geändert. Andreas Hüttemann resümiert: »Eine restlos überzeugende Theorie der Naturgesetze gibt es nicht. $\aleph^{50}$

48 Sandra D. Mitchell: Ceteris Paribus: An Inadequate Representation for Biological Contingency. In: Erkenntnis. An International Journal of Analytic Philosophy, 57(2002), S. 329-350, hier S. 329.

49 Routledge Encyclopedia of Philosophy (1998): Eintrag »Laws, natural«. Vol. 5, S. 474.

50 Andreas Hüttemann: Naturgesetze. In: Andreas Bartels/Manfred, Stöckler (Hrsg.): Wissenschaftstheorie, Paderborn 2007, S. 135-154, hier S. 153. 


\section{BASISWISSEN 7: Was sind Naturgesetze?}

Will man den Naturgesetzbegriff verstehen, so muss man sich zunächst klar machen, dass dieser Begriff selbst nicht naturwissenschaftlich begründet ist. In den Formulierungen von Gesetzen der Bewegung, Kraft, Optik oder Wärmelehre kommt der Gesetzesbegriff selbst nicht vor. (Vgl. Hampe 46; Vollmer) Diese Formulierungen werden als Gesetze betrachtet, eine naturgesetzliche Definition des Gesetzesbegriffs gibt es aber nicht.

In der Begriffswelt der griechischen Antike bilden Natur (physis) und Gesetz (nomos) zunächst ein Gegensatzpaar. Natur als das, was von selbst entsteht, vergeht und sich bewegt, steht im Gegensatz zu den Gesetzen, die Menschen erlassen und einrichten. Ausdrücklich metaphorisch konnte zwar auch schon in der klassischen Antike die Natur als gleichsam gesetzlich geordnet beschrieben werden, doch durch solche rhetorischen Wendungen wurde der Gegensatz nicht aufgehoben, sondern in Gebrauch genommen. Das änderte sich erst mit der Stoa und schließlich mit dem Konzept eines christlichen Schöpfergottes, der die Welt als eine gesetzmäßige Ordnung erschafft und einrichtet.

Die entscheidende Wendung kam aber erst mit der Etablierung der geometrischen Beweislehre in der frühen Neuzeit. Der Naturgesetzbegriff rückte nun allmählich an die Stelle des Axiomsbegriffs. Noch Kepler (und später auch Newton) sprechen von Axiomen, um die Sätze zu bezeichnen, aus denen sie Planetenbewegungen und -konstellationen geometrisch ableiten. In diesen Ableitungen kommt nun aber auch der Gesetzesbegriff zum Einsatz: »er bezeichnet vor allem diejenige Regel, die zur Beschreibung geometrischer Proportionen nötig ist«. (Hampe 66) Ob Gesetze in den natürlichen Elementen und ihren Beziehungen selbst liegen oder ob sie ihnen von außen auferlegt sind (etwa durch eine göttliche Macht), ob sie real sind oder ideelle Denkvoraussetzungen - diese Fragen sind seitdem umstritten. (vgl. Hampe 71-76) Für die moderne Wissenschaftstheorie wurde vor allem die Frage zentral, wie sich Naturgesetze zu empirischer Allgemeinheit verhalten. Denn der Naturgesetzbegriff transportiert in seiner Herkunft aus der geometrischen Beweis- 
lehre das Moment der Notwendigkeit mit sich. Naturgesetze in diesem Sinne bezeichnen keine bloßen Regelmäßigkeiten der Natur, sondern drücken einen Moment des Zwangs aus: eine Bewegung vollzieht sich in einer bestimmten Form, weil sie sich, gemäß des Naturgesetzes, nicht anders verhalten kann (vgl. Hüttemann 149). Eine empirische Allgemeinheit wie die Aussage, dass salle Schwäne weiß sind (Chalmers, s. BASISWISSEN 6), kann nicht als Naturgesetz gelten, da jede weitere Beobachtung tatsächlich ein anderes Resultat liefern könnte. Andererseits kann der naturgesetzliche Zwang aber auch nicht mit dem Zwang logischer Schlussfolgerung identifiziert werden. Denn die natürlichen Erscheinungen verhalten sich nur unter ganz bestimmten Bedingungen so, wie die naturgesetzliche Formulierung es vorsieht. Galileis Fallgesetz gilt z.B. nur im Vakuum. Man spricht daher von Naturgesetzen als Ceteris-Paribus-Gesetzen (von lat. »anderes gleichbleibend«) und so liegt der Schluss nahe: »Naturgesetze sind typischerweise Ceteris-Paribus-Gesetze. Sie beschreiben das Verhalten von Gegenständen unter spezifischen Umständen.« (Hüttemann 152). Der Verweis auf spezifische Umstände zeigt an, wie sehr das Konzept von Naturgesetzen an die Realisierung von idealen Bedingungen gebunden ist, die in der Natur kaum je und annäherungsweise nur im Labor gegeben sind.

Michael Hampe: Eine kleine Geschichte des Naturgesetzbegriffs, Frankfurt a.M. 2007.

Gerhard Vollmer: Was sind und warum gelten Naturgesetze? In: Philosophia naturalis. Journal for the Philosophy of Nature. Band 37/2 (2000). Andreas Hüttemann : >Naturgesetze . In: Andreas Bartels/Manfred Stöckler(Hrsg.): Wissenschaftstheorie, Paderborn 2007, S. 135-154. 


\section{Wo liegt das Problem?}

Je umfassender die Wissenschaftstheorie in den Blick nahm, wie mathematisierte und experimentierende Wissenschaft tatsächlich arbeitet, desto mehr zerfiel ihr das beweistheoretische Bild und desto stärker veränderte sich ihr der Begriff des Naturgesetzes. Schon um die Jahrhundertwende um 1900 geriet das Bild von Gesetzen, die auf empirischem Wege erschlossen werden können, ins Wanken. Neben Ernst Mach und Henri Poincaré war es vor allem Pierre Duhem, der argumentierte, dass die Physik keineswegs induktiv von der Erfahrung zur Theorie voranschreitet. Am Beispiel von Ampères Theorie der Elektrodynamik zeigt Duhem, dass die experimentelle >Basis`für theoretische Schlussfolgerungen zumeist rudimentär ist, was impliziere, dass die stheoretische Fassung der Phänomene nicht empirisch vorbestimmt sein kann. In diesem Zusammenhang schreibt Duhem nun von der »Notwendigkeit für den Physiker, die experimentellen Tatsachen symbolisch auszudrücken ${ }^{51}$ und erläutert: "Die Tatsachen des Experiments wären, roh, wie sie von Natur aus sind, nicht der mathematischen Behandlung zugänglich gewesen. Um diese Behandlung zu ermöglichen müssen sie umgebildet und in symbolische Form gebracht werden. $\aleph^{52}$ Die unzureichende experimentelle Basis bedeutet nun aber für die Form der Symbolisierung, dass sie unabhängig vom Empirischen festgelegt werden muss: "Bei so wenig genauen Experimenten bleibt dem Physiker die Sorge überlassen, unter einer Unzahl gleich guter symbolischer Übersetzungen zu wählen. ${ }^{53}$ Eine solche Übersetzung ist für Duhem keine Ausnahme, sondern die Regel, sie lässt sich etwa auch in der Übertragung der Keplerschen Gesetze in die »symbolische Form « ${ }^{54}$ der Newtonschen Dynamik nachweisen. ${ }^{55}$ Diese Denkfigur einer Übersetzung aus dem

51 Pierre Duhem (im Orig. 1906): Ziel und Struktur der physikalischen Theorien, Hamburg 1998 , S. $262 f$.

52 Duhem, 1998, S. $261 f$.

53 Duhem, 1998, S. 264.

54 Duhem,1998, S. 259.

55 Instruktive Studien, wie die Multiplizierung von Möglichkeiten durch operative Symbolismen im Forschungsprozess wirksam wird, finden sich auch in den Arbeiten von Ursula Klein. Ihre Untersuchungen zum Einsatz der Formelschreibweise in der Chemie zeigen beispielsweise, wie durch Transformation der Summenformel sich immer neue Konfigurationen bilden ließen, die jeweils unterschiedliche Interpretationen über die enthaltenen Stoffe implizierten und wie dadurch eine Fülle von Ansätzen für weitere experimen- 
Empirischen ins Symbolische anstelle einer Beweisführung ist im 20. Jahrhundert von vielen Wissenschaftstheoretikern ausbuchstabiert worden.

\section{$\checkmark$ VERTIEFEND Symbolismen in den Wissenschaften}

Unter anderen haben Elisabeth Anscombe, Georg Henrik v. Wright und Thomas S. Kuhn ${ }^{56}$ Beispiele und subtile Argumente beigetragen, in jüngerer Zeit hat die Physikerin und Philosophin Nancy Cartwright die Problematik in einige prägnante Formulierungen gefasst.

Cartwrights How the Laws of Physics Lie von 1983 beschreibt das Verhältnis von Theorie, Empirie und Wirklichkeit in einem dreistufigen Schema: »The route from theory to reality is from theory to model, and then from the model to the phenomenological law. The phenomenological laws are indeed true of the objects in reality - or might be; but the fundamental laws are true only of

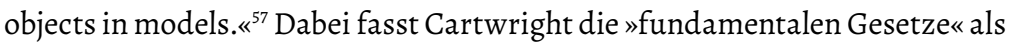
symbolische Form einer mathematischen Theorie. Der Transfer in den sym-

telle Untersuchungen entstanden. Ursula Klein (2003): Experiments, Models, Papertools. Cultures of Organic Chemistry in the Nineteenth Century, Stanford.

56 Vgl. Gertrud E. M. Anscombe: Causality and Determination. In: Metaphysics and the Philosophy of Mind (The Collected Philosophical Papers: 2), Oxford 1981; Georg H. Wright: >Laws of Nature In: Truth, Knowledge and Modality, Philosophical Papers. 3 (1984), S. 135-149; Thomas S. Kuhn: Die Entstehung des Neuen: StudienzurStrukturderWissenschaftsgeschichte, Frankfurta.M.1984. Eine besonders instruktive Darstellung findet sich in Holm Tetens Buch Experimentelle Erfahrung (Hamburg1987):DasTheoremvon Lakatos, dasswissenschaftliche»Forschungsprogramme» einen »harten Kern« enthalten, zurückverfolgend, führt Tetens den Begriff der Exhaustion von Hugo Dingler ein. Unter Exhaustion versteht Dingler die Einführung gewisser »fundamentale(r) Begriffe«»in die Wirklichkeit« und zwar »geistig, indem die Begriffe und Vorgänge, soweit sie einschlägig, in Ansatz gebracht werden und alles, was durch sie noch nicht gedeckt ist, als überlagernde Erscheinung definiert wird. Manuell geschieht sie, indem die Umstände so lange variiert werden, bis die genaue Wirkung eintritt. Dadurch erscheint dieses `Variieren der Umstände`als ein `Fortschaffen störender Umständeく. (Dingler, zitiert nach Tetens S. 8.) Tetens führt diese Überlegungen zum Justieren des Experimentalsystems folgendermaßen weiter aus: »Widersprechen experimentelle Befunde zunächst einem Fundamentalgesetz, so versuchen die Experimentatoren die [...] unterstellten störenden Faktoren durch Variieren bis dahin noch nicht berücksichtigter Umstände zu identifizieren und durch ihre Isolation oder ihr Konstanthalten, also durch technischen Umbau der apparativen Versuchsanordnung unwirksam zu machen, so daß der im Experiment schließlich herbeigeführte Verlauf immer vollkommener, störungsfreier nach den Fundamentalgesetzen des Forschungsprogramms abläuft.«Tetens, 1987, S. 9.

57 Cartwright, Nancy: How the Laws of Physics Lie, New York 1983, S. 4. 
bolischen Formalismus ist für Cartwright nicht einfach eine Repräsentation, vielmehr eine Übersetzung in ein anderes mediales System eigener Gesetzmäßigkeit. Cartwright beschreibt dies (nun in umgekehrter Richtung) folgendermaßen: »I think theory entry proceeds in two stages. We start with an unprepared description, which gives as accurate a report as possible of the situation. The first stage converts this into a prepared description. At the second stage the prepared description is matched to a mathematical representation from the theory. Ideally the prepared description should be true to the unprepared. But the two activities pull in opposite directions, and a description that is adequate to the facts will seldom have the right mathematical structure. ${ }^{58}$

Betrachtet man den Symbolismus als eigenständige mathematische Struktur, als Darstellungs- und Folgerungstechnik, so ist klar, dass er nicht schlechthin die Ordnung der Wirklichkeit zu repräsentieren vermag, dass er vielmehr ein Ordnungssystem darstellt, das eigenen Regeln und Strukturbedingungen gehorcht.

Die Rolle von "präparierten Beschreibungen« oder »Modellen« als Mediatoren zwischen Empirie und Theorie, wie Cartwright sie beschreibt, wurde in der Folgezeit zu einem viel diskutierten Thema. ${ }^{59}$ Dass diese Rolle eine doppelte ist, hatte bereits Thomas S. Kuhn in seinem Postscriptum (von 1969) zu seiner Theory of Scientific Revolutions gezeigt: Kuhn legt auseinander, dass "symbolische Verallgemeinerungen «, also jene »Formeln, die problemlos von allen Gruppenmitgliedern gebraucht werden und ohne weiteres z.B. auf die logische Form (x) (y) (z) $\phi(x, y, z)$ gebracht werden können « ${ }^{60}$ für die Wissenschaftler sowohl die Rolle von Naturgesetzen als auch definitorische Funktion haben. Das heißt, dass sie sowohl die Rolle von Instrumenten als auch die Rolle von Resultaten spielen können - und zwar so, dass sie zwischen diesen beiden Rollen auch wechseln können, je nachdem, wie das »disziplinäre System « einer Wissenschaft ausgeprägt ist. ${ }^{61}$

58 Cartwright, 1983, S. 15.

59 Ulrich Gähde: Modelle der Struktur und Dynamik wissenschaftlicher Theorien. In: Andreas Bartels/Manfred Stöckler (Hrsg.): Wissenschaftstheorie, Paderborn 2007, S. 45-68, hier S. 64. Siehe dort zu weiterer Literatur zum Thema.

60 Thomas S. Kuhn: Die Entstehung des Neuen: Studien zur Struktur der Wissenschaftgeschichte, Frankfurt a.M.; S. 194.

61 Kuhn, 1988b, S. 198. 
Wir können für den Typus Laborwissenschaften also festhalten:

Theoretische Modelle sind in den Laborwissenschaften keine Repräsentationen der Wirklichkeit, sondern Übersetzungen in ein System, das seine eigene Logik hat. Soweit dies nur die Einsicht in die Unabhängigkeit zumindest einiger Teile einer jeweiligen Theorie von empirischen Befunden betrifft, ist dieser Punkt für die Wissenschaftsphilosophie seit Duhem trivial geworden. Doch die Einsicht, dass diese Unabhängigkeit besteht wie sie besteht, weil die Übersetzung eine Übersetzung in ein Symbolsystem mit symbolsystemischen Implikationen ist, ist alles andere als trivial. Denn zu diesen symbolsystemischen Implikationen gehört, dass sie als Folgerungstechniken zu gebrauchen sind, das heißt: Was herkömmlicherweise Theorie heißt, stellt sich hier als ein eigenständiges Feld der Praxis dar. Wir haben es mit zwei Feldern von Praxis zu tun, die auf eine für den Typus Laborwissenschaften charakteristische Weise miteinander korreliert sind.

\section{Noch einmal zum Verstehen: Das Forschungsparadigma der Hermeneutik - Was haben Verstehenslehren mit Kriminalistik zu tun? Der Ansatz der Rekonstruktion}

Ebenso wie die Scientia-Tradition bildet auch die Verstehenslehre einen Komplex von Ideen und Verfahren, der nur aus der Ferne wie eine geschlossene Einheit aussieht. Schauen wir näher hin, dann erkennen wir auch hier mindestens drei verschiedene Ansätze dafür, was Wissenschaft im Kern ausmacht.

Einer dieser Ansätze ist mit dem Begriff der Rekonstruktion, mit der Beziehung von Teil und Ganzem - und damit auch mit Analyse und Synthese verbunden. Um welche Disziplinen geht es, und um welche Zeit?

Herausgebildet hat sich dieser Ansatz in der ersten Hälfte des 19. Jahrhunderts, und zwar in den - zu dieser Zeit erstarkenden - Philologien und Geschichtswissenschaften, mit Ausstrahlung in die Rechtswissenschaften, aber auch in Naturphilosophie und Erkenntnistheorie. Seine populäre und wirkmächtige Form fand er schließlich gegen Ende des 19. Jahrhunderts in Wilhelm Diltheys Abgrenzung einer Methodik der Geisteswissenschaften von einer der Naturwissenschaften. Doch hatte sich hier längst das Paradigma der hermeneutischen Forschung mit einer ganzen Reihe anderer Motive vermengt, sodass seine Konturen nur mehr schwer zu erkennen sind. Sehen 
wir genau hin und lassen uns nicht irritieren von einer Sprache, die uns heute unvertraut ist.

Viele der uns in diesem Feld begegnenden Vokabeln - wie Intuition, Divination, Empathie, Mitwisserschaft, Mitgefühl ${ }^{62}$ - erwecken den Anschein, dass es sich beim Verstehen um eine irrationale Sache des Einfühlens handele. Doch dem Forschungsparadigma der Hermeneutik liegen sehr klare, strukturelle Überlegungen zugrunde. So bedeutet z.B. Divination, ein Begriff, den Friedrich Schleiermacher, der gemeinhin als Begründer einer wissenschaftlichen Hermeneutik gilt, ${ }^{63}$ prominent machte, schlicht vermuten und erraten (von lateinisch: divinare). Und dass ein solches Moment nötig ist, liegt schon an der Aufgabenstellung: Texte bestehen aus Teilen, Wörtern, Sätzen, Abschnitten. Die Bedeutung eines Textes, also wie er zu verstehen ist, hängt von seinen Teilen ab. Umgekehrt hängt aber die Bedeutung eines jeden Teils von seinem jeweiligen Kontext, letztlich vom Ganzen ab. Teil und Ganzes bestimmen sich gegenseitig. Das heißt, dass jeder Teil mit Blick auf seine möglichen Rollen im Ganzen und die Auffassung des Ganzen aus möglichen Arrangements der Teile entwickelt wird. Weder Teile noch Ganzes sind fix vorgegeben, sodass in die eine oder andere Richtung schlicht abgeleitet werden könnte.

Die für das Textverstehen charakteristische Bewegung zwischen Teil und Ganzem hat auch in den Geschichtswissenschaften einen zentralen Stellenwert. Denn auch hier gibt es, so Johann Gustav Droysen, wichtigster Methodologe der Historik im 19. Jahrhundert, keinen fixen Ausgangspunkt, von dem her sich ein historisches Phänomen erklären ließe. Droysen lehnt jedes Denken $a b$, das einen absoluten Anfang, einen Ursprung oder ein Wesen einer historischen Erscheinung annimmt. »[E]s ist einfach eine methodische Gedankenlosigkeit «, schreibt er, »wenn man forschend zu einem Punkt gelangen zu können meint, der anders als relativ der Anfang wäre, d.h. der sich anders als in dem, was daraus geworden ist, als Anfang ausweist $« .{ }^{64}$ Das

62 Meinrad Böhl/Wolfgang Reinhard/Peter Walter (Hrsg.): Hermeneutik. Die Geschichte der abendländischen Textauslegung von der Antike bis zur Gegenwart, Wien u.a. 2013, S. 442-548, hier S. 385.

63 Vgl. dazu den Eintrag >Verstehen<, in: Joachim Ritter (Hrsg.): Historisches Wörterbuch der Philosophie, Bd. 11, Basel 2001, S. 47291-47350, hier S. 47298-47302.

64 Johann Gustav Droysen: Historik. Band 1. Historisch-kritische Ausgabe von Peter Leyh, Stuttgart 1977 [1857/1858], S. 160. 
bedeutet, »dass wir [...] das Nacheinander, zu dem wir uns forschend das Gewordene rekonstruieren, nur nachzuahmen versuchen «. ${ }^{65}$

Dieser Begriff des Rekonstruierens ist zentral für das Forschungsparadigma der Hermeneutik. Im Wort Rekonstruktion steckt schon, dass der Erkenntnisgegenstand zusammengefügt (wörtlich: zusammengeschichtet) ist. Das Bedürfnis zu rekonstruieren kann nun aus zwei Gründen entstehen. In dem einen Fall sind von einem ehemaligen Zusammenhang nur Reste, Fragmente oder indirekte Zeugnisse wie Indizien, Symptome oder Spuren gegeben. Rekonstruieren bedeutet dann - wie bei einem Puzzle - die ursprüngliche Zusammensetzung so weit wie möglich wieder herzustellen.

Im anderen Fall bedeutet Rekonstruieren, zu einer gegebenen komplexen Erscheinung die Bedingungen ihrer Entstehung zu rekonstruieren, also: diese Bedingungen so weit aufzuklären, dass das Zustandekommen der Erscheinung verständlich, als schlüssige Zusammenführung der sie konstituierenden Faktoren erscheint. Der erste Fall kann als synthetische, der zweite als analytische Rekonstruktion bezeichnet werden. Doch in welchem Sinne Synthese und in welchem Analyse? Droysen hat, den zweiten Fall im Blick, eine prägnante Formulierung gefunden, was analytisches Verstehen in Abgrenzung vom szientifischen Paradigma bedeutet:

»Wir erklären nicht. Interpretation ist nicht Erklärung des Späteren aus dem Früheren, des Cewordenen als ein [notwendiges] Resultat der historischen Bedingungen, sondern ist Deutung dessen, was vorliegt, gleichsam ein Lockermachen und Auseinanderlegen dieses unscheinbaren Materials nach der ganzen Fülle seiner Momente, der zahllosen Fäden, die sich zu einem Knoten verschürzt haben, das durch die Kunst der Interpretation gleichsam wieder rege wird und Sprache gewinnt. ${ }^{66}$

Analyse (von analysis: Auflösung) bedeutet hier also nicht eine Aufteilung in einzelne, konstitutive Elemente, sondern ein Sichtbarmachen der Verhältnisse zwischen den Teilen, deren Beziehung dabei erhalten bleibt. Es geht um das Aus-Legen des Materials, um seine Ent-Faltung, um explicare (ausfalten), nicht um explanare (ausebnen).

65 Droysen, 1977, S. 159.

66 Droysen, 1977, S. 163. 


\section{BASISWISSEN 8: Analyse und Synthese - ein Begriffspaar fährt Achterbahn}

Das Begriffspaar Analyse und Synthese gehört zu den kompliziertesten Konzepten der Philosophie- und Wissenschaftsgeschichte. Dabei sind nicht die Worte das Problem: die griechische Vokabel analysis bedeutet Auflösung, synthesis Zusammensetzung. Kompliziert wird die Sache dadurch, dass sich in ihr Grundausrichtungen der Erkenntnistheorie niederschlagen - die Gegensätze von aristotelischer, euklidischer und atomistischer Auffassung von Erkenntnis prägen das Paar.

Zur Begriffsgeschichte: Das Begriffspaar Analyse/Synthese stammt, anders als häufig angenommen, nicht aus der antiken Philosophie. Nur analysis kann als ein Schlüsselbegriff bei Aristoteles gelten - titelgebend für zwei seiner Hauptwerke (Erste Analytik und Zweite Analytik). Doch es findet sich in den aristotelischen Werken keine Textstelle, in der analysis und synthesis auch nur gemeinsam erwähnt werden. Liest man zuweilen, Aristoteles habe methodische Leitlinien aus den Euklidischen Elementen übernommen, so steht dem schon die Chronologie entgegen.

Die Zusammenstellung von Analyse und Synthese taucht vermutlich erstmals in einem Zusatz zu Die Elemente von Euklid auf, der von dem um $100 \mathrm{n}$. Chr. lebenden Mathematiker und Ingenieur Heron von Alexandrien stammt. Dort liest man:

»Was ist eine Analysis und was eine Synthesis? Eine Analysis ist die Zugrundelegung des Gefragten als anerkannt um seiner auf anerkannt Wahres führenden Folgerungen willen. Eine Synthesis ist die Zugrundelegung des Anerkannten um seiner auf Vollendung oder Ergreifung des Gefragten führenden Folgerungen willen.«

Unschwer ist zu erkennen, dass der Kontext hier die geometrische Beweislehre ist, die als Erkenntnis more geometrico in der frühen Neuzeit Furore macht und sich von der aristotelischen Beweislehre genau in dem Punkt unterscheidet, dass Folgerungen bei Aristoteles keine Konstruktionsschritte sind, die das Gefolgerte tatsächlich produzieren (siehe oben 
BASISWISSEN 5). Deshalb ist der Komplementärbegriff zu Analysis bei Aristoteles nicht synthesis, sondern syllogismos, das heißt, die Zusammenstellung von Aussagen zu logischen Schlussfolgerungen. Synthesis wiederum verwendet Aristoteles in Kontexten der konkreten Zusammensetzung von Elementen, z.B. von Buchstaben zu Silben oder von Bausteinen zu einem Haus. Diese Verwendungsweise erklärt auch, warum in der aristotelischen Erkenntnislehre Synthese nicht das Gegenbild zu Analyse sein kann: An Elementen wie Buchstaben oder Bausteinen lässt sich nicht ablesen, wie sie zu sprachlichen Einheiten oder Gebäuden gefügt werden können, wer nicht über die Prinzipien der Sprache oder der Architektur verfügt. Diese Prinzipien sind deshalb das Ziel der aristotelischen analysis - nicht die synthetisierbaren Elemente (was einer atomistischen Erkenntnistheorie entspräche).

Die Idee einer Synthesis aus Prinzipien konnte nur über den Sonderfall des Mathematischen, in dem eine Schlussfolgerung zugleich eine Realkonstruktion aus Elementen, nämlich mathematischen Formen oder Buchstaben, bedeutet, in die Neuzeit vermittelt werden. Verbunden mit der christlichen Welt eines Schöpfergottes und mit dem neuen Selbstverständnis des Menschen als Homo faber konnte nun Wissenschaft als Disziplin der technischen Herstellung auf Grundlage mathematischer Konstruktion verstanden werden. Und dennoch: Der Glaube an die synthetische Herstellbarkeit beliebiger Produkte ist und bleibt ein Glaube, der die Geister scheidet. (Kogge/ Richter 2013)

Gabriele Gramelsberger/Peter Bexte/Werner Kogge (Hrsg.), Synthesis. Zur Konjunktur eines philosophischen Begriffs in Wissenschaft und Technik, Bielefeld 2013.

Werner Kogge/Michael Richter: »Synthetic biology and its alternatives:

Descartes, Kant and the Idea of Engineering Biological Machines«. In: Studies in History and Philosophy of Biological and Biomedical Sciences. Special Issue: >Philosophical Perspectives on Synthetic Biology<, Vol. 44, Issue 2, June 2013, S. 181-190. 
In der von Droysen pointierten Bewegung einer Analyse als ein Auseinanderziehen zeigt sich auch deutlich der Unterschied zur Auffassung von Wissenschaft als Beweisen und Erklären: Prinzipien und Axiome stehen dort als Ausgangspunkte fest, während im Verstehen die organisierenden >Prinzipien $<$ des Textes allererst erschlossen werden. Verstehen charakterisiert sich deshalb als eine suchende Bewegung des probeweisen Vorwegnehmens in einem Prozess über mehrere Stufen. Typischerweise läuft ein solcher Prozess etwa so ab: Wenn wir a als $\mathrm{x}$ auffassen, dann stellt sich der Zusammenhang so ... dar, was wieder bedeuten würde, dass b als y aufzufassen wäre und c als z, was aber nicht plausibel ist, weil ... eher könnte ... usw. Die Struktur kennen wir vom Rätsellösen und von vielen anderen Konstellationen, in denen es um Rekonstruktion von Zusammenhängen geht, etwa in der Aufklärung von Kriminalfällen und in der historischen Forschung.

Wie ein roter Faden zieht sich das so beschriebene Grundmotiv durch die verzweigte Geschichte der Verstehenslehren. Dass es auf den jeweiligen Kontext ankommt, erklärt schon Augustinus, ${ }^{67}$ und die Rolle der ScientiaDisziplinen besteht für ihn in nichts anderem als darin, Kontextwissen zum Verständnis des rätselvollen Zusammenhangs der Heiligen Schrift bereitzustellen. Zwar geht von Augustinus auch die Vorstellung aus, unklare Textstellen durch Vergleich mit klaren zu verstehen; und damit auch die Vorstellung von einer Kunst der Auslegung, die nach Regeln verfährt. Doch sind auch die Kunstlehren des Verstehens, die explizit auf rationale Verfahren setzen, dem forscherischen Motiv des Verstehens verpflichtet. Friedrich Schleiermacher drückt die Konstellation des Verstehens in der Formulierung aus, dass wir »öfter vom Ende zum Anfang zurückkehren und das Auffassen ergänzend von neuem beginnen; je schwieriger die Gliederung des Ganzen zu fassen ist, desto mehr suchend ihr vom Einzelnen aus auf die Spur [...] kommen, je reichhaltiger und bedeutsamer das Einzelne ist, um so mehr suchend es vermittelst des Ganzen in all seinen Beziehungen [auffassen]. ${ }^{68}$

Überhaupt spielt in diesem Forschungsparadigma das Detail in seiner Aussagekraft für das Ganze eine entscheidende Rolle: feine Unterschiede

67 Aurelius Augustinus: Die christliche Bildung (De doctrina christiana) [426/427], Stuttgart 2002, Zweites Buch, XII, 42; Drittes Buch XXV, 37.82 (S. 60 u. S. 128).

68 Friedrich Schleiermacher: Über den Begriff der Hermeneutik mit Bezug auf F.A. Wolfs Andeutungen und Asts Lehrbuch. In: ders.: Hermeneutik und Kritik, Frankfurt a.M. 1977, S. 309-346, hier S. 333f. 
sind hier wichtig. Carlo Ginzburg, italienischer Historiker und Kulturwissenschaftler, publizierte im Jahr 1979 Spie. Radici di un paradigma indiziaro. Ginzburg entwickelt hier den Begriff eines Indizienparadigmas als einen neuen Typ von Wissenschaft - dessen Verwandtschaft mit dem Forschungsparadigma der Hermeneutik aber auf der Hand liegt: wenn der Kunsthistoriker Giovanni Morelli Gemälde an wenig beachteten Details identifiziert, wenn Sherlock Holmes einen Tathergang aus der Beschaffenheit von Zigarettenasche erschließt und Freud psychische Konstellationen vom Lapsus her interpretiert, dann werden anhand von Details, Relikten und Unwillkürlichkeiten Rückschlüsse auf Gesamtzusammenhänge gezogen. Auch Ginzburg spricht davon, dass es in diesem Typ von Wissen darum geht, mithilfe »kleinster Indizien [etwas zu] rekonstruieren « ${ }^{69}$

Die Arbeiten von Gustav Droysen und Carlo Ginzburg trennen gut hundert Jahre. Und auch ansonsten scheint sie nicht viel zu verbinden. Doch betrachtet man beide in Hinblick auf das für die Geschichtswissenschaften zentrale Verfahren der Rekonstruktion, dann zeigen sie sich gemeinsam als Vertreter eines wissenschaftlichen Paradigmas - nämlich des Forschungsparadigmas der Hermeneutik. Ginzburg hebt sein Indizienparadigma vom Galileischen Paradigma der Wissenschaft ab und schreibt:

»An diesem Punkt eröffnen sich zwei Möglichkeiten: entweder man opfert die Erkenntnis des individuellen Elementes zugunsten der (mehr oder weniger streng mathematisch formulierbaren) Verallgemeinerung, oder man versucht - sich langsam vortastend - ein anderes Paradigma zu erarbeiten, das sich auf die wissenschaftliche Erkenntnis des Individuellen stützt (wobei es sich um

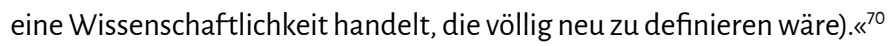

Dass diese Form der Wissenschaftlichkeit weder neu noch erst zu definieren wäre, haben wir gesehen. Aber halten wir fest: In einer Hauptlinie lässt sich die hermeneutische Tradition als Kern von Forschung im buchstäblichen Sinne auffassen. Re-Search/Forschung: wo geforscht wird, wird gesucht,

69 Carlo Ginzburg: Spurensicherung. Der ]äger entziffert die Fährte, Sherlock Holmes nimmt die Lupe, Freud liest Morelli - Die Wissenschaft auf der Suche nach sich selbst. In: ders.: Spurensicherung. Über verborgene Geschichte, Kunst und soziales Gedächtnis, München 1988, S. 78-125, hier S. 88 [Herv. WK] (im Orig.: Spie. Radici di un paradigma indiziaro, Torino 1979). 70 Ginzburg, 1988, S. 108. 
probiert, variiert, angepasst, neu konzipiert - unabhängig davon, ob die Teil-Ganzes-Relation zwischen Textstelle und Textganzem, zwischen historischem Akteur und politischem Geschehen oder zwischen Mikroorganismus und Krankheit methodisch hin- und hergeht. Das Kreuzworträtsel und das Puzzle sind Modelle einer solchen Konzeption. Und daher ist es ist kein Zufall, dass Thomas S. Kuhn das Puzzle-Solving als die Praxis wissenschaftlichen Forschens schlechthin angesehen hat. ${ }^{71}$ In jedem Fall geht es - wie in einem Kriminalfall - darum, Rätselhaftes zu entschlüsseln, indem es einem Gesamtzusammenhang schlüssig integriert wird, der selbst erst zu rekonstruieren ist. Das hermeneutische Verfahren stellt sich im Paradigma der Rekonstruktion - analytisch oder synthetisch - als ein Hin- und Hergehen in der Teil-Ganzes-Relation dar. Dabei ist keiner der beiden Pole der Bewegung fix gegeben, vielmehr erschließt sich der Sinn des Ganzen sukzessive aus den Details und die Rolle der Details aus ihrer Position im Zusammenhang.

\section{Adäquatheit - Von der Anpassung der Konzepte zur Einfühlung und zurück}

In der Tradition von Interpretation und Hermeneutik verschachteln und verzweigen sich aber auch andere Motive. So ist es eine der ältesten und uns auch geläufigsten Vorstellungen, dass Erkenntnis darin besteht, das Auffassen in Übereinstimmung mit dem Gegenstand zu bringen. Ob wir Konzept, Begriff, Repräsentation, Beschreibung oder - traditionellerweise Idee oder Intellekt dazu sagen: Immer geht es darum, dass Form und Struktur, worin wir etwas auffassen, dem entspricht oder sich zumindest dem angleicht, was aufgefasst wird.

71 »Die Metapher des >Rätsel-Lösen [puzzle-solving]< zur Charakterisierung der normalen Wissenschaft spielt in Kuhns Schriften an vielen Orten eine zentrale Rolle. Kuhn hat als Quelle der Analogie etwa Kreuzworträtsel, Zusammensetzspiele (Puzzles) und Schachprobleme im Blick. Für Kuhn ist die Analogie der normalwissenschaftlichen Forschungsarbeit mit dem Rätsellösen so tiefgehend, dass er am ehesten in dieser Analogie ein Abgrenzungskriterium sieht, mit dem die Wissenschaften von anderen kreativen Unternehmen - wie den Künsten in einem weiten Sinn oder der Philosophie unterschieden werden können.«Paul Hoyningen-Huene: Die Wissenschaftsphilosophie des Thomas S. Kuhns. Rekonstruktion und Crundlagenprobleme, Braunschweig 1989, S. 168, mit einer Fülle von Belegen. 
Die Idee des Verstehens durch Angleichung lässt sich zurückverfolgen bis zu Textstellen bei Platon, sie findet eine Widerspiegelung in der Schrift perí hermēneías des Aristoteles (Verstehen als sympatheia: „Verstehen [...] findet dann statt, wenn der verstehenden Seele dasselbe widerfährt, was der Seele des Sprechers widerfuhr ${ }^{7^{2}}$ ) sie lässt als homoion-homoio-Prinzip (»Gleiches zu Gleichem «) an diversen Stellen im antiken Denken nachweisen, ${ }^{73}$ taucht beim Neuplatoniker und Aristoteles-Kommentator Porphyrios in dem Satz, "alle Erkenntnis sei eine Verähnlichung mit dem Erkannten « ${ }^{74}$ auf und wird im Mittelalter zur stehenden Wendung: »jede Erkenntnis erfolgt durch eine Art Angleichung [assimilatio] des Erkennenden an das Erkannte ${ }^{75}$, schreibt Thomas von Aquin und Nikolaus von Kues spricht von einer »vis assimilativa« als einer »Fähigkeit, sich selbst den Gegenständen zu verähnlichen (sse assimilare $) \ll \cdot{ }^{76}$ Die »adaequatio rei et intellectus«, die Thomas von Aquin als eine klassische Wahrheitskonzeption referiert, gehört ebenfalls hierher. ${ }^{77}$

Dieser Gedanke einer Angleichung oder Anpassung des Intellekts an die Sache blieb aber stets im Kontext der Angleichung an die Struktur einer als göttlich oder kosmologisch gedachten Weltordnung. Was nun im 19. Jahrhundert neu ist, sich zumindest hier erst deutlich ausprägt, ist die Übertragung dieses Motivs auf das Verstehen individueller Autoren oder historischer Akteure.

Schleiermacher hatte als Aufgabe bestimmt, »den ganzen inneren Verlauf der komponierenden Tätigkeit des Schriftstellers auf das vollkommenste nachzubilden ${ }^{78}{ }^{78}$ Dies ließ sich unter dem Aspekt umsetzen, dass man versteht, indem man den Entstehungsprozess von den Anfängen zum Ganzen rekonstruiert, aber auch so, dass man versteht, indem man sich dem Gegenstand anverwandelt. Zwei Relationen: zum einen die von Teil und

72 Matthias Jung/Arne Moritz/Magnus Schlette: Philosophie. In: Meinrad Böhl/Wolfgang Reinhard/Peter Walter Hermeneutik. Die Geschichte der abendländischen Textauslegung von der Antike bis zur Gegenwart, Wien u.a. 2013, S. 442-548, hier S. 447f.

73 Axel Horstmann: Das Fremde und das Eigene - >Assimilation< als hermeneutischer Begriff. In: Archiv für Begriffsgeschichte, Bd. 30, Bonn 1986/87, S. 7-43.

74 Vgl. Horstmann, 1986-87, S. 15.

75 Vgl. Horstmann, 1986-87, S. 15.

76 Vgl. Horstmann, 1986-87, S. 18.

77 Vgl. den Eintrag >Wahrheit< in: Joachim Ritter, Joachim (Hrsg.): Historisches Wörterbuch der Philosophie, Bd. 12, Basel 2005, S. 48552-48784, hier S. 48612.

78 Schleiermacher 1977, S. 321. 
Ganzem, zum anderen die von Ich und $\mathrm{Du}$. Die zweite bestimmte die romantische Hermeneutik und das Bild, das in der Folgezeit die Vorstellung vom Verstehen als Einfühlen beherrscht. So formulierte etwa Droysen (allerdings nur in Bezug auf einen Typ Interpretation - die spsychologische`), dass wir um »zu verstehen gleichsam in ihre Seele [der schöpferisch Tätigen, Anmerkung des Verfassers] hineinzuversetzen suchen müssen, um den Tatbestand [...] auch in seinem Werden durch den Willen und die Leidenschaften der Führenden und Handlenden zu erkennen. $\ll^{79}$ Radikaleres lesen wir aus dieser Zeit bei dem Historiker Leopold v. Ranke (»Ich wünschte mein Selbst gleichsam auszulöschen ... $\ll^{80}$ ) und bei dem Altphilologen August Boeckh (»[es] wäre aber nöthig, dass man vollständig in eine fremde Individualität einginge $\ll^{81}$ ).

Ein Feld, in dem diese Differenz von Wissenschaftskonzeptionen im 20. Jahrhundert ausgetragen wurde, ist eine wissenschaftstheoretische Kontroverse in der Ethnologie und Cultural Anthropology. Ausgangspunkt war das Bemühen, die Ethnologie stärker wissenschaftlich auszurichten, und zwar sollte dies - so Bronislaw Malinowski, der führende Akteur dieser Bewegung in den 1910 bis 1940er Jahren - durch Feldforschung einerseits und durch funktionale Analyse der Strukturen einer Gesellschaft andererseits geschehen.

Allerdings wurde dieser Ansatz seit Ende der 1960er Jahre mehr und mehr infrage gestellt: Ist es überhaupt möglich, eine angemessene Beschreibung einer fremden Kultur zu erstellen, wenn diese Beschreibung doch stets in der jeweils eigenen Kultur des Wissenschaftlers erfolgt? Projizieren wir nicht nur unsere eigenen kulturellen Denkmuster auf die Gesellschaft, die wir untersuchen?

Als Reaktion auf dieses Dilemma kristallisieren sich zwei Forschungsansätze heraus, die den beiden hermeneutischen Paradigmen der forschenden Rekonstruktion und der Adäquation entsprechen. Zum einen nämlich hat Clifford Geertz, ein US-amerikanischer Anthropologe, der in den 1960er bis 1990er Jahren die Debatte mitprägte, einen hermeneutischen Ansatz ent-

79 Droysen, 1977, S. 165.

80 Leopold von Ranke: Sämmtliche Werke, 54 Bde (Leipzig 1867-90) Bd. 15, 103. Zitiert nach Horstmann, 1986/87, S. 26.

81 August Boeckh: Encyclopädie und Methodologie der philologischen Wissenschaften, hrsg. v. Ernst Bratuscheck, Wiesbaden 1886, S. 140. 
wickelt, der das rekonstruktive Forschungsparadigma wieder aufrief: Kulturen seien »selbstgesponnene [...] Bedeutungsgewebe «, ${ }^{82}$ die sich aus dem Selbst- und Weltverständnis ihrer Mitglieder ergeben. Ethnographische Forschung bestehe daher im Kern darin, das Gewebe dieses Verständnisses zu rekonstruieren. Im Unterschied zum Forschungsansatz der Malinowski-Schule gibt es für Geertz keine universalen sozialen Strukturen, die am Gegenstand aufgedeckt werden können, sondern je spezifische - individuelle - Bedeutungswelten, die mit Sinn fürs Detail und Gespür für weite Zusammenhänge nachvollzogen, oder - wie Geertz es ausdrückt, »über die Schultern derjenigen, für die sie eigentlich gedacht sind, zu lesen « sind..$^{83}$

Vom Denken der romantischen Hermeneutik des 19. Jahrhunderts grenzt sich Geertz mit solchen Worten ab: »Es geht nicht darum, eine innere Korrespondenz mit seinen Informanten herzustellen, die daraufhin ohnehin keinen besonderen Wert legen, da sie, wie wir alle, ihre Seele lieber als ihre eigene Angelegenheit betrachten. Es geht vielmehr darum herauszufinden, wie sie sich überhaupt selbst verstehen. ${ }^{84}$

Doch auch die andere Seite entwickelte eine in sich kohärente Argumentation: Wenn nämlich klar ist, dass jede Interpretation auch eine Übersetzung in den Verständnishorizont einer wissenschaftlichen Community ist und dass damit, trotz aller Bemühung, den Gegenstand aus sich heraus zu verstehen, ein Moment der Projektion eingeht, dann bleibt jede Interpretation hinter ihrem selbstgesteckten Objektivitätsanspruch zurück. Es bleibt dann nur, wie Vincent Crapanzano schreibt, sich in einem Prozess »beständiger Reinterpreatation und Neuanpassung ${ }^{85} \mathrm{zu}$ halten. So manifestierte sich in der Ethnologie das Gebot der Anpassung der Konzepte an den Gegenstand als ein radikal selbst-kritisches und gerade deshalb - in einem bestimmten avancierten Sinne - wissenschaftliches Unternehmen.

Im Resultat führte diese Radikalisierung wissenschaftlicher Objektivität aber dazu, dass hinter der Fokussierung auf das Gepräge des Erkenntnisvor-

82 Clifford Geertz (im Orig. 1973): Dichte Beschreibung. Beiträge zum Verstehen kultureller Systeme, Frankfurt a.M. 1991, S. 9.

83 Geertz,1991, S. 259. Vgl. dazu BirgitGriesecke: Japandicht beschreiben. Produktive Fiktionalität in der ethnographischen Forschung, München 2001.

84 Geertz, 1991, S. 292.

85 Vincent Crapanzano:, Tuhami. Porträt eines Marokkaners, Stuttgart 1983, S. 184. Vgl. dazu Werner Kogge: Die Grenzen des Verstehens: Kultur-Differenz-Diskretion, Weilerswist 2002, S. 143 f. u. S. 153-162. 
gangs der Gegenstand - hier: die untersuchte Kultur - in den Hintergrund rückte. Auch das wiederum erwies sich als schwer vereinbar mit Geboten von Wissenschaftlichkeit. So zeigt sich, dass Ansprüche an Wissenschaftlichkeit ab einem bestimmten Punkt ihrer Radikalisierung mit anderen solchen Ansprüchen in Konflikt geraten können.

Das sieht nach Dilemma aus. Doch, pragmatisch gewendet, läuft das Adäquationsparadigma schlicht auf die Frage zu: Wie muss ich meine eigenen Begriffe, mein Vorwissen, die Struktur meiner Überzeugungen und Auffassungen befragen und neu formieren, um den Eigenarten meines Erkenntnisgegenstandes gerecht $\mathrm{zu}$ werden ${ }^{86}$ Und dies ist sicherlich ein Wissenschaftsideal von eigenem Wert.

\section{$\checkmark$ VERTIEFEND Zur Begriffsgeschichte von sObjektivitätı}

Die Idee, einer Sache wissenschaftlich gerecht zu werden, indem die eigenen Formen der Auffassung verändert und der Sachlage angepasst werden - diese Idee ist eng mit der Begriffsgeschichte von Objektivität verbunden. Werfen wir einen Blick auf diese Geschichte, um zu sehen, welche Verwicklungen es so schwierig machen zu klären, was es bedeutet, wenn sich Wissenschaft heute auf Objektivität beruft.

Das Wort Objektivität geht auf das mittelalterlich-lateinische Adjektiv obiective und das wiederum auf das Nomen obiectum zurück. Die spannende Wendung im Begriff Obiectum liegt darin, dass ein spätantiker Aristoteleskommentator und frühchristlicher Autor, nämlich Anicius Manlius Severinus Boethius (ca. 480-526), die griechisch-antike Erkenntnistheorie mit diesem neuen Begriff versah und ihr damit einen ganz neuen Dreh gab.

Der Grundgedanke der klassisch-antiken Erkenntnistheorie besteht darin, Erkenntnis als ein Streben (orexis) anzusehen, bei dem das Zu-Erkennen-

86 Bemerkt werden soll an dieser Stelle, dass die Hermeneutik des 19. Jahrhunderts mit ihrem lebensphilosophischen Rückgriff das Problem süberwand, indem sie es schlicht aussetzte und zwar, indem sie eine Kontinuität in der menschlichen Natur und Ceschichte voraussetzte (Dilthey: »Das Verstehen ist ein Wiederfinden des Ich im Du ... (Dilthey, Wilhelm (im Orig. 1910): Der Aufbau der geschichtlichen Welt in den Ceisteswissenschaften, Frankfurt a.M. 1993, S. 235), worauf wiederum die philosophische Hermeneutik des 20. Jahrhunderts (Heidegger, Gadamer, Ricoeur, Taylor) im Sinne vertiefter Problemwahrnehmung reagierte. Vgl. Werner Kogge: Verstehen und Fremdheit in der philosophischen Hermeneutik: Heidegger und Gadamer, Hildesheim 2001. 
de die Erkenntnisbemühung in Bewegung setzt und auf sie anziehend wirkt, sodass das Erkennen wiederum sich auf das Zu-Erkennende als Zielpunkt ausrichtet. Wir haben es also mit einer Denkfigur der Entelechie (wörtlich: 'Ins-Ziel-Haltens) und der Angleichung des Erkennens an das Erkennbare zu tun. Platons Sonnengleichnis in der Politeia (VI. Buch) und Aristoteles Ausführungen Über die Seele (Buch II u. III) liefern ausführliche Darstellungen dieser Denkfigur.

Für das Strebensziel des Erkennens gibt es im griechischen Denken aber kein Wort wie Gegenstand oder Objekt. Die Texte sprechen stets vom Wahrnehmbaren und Erkennbaren (erst die Übersetzungen ergänzen hier regelmäßig Objekt). Ein Begriff für ein solches Gegenüber (wörtlich: Entgegengeworfenes; Entgegenstehendes) hat erst viele Jahrhunderte später eben jener Boethius geprägt, indem er das in vielen Kontexten geläufige lateinische Wort obiectum in diesen Kontext einführt:

„Wenn aber bei der Wahrnehmung der Körper (in corporibus sentiendis), obwohl hierbei von aussen (forinsecus) entgegentretende Beschaffenheiten (obiectae qualitates) die Sinneswerkzeuge (instrumenta sensuum) beeinflussen (afficiant) und das leidende Empfinden (passio) des Körpers der Kraft des tätigen Ceistes vorausgeht, was die Tätigkeit des Geistes auf sich lenkt (provocet) und die inzwischen innen (intrinsecus) ruhenden Formen erweckt (excitet), wenn [...] bei der Wahrnehmung der Körper der Geist nicht durch Leiden Eindrücke erfährt, sondern aus eigener Kraft die vom Körper abhängige Empfindung (subiectam corpori passionem) beurteilt, um wieviel mehr folgt das, was von allen Berührungen durch Körper frei ist, beim unterscheidenden Erkennen nicht dem von aussen Entgegentretenden (obiecta extrinsecus), sondern setzt vielmehr die Tätigkeit des eigenen Ceistes in Bewegung. (87 $^{87}$

87 Anicius Manlius Severinus Boethius: Consolatio philosophiae III, 7. Prosa-10. Prosa. In: Trost der Philosophie. Übers. u. hrsg. v. Karl Büchner. Mit einer Einf. v. Friedrich Klingner, Stuttgart 1971. Zitiert nach: Kurt Flasch: Ceschichte der Philosophie in Text und Darstellung. Mittelalter, Stuttgart 1982, S. 125. 
Indem Boethius in »dieser beachtenswerten Kritik an der stoischen Abbildtheorie ${ }^{88}$ die Produktivität des menschlichen Denkens $\ll^{89}$ herausarbeitet, liefert er den scholastischen Debatten um die Erkenntnisfähigkeit der Seele ein Konzept, das dort weithin Wirkung entfaltete. Im 13. und 14. Jahrhundert ist die Philosophie intensiv mit dieser Konzeption befasst. ${ }^{90}$ Zwei sich überlagernde Problemkomplexe entfalteten ihre Wirkung: zum einen das Bild vom Weg der Erkenntnis von den Wahrnehmungen, bei denen sie beginnt, zu den Einsichten, auf die sie zielt, zum anderen das Verhältnis von passiver Affiziertheit und aktiver Denkleistung. Zusammen spannen sie eine Konzeption auf, in deren Mittelpunkt jeweils das >Obiectum< steht.

Entscheidend für die langfristige Entwicklung des Objektivitätskonzepts wird dabei die Semantik sein, die Boethius am Rande anklingen lässt: das Innere und das Äußere. Der Zielpunkt (obiectum), auf den sich Erkenntnis richtet, liegt in der Außenwelt, der Austragungsort, in dem sich Erkenntnis vollzieht, ist die innere Welt. Das christliche Denken hatte - mit großer

88 Die zitierte Passage schließt an einen poetischen Textteil an, eines der Cedichte (Carmina), mit denen Boethius die prosaischen Textteile versetzt: »Einstmals brachte der Stoa Kreis/ Alte, neblige Männer hervor,/Die da meinten, es sei dem Geist/Von den Körpern von außen her/Bild und Sinne so aufgeprägt,/Wie der emsige Griffel oft/Auf die ebenen Tafel, die/ Noch von Zeichen nicht eine Spur/Auf sich trägt, seine Lettern setzt./Doch wie drückte lebendger Geist/ohne eigne Bewegung sich aus,/Wenn er selbst nur geduldig liegt,/ Sich dem Eindruck der Körper fügt,/Wenn er tot wie ein Spiegelglas/Gibt ein Abbild der Außenwelt? Woher käme das Wissen dem Geist,/Das ihn stark macht, das All zu schaun?/ Wo die Kraft, die das Einzelne sieht/Und die aufteilt, was sie erkennt,/Das Ceteilte von neuem eint,/Daß sie wechselnd die Wege wählt,/Jetzt dem Höchsten das Haupt gesellt,/ Jetzt zum Tiefsten heruntersteigt,/Wieder dann zu sich selber kehrt/Und mit Wahrheit das Falsche besiegt?/Dies ist der mächtig bewirkende Grund,/Weit über jenen andern hinaus,/Der in der Art des trägen Stoffs/Jeden Eindruck nur duldend trüg,/Freilich geht ihr erregend vor,/Was des Geistes Kräfte bewegt:/Lebender Körper Empfänglichkeit,/Wenn das Licht in die Augen fällt/Und die Stimme im Ohr schallt./Dann erweckt auch des Geistes Kraft,/Was an innerer Schau er trägt, Ruft zu gleicher Bewegung auf, Paßt es äußerem Eindruck an/Und vermählt im Innern nun/der verborgenen Form das Bild. «195f. Boethius führt hier die aktive Geistestätigkeit des dialektischen Unterscheidens (siehe Kapitel 14: Kritik) so ins Feld, dass durch diese methodische Tätigkeit die geistigen Formen aktiv auf die empfangenen Eindrücke angewandt werden (die Übersetzung ist hier recht frei, im Lateinischen lesen wir: »Tum mentis vigor excitus/quas intus species tenet/ad motus similis vocans/notis applicat exteris/introrsumque reconditis/formis miscet imagines.«

89 Flasch, 1982, S. 108.

90 Vgl. Historisches Wörterbuch der Philosophie, hrsg. v. Joachim Ritter, 〉Objekt<, Bd. 6, insbes. 1026-1035. 
Wucht schon bei Augustinus (354-430) - im Unterschied zum antik-griechischen Denken den Selbstbezug des Menschen als Hinwendung auf die eigene Seele, also auf einen emphatisch aufgeladenen Innenraum, konzipiert. ${ }^{91}$

Das Begriffspaar Subjekt/Objekt bildet sich auf dieser Grundlage ebenfalls in der Scholastik aus. Boethius hatte das aristotelische $>$ Zugrundeliegende< (hypokeimenon) mit ssubiectum übersetzt und damit (gemäß der aristotelischen Kategorienschrift) das Verhältnis von Wesen (Substanz) und zufälligen Eigenschaften (Akzidenz) bestimmt: Eigenschaften können nur in einem Zugrundeliegenden (subiectum), einer Substanz auftreten. Subjekt bezeichnet also Substanz als Träger von Eigenschaften. Entsprechend bedeuten die Adjektive subiektive/obiektive in der Hochscholastik zwei Weisen oder Stadien, in denen etwas im Intellekt bzw. der Seele sein kann: als Erkenntnis dessen, was einem Träger akzidentell zukommt (wie das weiß einer Oberfläche) (»Esse in intellectu subiective est inhaerere ipsi, sicut accidens suo subiecto, ut albedo superficiei«) und als Erkenntnisakt, wie er sich vollendet. (»Esse in intellectu obiective est terminare actum intellectus $)^{92}$

Obwohl bis weit in die moderne Philosophie die Unterscheidung von Trägersubjekt (mitsamt zukommender Eigenschaften) und Zielobjekt des Erkenntnisakts erhalten blieb, wurde mehr und mehr das Moment des Zufälligen im Verhältnis von Trägersubstanz und Akzidenz semantisch wirksam, zumal das zugrundeliegende teleologische (zielorientierte) Erkenntnismodell in der Neuzeit durch ein mechanistisches ersetzt wurde - was die Beziehung von Geist zu Erkenntnisgegenstand aus der vormaligen Integration löste und einem fundamentalem Zweifel aussetzte (Descartes). In diesem neuen Paradigma konnte das Subjektive bald als Ort willkürlicher Zuschreibung, das Objektive als Instanz eines begründeten Urteils aufgefasst werden - so etwa beim Jesuiten Alfonso Antonio de Sarasa (1618-1667). Dort heißt es:

»Diejenige Gewißheit, die aus einer positiv vorliegenden Evidenz oder aus Gründen entspringt, welche hinreichend sind, damit man rationalerweise

91 Birgit Criesecke: Der Innenraum der Erfahrung. Selbstbezug, Selbstobjektivierung und die Genese des Selbstexperiments. In: Nicolas Pethes/Birgit Criesecke/Marcus Krause/ Katja Sabisch: Menschenversuche. Eine Anthologie 1750-2000, Frankfurt a.M. 2008, S. 37-44 (mit Rekurs auf Werner Kogge: Begreifen von Erfahrung. Über den Verlust der Erfahrung in der Geschichte des Denkens, unveröffentl. Manuskript eines Vortrags in Leipzig 2007).

92 Zitiert nach Historisches Wörterbuch der Philosophie, hrsg. v. Joachim Ritter, sSubjekt/ Objekt, subjektiv/objektiv«: Bd. 10, S. 401; mit unklarer Quellenangabe. 


\section{BASISWISSEN 9: Was bedeutet `Objektivität‘?}

Objektivität steht so sehr für Wissenschaftlichkeit, dass >objektive Wissenschaft fast schon nach einer Verdopplung klingt. Wissenschaft objektiviert, was subjektiv empfunden oder gemeint ist. So jedenfalls wird heute gedacht und gesprochen. Doch welcher Gedanke steckt in diesen Worten?

Die Wissenschaftsgeschichte rekonstruiert für das 18. und 19. Jahrhundert, wie eine ontologische Auffassung von Objektivität durch moderne Konzepte von Objektivität ergänzt und abgelöst wurde. Doch >ontologisch trifft den historischen Kern des Begriffs nicht: vielmehr als um einen Begriff der Seinslehre handelt es sich um einen der Erkenntnistheorie.

Der Begriff Objekt stammt aus einer Interpretation der antik-griechischen Erkenntnistheorie durch Boethius (ca. 480-526). Mit Objekt wird gemäß dieser Interpretation das Strebensziel des Erkennens bezeichnet, und zwar als ein Gegenüber (wörtlich: Entgegengeworfenes; Entgegenstehendes), das gegenüber den im Intellekt befindlichen Auffassungsformen äußerlich ist.

Das Begriffspaar objektiv/subjektiv wurde in der Hochscholastik gebildet, indem der Ausrichtung auf das Strebensziel (auf das Objekt gerichtet: objektiv) die Trägersubstanz gegenübergestellt wurde, deren Eigenschaften $\mathrm{zu}$ bestimmen sind. Als Bestimmungsgrund hieß die Trägersubstanz schon bei Boethius Subjekt (Untenstehendes; übers. v. griech. hypokeimenon) und so wurde das Zu-Bestimmende, wie es im Intellekt zunächst gegeben ist, zum Subjektiven.

urteilen kann, daß es sich tatsächlich so verhält, wie es sich dem Ceist darstellt, ist für >objektiv<, d.h. dem Objekt entsprungen, zu betrachten [...] Die andere Cewißheit stammt aus dem Subjekt. Sie liegt vor, wenn einer irgendeiner Meinung oder These verbissen anhängt [...] Diese Cewißheit [...] rührt 
Diese semantische Konstellation bildet die Grundlage für die moderne Auffassung von Objektivität. Das Konzept der Objektivität prägt sich als aperspektivische (auch: soziale) und als mechanische (auch: methodische) Konzeption von Objektivität aus. Aperspektivische oder soziale Objektivität ist mit der Überwindung individueller Perspektive durch Pluralisierung der `Standpunkteく, durch die Herstellung von Öffentlichkeit, durch wissenschaftliche Professionalisierung und Verfahren der Prüfung in der scientific community verknüpft; mechanische (auch: methodische) Objektivität mit der Automatisierung von Wahrnehmung und Datenverarbeitung, also mit dem Einsatz von Messinstrumenten, Quantifizierung und mathematischen Verfahren. (Daston 1992; Heintz 2000; Daston/Galison 2007)

Die mit dem Begriff Objektivität verbundene Validierung ließ sich sodann im Zeichen der Kritik (siehe Kapitel 13) weiter ausführen: Objektivität ist demnach nur so weit erreichbar ist, wie sich das Subjekt ebenso einer kritischen Prüfung unterzieht. (Harding 1995)

Lorraine Daston: Objectivity and the Escape from Perspective. In: Social Studies of Science, Vol. 22, No.4. 1992. S. 597-618.

Lorraine Daston/Peter Galison: Objektivität. Frankfurta.M. 2007.

Bettina Heintz: In der Mathematik ist ein Streit mit Sicherheit zu entscheiden. Perspektiven einer Soziologie der Mathematik. In: Zeitschrift für Soziologie, No. 5 (2000), S. 339-360.

Sandra Harding: >Strong Objectivity : A Response to the New Objectivity Question. In: Synthese,3 (1995), S. 331-349.

offensichtlich aus dem Subjekt selber her, d.h. aus dem sich Gewißheit fabrizierenden Menschen «. ${ }^{93}$

Wir befinden uns in der Mitte des 17. Jahrhunderts. Wenn die Wissenschaftsgeschichte für das 18. und 19. Jahrhundert eine aperspektivische (auch: so-

93 Zitiert nach Historisches Wörterbuch der Philosophie, hrsg. v. Joachim Ritter, sSubjekt/ Objekt, subjektiv/objektiv«: Bd. 10, S. 404. 
ziale) und eine mechanische (auch: methodische) Konzeption von Objektivität unterscheidet, so waren die Grundmotive von Objektivität in Abgrenzung von subjektiver Willkür und subjektiver Privatheit also längst vorbereitet.

Was die wissenschaftsgeschichtlichen Beobachtungen aber zeigen, ist, wie auf dieser Grundlage Objektivität immer mehr zur Verfahrensform wurde: Eine mechanische Erfassung des Gegenstandes durch Einsatz von Messinstrumenten, Quantifizierung und standardisierten Verfahren wurde zum Ideal; Sozialität durch wissenschaftliche Professionalisierung und durch Verfahren der Prüfung in der scientific community wurde zur Bedingung. Dass in diesem Umschlag in die Verfahrensform, dass im Namen von Objektivität die Sache, der es gerecht zu werden gälte, leicht aus dem Blick geraten kann - das liegt auf der Hand. Objektivität ohne Affektion durch das `Zielobjekt< des Forschens kann ihrerseits in Willkür umschlagen.

Dies ist der Einsatz einer reflexiven Objektivität im Zeichen des Paradigmas der Kritik (siehe Kapitel 13). Objektivität ist demnach nur so weit erreichbar, wie sich das Subjekt ebenso einer kritischen Prüfung unterzieht. ${ }^{94}$

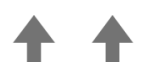

\section{Der "Sehepunkt» des Verstehens - das Paradigma der Kritik: Wissenschaftlichkeit durch Reflexivität}

Wenn die Beweislehre wissenschaftstheoretisch die prominenteste Traditionslinie der Wissenschaftskonzeptionen ist, so ist die der Kritik die verborgenste - und dennoch ist sie in der Praxis ebenso relevant. Im Kern geht es in dieser Traditionslinie darum, im schon Bekannten die Bedingungen, Merkmale und Konstitutionsmomente herauszuschälen, die für ein Phänomen entscheidend sind.

94 Vgl. Sandra Harding: Whose Science? Whose Knowledge? Thinking from Women's Lives, Ithaca 1991 (deutsch: Das Geschlecht des Wissens: Frauen denken die Wissenschaft neu, Frankfurt a.M. 1994); Sandra Harding: sStrong Objectivity«: A Response to the New Objectivity Question. In: Synthese, 3(1995), S. 331-349. 
Der Gedanke, dass Wissenschaft letztlich darin besteht, jede >Erkenntnis kritisch (von griechisch krinein: unterscheiden) daraufhin $\mathrm{zu}$ befragen, ob sie tatsächlich Bestand hat, dieser Gedanke ist der vielleicht am tiefsten verankerte, aber am wenigsten bewusste Gedanke zur Bestimmung von Wissenschaftlichkeit. Von der Platonischen Formel gnosthenta krinai (das Eingesehene unterscheiden) ${ }^{95}$ über die Aristotelische Konzeption eines Unterscheidungsvermögens als Kern der Erkenntnisfähigkeit ${ }^{96}$ und reflexiven Klugheit, ${ }^{97}$ über die Stoa, Cicero und Quintilian in die Neuzeit zu Petrus Ramus wird in bemerkenswerter Kontinuität diese Denkfigur entfaltet.

Ihren eminenten Stellenwert erhielt die Kritik dadurch, dass sie als Methodik der beiden grundlegenden Erkenntniswege der antiken Philosophie angesehen werden konnte. Sie liegt sowohl im Kern der Platonischen Dialektik mit ihrem Abschälverfahren als auch in dem der Aristotelischen Analysis, die ebenfalls auf Unterscheidungsfähigkeit aufbaut. Auf dieser Basis konnten z.B. die Stoiker Dialektik und Kritik identifizieren und von der Grammatik so absetzen, dass es in der Kritik wie schon bei Platon um kritische Reflexion von Gedachtem, nämlich »um die inhaltliche Beurteilung des von der Grammatik festgestellten Textes geht. ${ }^{98}$

In Reaktion darauf wiederum konnte Cicero - die Einteilung des aristotelischen Organons aufnehmend - gegen eine (unterstellte) Fixierung auf den Weg der Kritik (»via iudicandi«: »die Wissenschaft (scientia), die Dialektik genannt wird «) eine ars inveniendi (Erfindungskunst) im Sinne der Topik einfordern. ${ }^{99}$ Dieser Gegensatz von Kritik und Erfindungskunst wurde über Boethius und die Scholastik tradiert und blieb auch in der frühen Neuzeit

95 Platon: Politikos (Übersetzung von Friedrich Schleiermacher). Sämtliche Werke in zehn Bänden, Frankfurt/Leipzig 1991, 259c.

96 Aristoteles: Über die Seele, auf Grundl. d. Übers. v. W. Theiler hrsg. v. Horst Seidl Hamburg 1995, 432a 16. Vgl. zu Platon und Aristoteles den Eintrag ’Kritik« in: Historisches Wörterbuch der Philosophie, hrsg. v. Joachim Ritter, Bd. 4, insbes. S. 15195-15199.

97 Aristoteles: Nikomachische Ethik, übers. u. hrsg. v. Ursula Wolf, Reinbek bei Hamburg 2006, 1143a.

98 Eintrag «Kritikı in: Historisches Wörterbuch der Philosophie, hrsg. v. Joachim Ritter, Bd. 4, insbes. S. 15206.

99 Vgl. dazu: Historisches Wörterbuch der Philosophie, hrsg. v. Joachim Ritter, Bd. 4, S. 15207. Quintilian konnte mit revidierendem Rekurs auf Cicero resümieren: »Denn in jenen [den dialektischen Unterredungen] suchen gelehrte Menschen unter Gelehrten nach dem Wahren, durchforschen alles bis ins Kleinste und mit ängstlicher Genauigkeit und führen es zur Gewißheit und zum allgemein Zugestandenen, so daß sie für sich sowohl den Teil 
intelligibel, sodass im 16. Jahrhundert Petrus Ramus an die antike Denkfigur der sunterscheidenden Beurteilung von Eingesehenem formulieren konnte, dass »wir natürlicherweise zuerst gedanklich erfassen, was erörtert werden soll, und dann dieses Angeordnete unterscheidend behandeln ${ }^{100}$

Doch - wie unterscheiden wir eigentlich? Dieser Frageaspekt trat in den Vordergrund, als in der Neuzeit der Gang der Erfahrung desto prekärer erschien, je mehr man ihrer jeweiligen ssubjektiven Bedingungen gewahr wurde. Eine Ausprägung dieses Gewahrwerdens lässt sich im englischen Empirismus beobachten. So hat John Locke programmatisch die Aufgabe bestimmt, die »Betrachtung der Ideen und Wörter als der hauptsächlichsten Hilfsmittel der Erkenntnis« so "gründlich« voranzubringen, dass »sie uns vielleicht eine andere Art von Logik und Kritik liefern als bisher bekannt ist. ${ }^{101}$ Von da aus spitzte sich die Frage nach den Erkenntnisbedingungen $\mathrm{zu}$, und zwar über Hume bis hin zu Kant, für den das Wort Kritik titelgebend wurde für seine Hauptschriften. Eine Kritik der Vernunft zu schreiben, bedeutete für Kant, »ein System der Vorsicht und Selbstprüfungsberichte [der Vernunft], vor welchem kein falscher vernünftelnder Schein bestehen kann $\ll^{102}$ zu verfassen. Damit war der Gedanke der Kritik als spezifisches Verfahren etabliert: nämlich als Methode der Rückfrage auf die eigenen Grundlagen und Vorgehensweisen.

Parallel zu dieser erkenntnistheoretischen Entwicklung fand der Begriff der Kritik eine nähere Bestimmung in der philologischen Tradition. Tatsächlich waren beide Strömungen stets eng verflochten, denn sie standen in einem komplizierten Diskursgewebe zwischen Logik, Grammatik und Textauslegung miteinander in Verbindung. In der Textauslegung, also im Kontext der Verstehenslehren, ging es darum, zunächst einmal die Sachlage

der Findung wie den der Beurteilung in Anspruch nehmen, deren eine sie Topik, deren andere sie Kritik nennen.« (a.a.O. S. 15209).

100 Historisches Wörterbuch der Philosophie, hrsg. v. Joachim Ritter, Bd. 4, S. 15213-15217; Übers. wk.

101 John Locke führt die «Kritik« in seinem Kapitel »Über die Einteilung der Wissenschaften« unter der»Lehre von den Zeichen « (semeiotika) neben den physika (Naturwissenschaften) und den practica (Lehre von den menschlichen Handlungen; Ethik). Versuch über den menschlichen Verstand, Buch IV, Kap. XXI, Abs. 4, Hamburg 1988. Zitat auf S. 439.

102 Immanuel Kant: Kritik der reinen Vernunft 2. Werkausgabe Bd. 4, hrsg. v. Wilhelm Weischedel, Frankfurt a.M. 1974, S. 612 (A 711; B 739). 
zu sichern. So stellte etwa der Thesaurus Criticus (1602-1623) eine frühe Form dessen dar, was später philologische Kritik heißen würde, nämlich eine Vervollständigung, Korrektur und Kommentierung antiker Texte. ${ }^{103}$ Kritik bedeutet hier eine Prüfung von Texten und Quellen hinsichtlich dessen, wofür sie überhaupt stehen können; also welche Aussagen und Interpretationsansätze sie in Bezug auf angenommene Herkunft, Autorschaft, Zeit, Kontext und kulturellem Hintergrund überhaupt erlauben. Bis zum 19. Jahrhundert hatte sich diese Fragerichtung zur Wissenschaftsform der historischen Kritik ausgeprägt. Das lässt sich in aller Deutlichkeit wiederum bei Droysen nachlesen:

»Aus dem großen Aufschwung der Philologie, und namentlich nach der Seite der Altertumsstudien, ergaben sich die großen kritischen Forschungen [...] Ihr Wesen war, daß man die Erkenntnisquellen, aus denen die Kunde des Altertums zu erforschen war, zum Gegenstand der Forschung machte. [...] Die Ansicht ist hier, daß die historische Kritik den objektiven Tatbestand zu ermitteln habe, dass dieser aus der strengen Untersuchung und Vergleichung der Berichte zu gewinnen sei, daß die Kritik so die Berichte authentisch zu machen habe. «104

Die Wendung auf die Erkenntnisquellen erfolgte in diesem Bereich des Diskursgeflechtes nur etwas anders als im englischen Empirismus. Während dort das Subjekt als ein Apparat der Verarbeitung von Sinneswahrnehmungen hinsichtlich der Zuverlässigkeit dieses Verarbeitungsprozesses in Zweifel geriet, ${ }^{105}$ waren es hier die historischen und kulturellen Bedingungen, die als spezifische Bezogenheiten von Erkenntnis in den Blick kamen. Zunächst ging es noch um die persönlichen Lebensumstände, die bei der Interpretation zu berücksichtigen seien. Johann Martin Chladenius, dessen Einleitung zur richtigen Auslegung vernünftiger Reden und Schriften (1742) für die hermeneutische Tradition wichtig wurde, schreibt:

103 Vgl. Historisches Wörterbuch der Philosophie, hrsg. v. Joachim Ritter, Bd. 4, S. 15237.

104 Johann Gustav Droysen: Historik. Rekonstruktion der ersten vollständigen Fassung der Vorlesungen (1857), Grundriß der Historik in der ersten handschriftlichen (1857/1858) und in der letzten gedruckten Fassung. Textausgabe v. Peter Leyh, Stuttgart/Bad Cannstatt 1977, S. 113.

105 Thomas Hobbes: Leviathan, Frankfurt a.M. 1994, S. 14. 
»Diejenigen Umstände unserer Seele, Leibes und unserer ganzen Person, welche machen oder Ursach sind, dass wir uns eine Sache so und nicht anders vorstellen, wollen wir den Sehe-Punckt nennen«, diesen Sehe-Punkct sodann definierend als »der innerliche und äußerliche Zustand eines Zuschauers, insofern daraus eine gewisse und besondere Art, die vorkommenden Dinge anzuschauen und zu betrachten, fließt. «106

Spätestens hier war Idee des Perspektivismus geboren - und zwar aus dem Geiste der Kritik. Bei Schleiermacher lesen wir dann einige Jahrzehnte später:

»Der Sprachschatz und die Geschichte des Zeitalters eines Verfassers verhalten sich wie das Ganze, aus welchem seine Schriften als das Einzelne müssen verstanden werden, und jenes wieder aus ihm. ${ }^{107}$

Wir sehen also: Im Zusammenhang von erkenntnistheoretischer Radikalisierung und hermeneutischem Bewusstsein entsteht ein Gedanke, der die Berücksichtigung der Besonderheit und Unterschiedlichkeit von persönlichen und kulturellen Hintergründen zu einem zentralen Element ernsthafter Wissenschaft erklärte. Die Frage, wodurch Erkenntnis bedingt ist, lenkte den Blick sowohl auf die eigene Erkenntnisweise als auch auf die Differenz zwischen unterschiedlichen Bedingungen von Erkenntnis. Beides zusammen ergab dann das Konglomerat, aus dem sich im 19. Jahrhundert sowohl die Kritik des Marxismus (die klassenmäßigen Bedingungen des Erkennens) als auch der Perspektivismus Nietzsches (die triebmäßigen Bedingtheiten des Erkennens) speisten.

Im 20. Jahrhundert prägte sich das Grundmotiv der Kritik auf verschiedene Weisen weiter aus. Es findet sich früh schon entwickelt in der Phänomenologie Husserls und Heideggers mit ihrer Kernbotschaft, dass Erkenntnis mehr sei als Gegenstandswissen, nämlich ein Wissen um Gegenstände in der Art und Weise ihres Gegebenseins; es findet sich in der Kritischen Theorie, die im Wissen die Momente von Herrschaft herausstellt, in soziologisch und strukturalistisch gewendeten Wissens- und Wissenschaftstheorien etwa bei Ludwik Fleck, Thomas S. Kuhn und Michel Foucault, die zeigen, wie wissen-

106 Johann Martin Chladenius: Einleitung zur richtigen Auslegung vernünftiger Reden und Schriften (Leipzig 1742), Düsseldorf 1969, S. 309.

107 Schleiermacher, 1977, S. 95. 
schaftliche Erkenntnis stets innerhalb je spezifischer sozialer, praktischer und materialer Konstellationen steht; sie findet sich bei Autoren wie Maturana, Varela, Heinz von Förster und Niklas Luhmann, die, inspiriert von biologischen Konzepten, darlegen, wie Wissen in Systemen produziert wird (seien es biologische oder soziale); sie findet sich auch in den jüngst noch als avancierteste Form der Erkenntnistheorie geltenden Positionen der Postmoderne und `Dekonstruktion<, am deutlichsten in Jacques Derridas Ansatz, Denksysteme auf ihre in sich nicht mehr legitimierte Grundentscheidungen zurückzuführen und so ihrer letztgültigen Autorität zu berauben.

Eine besonders pointierte Auffassung zur Herangehensweise der Kritik formuliert der französische Philosoph und Wissenshistoriker Michel Foucault:

»Von der Romantik bis zur Frankfurter Schule wurde immer wieder die Rationalität mit dem ihr eigentümlichen Gewicht der Macht in Frage gestellt. Nun besteht die Kritik der Erkenntnis, die ich Ihnen vorlegen werde, nicht nur darin, das beständig [...] unterdrückende Moment der Vernunft anzuprangern, denn schließlich, glauben sie mir, ist die Unvernunft genauso unterdrückend. [...] Die Kritik, die ich Ihnen vorschlage, besteht darin zu bestimmen, unter welchen Bedingungen und mit welchen Auswirkungen sich eine Veridiktion vollzieht. [...] Das Problem besteht darin, die Bedingungen sichtbar zu machen, die erfüllt sein mußten, damit man über den Wahnsinn - aber dasselbe gilt für die Delinquenz und für die Sexualität - sprechen, Diskurse halten kann, die wahr oder falsch sein können, und zwar nach den Regeln der Medizin oder der Beichte oder, darauf kommt es nicht an, der Psychoanalyse.« ${ }^{108}$

Kritik als wissenschaftliche Methode in diesem Sinne ist durchaus auch gängige Praxis in Einzelwissenschaften. So beschreibt die Biologin Evelyn Fox Keller die Entwicklung in der modernen Molekularbiologie als den Vorgang einer konzeptuellen Verdeckung des Gegenstandes: »Der Gen-Diskurs hatte eine räumliche Karte, die das Zytoplasma vom wissenschaftlichen Standpunkt aus unsichtbar machte. ${ }^{109}$ Reflexion im Genre der Kritik findet

108 Michel Foucault: Die Geburt der Biopolitik Geschichte der Gouvernementalität II, Frankfurt a.M. 2006, S. 61.

109 Evelyn Fox Keller: Das Leben neu Denken. Metaphern der Biologie im 20. Jahrhundert, München 1998, S. 43. 
auch statt, wo es z.B. um »Missverständnisse um chemische Konzepte« oder um »Alternative Metaphors for Artificiel Intelligence " geht. ${ }^{110}$

Halten wir fest: Im Wissenschaftstypus der Kritik wird der Anspruch erhoben, einen strengeren, tiefgreifenderen und umfassenderen Wissenschaftsbegriff einzulösen, als es ein einfacher, nur auf den Erkenntnisgegenstand bezogener leisten kann, und zwar, indem die Bedingungen von Wissensbildung in den Erkenntnisprozess aktiv und reflexiv einbezogen werden.

\section{Noch einmal zum Beschreiben: Das Wissenschaftsideal der Deskription - Beobachten, Beschreiben, Tatsachen (Bezüge zu Empirismus und Positivismus)}

Einige wissenschaftliche Disziplinen tragen das Ideal der Deskription schon in ihrem Namen - etwa Geographie und Ethnographie (graphein: das griechische Wort für ritzen, schreiben). In vielen anderen Disziplinen ist das Deskriptive mehr eine Tiefenüberzeugung: Im Kern bestehe Wissenschaft in genauer Beobachtung, in der Feststellung von Tatsachen und in ihrer möglichst detailgetreuen Beschreibung. So sieht ein Bild von Wissenschaft aus, das vor allem auf nüchterne Betrachtung setzt und sich gegen jede Art von Spekulation wendet. Die klassischen Gegenüberstellungen sind die von Beschreiben versus Interpretieren und Beschreiben versus Erklären. Das Beschreiben will »Zurück zu den Sachen selbst! «111, es fordert: »Denke nicht,

110 Martin Jansen/Ulrich Wedig: Das Teil im Ganzen - Missverständnisse um chemische Konzepte. In: Angewandte Chemie: 2008, 120, S. 10176-10180; David M. West/Larry E. Teravis: From Society to Landscape. Alternative Metaphors für Artificial Intelligence. In: Al Magazine, 2 (1991), S. 69-83.

111 Dieses der phänomenologischen Philosophie zugeschriebene Motto findet sich bei Edmund Husserl als abgrenzenden Anschluss an den Empirismus, dem er eine Verwechslung von originärer Erfahrung und Natursachen vorwirft. Was anstelle eines naiven Sachbezuges aber gefordert ist, so Husserl: „sich nach den Sachen selbst richten bzw. von den Reden und den Meinungen auf die Sachen selbst zurückgehen, sie in ihrer Selbstgegebenheit befragen und alle sachfremden Vorurteile beiseitetun." Eine Selbstgegebenheit der Sachen >vor allem Diskurs anzunehmen, die allerdings als Gegebenheit nicht einfach >da< ist, sondern der Befragung bedarf, dies kann als der genuine Einsatz der philosophischen Phänomenologie gelten. Edmund Husserl: Ideen zu einer reinen Phänomenologie und phänomenologischen Philosophie (1913), Ges. Schriften Bd. 5, hrsg. v. Elisabeth Ströker, Hamburg 1992, (Husserliana Bd. III,1, V), S. $41 f$. 


\section{BASISWISSEN 10: Fakten und Daten}

Die Tradition der Naturalis Historiae hat als eine ihrer Ausprägungen eine Denkfigur hervorgebracht, die Wissenschaft als Feststellung, Sicherung und Beschreibung von Tatsachen bzw. Fakten betrachtet. Was hat es mit diesen - bei genauerem Hinsehen eigenartigen - Worten auf sich?

Fakten erscheinen im heutigen Sprachgebrauch als das sicherste und härteste im Wissen überhaupt. Bedenkt man aber die Herkunft des Wortes, nämlich das lateinische facere-machen, dann stellt sich die Frage, wie gerade etwas Gemachtes das sicherste Fundament von Wissen bilden soll. Plausibel wird dieser Zusammenhang aber dann, wenn wir nachvollziehen, dass die matter offacts, die ins Deutsche mit Tatsachen übersetzt wurden, als die Tatprodukte eines Schöpfergottes gedacht waren, also gerade als dasjenige, was, ohne dass es >notwendig zu sein bräuchte, als von einer übergeordneten Macht hergestellt schlicht besteht - gottgegeben sozusagen. (vgl. Historisches Wörterbuch der Philosophie, hrsg. v. J. Ritter, 10, 42.233) Als solche Gegebenheiten erscheinen Fakten als das Rohmaterial (brute facts) von Erkenntnis, das noch keiner intellektuellen und interpretativen Transformation unterzogen, noch keinem sallgemeinen Gesetz« subsumiert wurde. Und wenn Wissenschaft die Welt - im Gegensatz zu allen autoritären und spekulativen Deutungen - realistisch darstellen soll, dann kann es plausibel erscheinen, sie auf die Identifizierung und Zusammenstellung von Fakten bzw. Tatsachen verpflichten zu wollen.

Was aber sind Daten? Das Wort ist ein eingedeutschter Plural von lateinisch datum, das Partizip Perfekt von dare, ein Verb mit der Bedeutung geben. Seit dem 18. Jahrhundert hat sich daraus in der Wissenschaftssprache die Bedeutung gegebene Größe, Angabe, Beleg herauskristallisiert (vgl. Eintrag >Datum in: Etymologisches Wörterbuch des Deutschen, A-G, Akademie Verlag Berlin 1989). In diesem Kontext wurden Daten im 20. Jahrhundert zum wissenschaftsphilosophischen Problem. Es wurde argumentiert, dass Daten ebenso wenig wie brutefacts schlichtes Rohmaterial sind, sondern stets unter Bedingungen erhobene Daten. Man sprach von einem Myth of the Given (Sellars: Empiricism and the Philosophy of Mind, 1956) und diskutierte die Theoriegeladenheit (Theory-ladenness) der Beobachtung (Hanson: Patterns of Discovery, 1958). 
sondern schau! «112 So drückt sich diese Auffassung im philosophischen Denken zu Beginn des 20. Jahrhunderts aus, und zwar in zwei Ansätzen, die im Beschreiben eine besonders disziplinierte und kritische Form von Erkenntnis erblickten. Insofern ist das Beschreiben eng verwandt mit den Positionen der Kritik, die wir im letzten Abschnitt behandelt haben; und durchaus auch mit dem Paradigma der Adaequation, das wir uns davor angeschaut haben: Nur, dass die Annäherung an den Gegenstand gerade nicht durch eine fortgesetzte Anpassung der Interpretation, sondern - im Gegenteil - durch eine weitestmögliche Rücknahme von Interpretation erfolgen soll; eine entgegengerichtete Geste also.

Grundzüge einer faktenbezogenen Wissenschaftsauffassung waren für zwei philosophische Strömungen maßgeblich, die die Wissenschaftstheorie im 19. und frühen 20. Jahrhundert prägten: Empirismus und Positivismus. Doch aus beiden Strömungen gingen sehr heterogene, ja, in manchen Aspekten sogar widersprüchliche Überzeugungen in unsere heutigen Begriffe von Wissenschaft ein. Die Ausdrücke empirische Wissenschaft und positive Wissenschaft implizieren sicherlich Ideale von Wissenschaftlichkeit. Doch was für welche? Die Geistesgeschichte hat in diesen Begriffen einige Verwicklungen produziert, deren Fäden wir auseinanderziehen müssen, um Klarheit über diese Konzeptionen zu gewinnen.

Packen wir das Problem an der Wurzel: Unser Begriff Empirie geht zurück auf das griechische Wort empeiría, das, wie erläutert (Abschnitt BASISWISSEN 6: Induktion und Empirie) bei Aristoteles eine zentrale Rolle spielt.

112 Ludwig Wittgensteins Spätphilosophie kann insgesamt als deskriptive Wende der Philosophie verstanden werden. In diesem Kontext steht die Forderung: »Denke nicht, sondern schau! (Ludwig Wittgenstein: Philosophische Untersuchungen. In: Werkausgabe Bd. 1, Frankfurt a.M. 1982, § 66). Konzepte und Begriffsordnungen werden hier nicht mehr als intellektuell unmittelbar zugängliche Ordnungen verstanden (»denke nicht!«), sondern als beschreibbare soziale Praktiken. Durch Untersuchung der Sprachpraxis zeigt sich z.B. das Feld der sSpiele` als ein durch Familienähnlichkeiten gewobener Zusammenhang von Fällen, dessen Strukturen in einer Untersuchung der Sprachpraxis sichtbar werden (schau!). Dass es dabei nicht um die empirisch vorfindliche, sondern um die durch strukturelle Analogien angelegte Sprachpraxis geht, wird in Teilen der Wittgenstein-Forschung zu wenig berücksichtigt. Vgl. Werner Kogge/Birgit Criesecke: Ein Arbeitsprogramm, kein Abgesang. Wittgensteins grammatische Methode als Verfahren experimentellen Denkens. In: Stefan Tolksdorf/Holm Tetens: In Sprachspiele verstrickt, oder, Wie man der Fliege den Ausweg zeigt: Verflechtungen von Wissen und Können, Berlin/New York 2010, S. 101-126. 
Übersetzt wurde dieses Wort ins Lateinische mit experientia und experimentum - Worte, die im Deutschen sowohl mit Erfahrung als auch mit Experiment wiedergegeben worden sind. Hier müssen wir genauer hinsehen und Bedeutungsunterschiede festhalten, die in der modernen Wissenschaftstheorie häufig übergangen werden. In der Wissenschaftstheorie kennt man nämlich Erfahrung seit der frühen Neuzeit lediglich als Sinneswahrnehmung oder als künstlich eingerichtetes Experiment. Die aristotelische empeiría ist aber etwas Drittes. Empeiria ist für Aristoteles ein eigenständiges Potenzial, das sich im Menschen naturwüchsig, durch sein erprobendes Tätigsein, ausprägt. Älter zu werden bedeutet zumindest potentiell, Unterscheidungsfähigkeit zu gewinnen. Aristotelisch gedacht wäre eine Erfahrungswissenschaft also eine, die durch die Erfahrenheit ihrer Beteiligten geprägt ist (ein Gedanke, der in der Wissenschaftsforschung seit Luwik Fleck und Michael Polanyi mit ihren Überlegungen zu Denkstil und Tacit Knowledge durchaus aktuell ist).

Doch der historische Empirismus, der sich seit dem 17. Jahrhundert ausprägte, ist völlig anders gestrickt: Er kehrt das Muster des aristotelischen Erfahrungsprozesses an entscheidender Stelle um. Der Empirismus ist einerseits mit dem Ideal der unmittelbaren sinnlichen Wahrnehmung verbunden, zugleich liegt im Moment seines Entstehens der radikalste Zweifel an der Möglichkeit von Erkenntnis aus sinnlicher Wahrnehmung. Das bedeutet im Resultat: Aus der sinnlichen Wahrnehmung kann die Erkenntnis nur das verarbeiten, was festgehalten, gesichert, am besten sogleich überführt werden kann in ein System zeitloser Einheiten und Relationen. Aus dem Leiden an der Sinnlichkeit entsteht so die Leidenschaft für formale Logik und Mathematik. Empirismus profitiert zwar noch von seinem nominellen Bezug zu Erfahrung, tatsächlich aber ist der sinnliche Bezug zur Materialität des Gegenstandes nur noch Apercu; der Empirismus zeigt sich somit als Begleitideologie der Mathematisierung (und es sind erst die jüngeren Strömungen der Wissenschaftsforschung und Experimentaltheorie, die das aristotelische Moment der Empirie wieder aufrufen).

Eng verbunden mit der Geschichte des Empirismus ist die Entwicklung des Positivismus. Beide Strömungen beziehen ihr Renommee zwar von der scheinbaren Nähe zu Tatsachen und Fakten, propagieren in der Tat aber massiv die Übersetzung ins mathematische Medium, an Stelle einer Annäherung an das Untersuchungsmaterial - wie ein vertiefender Blick zeigt. 


\section{VERTIEFEND Empirie im Empirismus und Positivismus}

$\mathrm{Zu}$ besichtigen ist dies gleichsam in Echtzeit bei einem der ersten Vertreter des Empirismus, bei Thomas Hobbes. Sehen wir uns die einschlägige Textstelle in Hobbes Hauptwerk, dem Leviathan, an. Wie für Aristoteles beginnt für Hobbes die Erfahrung mit der Sinneswahrnehmung. Und genau wie Aristoteles bestimmt Hobbes Erfahrung als »[v]iel Erinnerung oder Erinnerung an viele Dinge«. Doch anders als bei Aristoteles entsteht aus dieser Erinnerung keine sich anreichernde Erfahrenheit - im Gegenteil: Hobbes denkt Erinnerung als »zerfallende Empfindung« im Sinne eines Abbaus: »[D] ie ständige Veränderung des menschlichen Körpers zerstört bald die Teile, die bei der Empfindung bewegt worden waren «. ${ }^{113}$ So führt für Hobbes zwar Erfahrung zu »Klugheit ${ }^{114}$ - so weit folgt er Aristoteles - Klugheit aber steht für Hobbes - anders als die aristotelische phrónēsis - außerhalb eines wissenschaftlichen Ansprüchen genügenden Wissens: »Die Zeichen der Klugheit sind alle unsicher «, schreibt er, »denn es ist unmöglich, durch Erfahrung $\mathrm{zu}$ beobachten und sich an alle Umstände zu erinnern, die einen anderen Ausgang bewirken können. ${ }^{115}$ Wissenschaft baut daher bei Hobbes gerade nicht auf Erfahrung, sondern darauf, durch »exakte Definitionen ${ }^{116}$ ein quasi-mathematisches System des logischen Schließens in Gang zu setzen.

Sehen wir uns nun die Entwicklung des Positivismus an, die eine sehr ähnliche Wendung nimmt wie die des Empirismus.

Worum geht es? 1876 schreibt Gustav Kirchhoff in der Vorrede zu seinen Vorlesungen über Mathematische Physik: Ich stelle »es als Aufgabe der Mechanik hin, die in der Natur vor sich gehenden Bewegungen zu beschreiben, und zwar vollständig und auf die einfachste Weise zu beschreiben. Ich will damit sagen, dass es sich nur darum handeln soll, anzugeben, welches die Erscheinungen sind, die stattfinden, nicht aber darum, ihre Ursachen zu ermitteln. $\aleph^{117}$ Dieses Ideal einer möglichst einfachen und klaren Deskription physikalischer Phänomene, die ausdrücklich auf die Vorstellung zugrundeliegender Ursachen verzichtet, fand so prominente Anhänger wie Heinrich

113 Thomas Hobbes: Leviathan, Frankfurt a.M. 1994, S. 14.

114 Hobbes, 1994, S. 37.

115 Hobbes, 1994, S. 38.

116 Hobbes, 1994, S. 38.

117 Gustav Kirchhoff: Vorlesungen über mathematische Physik. Mechanik, Leipzig 1876, S. III. 
Hertz ${ }^{118}$ und hatte so berühmte Vorläufer wie Ernst Mach. Den Grundgedanken, »den Blick von den bewegenden Ursachen« abzuwenden, »um einzig und allein die hervorgebrachte Bewegung zu betrachten« und die »dem Körper inhärierenden Kräfte« als »dunkle, der Metaphysik angehörigen Begriffe $\ll^{119} \mathrm{zu}$ verbannen, hatte aber auch schon Jean d'Alembert, einer der Begründer des Positivismus, ${ }^{120} 150$ Jahre früher vermerkt.

Ernst Mach schildert sehr anschaulich wie der Versuch, in der Physik ohne den Kraftbegriff auszukommen, motiviert ist.

»Betrachten wir ein magnetisches Stahlstück neben einem sonst gleich beschaffenen unmagnetischen. Während letzterer sich gegen Eisenfeile gleichgültig verhält, zieht ersterer dieselbe an. Auch wenn die Eisenfeile nicht vorhanden ist, müssen wir das magnetische Stück in einem anderen Zustand denken als das unmagnetische. Denn, dass das bloße Hinzubringen der Eisenfeile nicht die Erscheinung der Anziehung bedingt, zeigt ja das andere, unmagnetische Stück. Der naive Mensch, dem sich zur Vergleichung sein eigener Wille als bekannteste Kraftquelle anbietet, denkt sich in dem Magnet eine Art Ceist. «121

Mach schildert weiter, wie dann in einer ersten wissenschaftlichen Sichtweise aus der dämonischen Kraft eine Art Stoff wird, dessen Bewegung das Phänomen hervorbringt, bis sich schließlich die indirekte Beschreibung (z.B. über dämonische und stoffliche Ursachen) in eine direkte Beschreibung überführen lässt, »welche nichts Unwesentliches mehr enthält, und sich lediglich auf die begriffliche Fassung der Tatsachen beschränkt.«122 Und er wagt die Prognose: »Es zeigt sich hier deutlich der Weg, auf dem sich eine allgemeine,

118 Heinrich Hertz: Die Prinzipien der Mechanik, Leipzig 1894.

119 Jean d'Alembert: Abhandlung über Dynamik; in welcher die Cesetze des Cleichgewichts und der Bewegung der Körper auf die kleinstmögliche Zahl zurückgeführt und in neuer Weise abgeleitet werden, und in der ein allgemeines Princip zur Auffindung der Bewegung mehrerer Körper, die in beliebiger Weise aufeinander wirken, gegeben wird, Übers. u. Anm. v. A. Korn, Thun/Frankfurt a.M. 1997 [im Orig. 1743], S. 13.

120 Vgl. Georg Misch: Zur Entstehung des französischen Positivismus, Darmstadt 1969.

121 Ernst Mach: Die Vergleichung als wissenschaftliches Princip. In: Die Principien der Wärmelehre. Historisch-kritisch entwickelt von Ernst Mach, Leipzig 1896 (3. Aufl. 1919), S. 396-405, hier S. 400.

122 Mach, 1896, S. 401. 
alle Gebiete umfassende physikalische Phänomenologie, eine hypothekenfreie Darstellung der Physik entwickeln wird. ${ }^{123}$ Mach selbst hat ein solches Programm in gewisser Weise verfolgt - andere Vertreter der positivistischen Physik und die Hauptströmung der Wissenschaftstheorie allerdings bewegten sich in Richtung dessen, was Mach in Bezug auf Hertz bemerkt: "Die Physik gewöhnt sich allmählich ohnehin, die Beschreibung der Tatsachen durch Differentialgleichungen als ihr eigentliches Ziel anzusehen«, wodurch »die allgemeine Anwendbarkeit der Hertzschen mathematischen Aufstellung anerkannt [ist], ohne daß man sich auf weitere Interpretation der Kräfte oder Verbindung einlassen müsste. ${ }^{124}$ So war die positivistische Konzeption auch schon bei d'Alembert angelegt, der »insbesondere die Mechanik auf die mathematische Beschreibung der Wirkungen einschränkt, ohne auf bewegende Ursachen einzugehen«; mit dieser Darstellung, »welche die auf Phänomene reducierte Erkenntniss weiter einschränken auf Erfassung blosser Abhängigkeitsverhältnisse rein logischer Art [...] ist der Standpunkt des Positivismus gegeben.« ${ }^{125}$

Wir sehen also: In der Physik konnte die Restriktion auf Beschreibungen und Tatsachen so gedeutet werden, dass sie ein möglichst sparsames Set an mathematisch-logischen Formen zum Ausgangspunkt nahm. Damit schlägt auch der Positivismus um zum Paradigma der apodeixis in seiner mathematisierten Form. Tatsachen zeigen sich in Abhängigkeit und Funktion einer forciert reduzierenden mathematischen "Aufstellung«, sie selbst sind nicht das Ziel der wissenschaftlichen Bemühung.

Ebenso wie der Begriff der empirischen Wissenschaft bezeichnet auch jener der positiven Wissenschaft gerade nicht die Hinwendung auf den untersuchten Gegenstand in seiner phänomenalen Materialität, sondern deren Reduktion auf eine mathematisch >beschreibbare< Form - und das heißt in diesem Fall: auf eine Formalisierung. Das Paradigma der Beweislehre erscheint hier nur in einem neuen Gewand.

123 Mach, 1896, S. 403.

124 Ernst Mach: Die Mechanik in ihrer Entwicklung. Historisch-kritisch dargestellt. Hrsg. u. m. einem Anh. vers. v. Renate Wahsner u. Horst-Heino von Borzeszkowski, Berlin 1988 [1883], S. 285.

125 Misch, 1969, S. 36. 
Doch der Wissenschaftstypus des Beschreibens prägte durchaus eine eigene Form aus: Sie zeigt sich in all den Verfahren, die den gegebenen Sachverhalt nicht reduktiv in Bezug auf eine vorgegebene Theorieform, sondern möglichst umfassend aufzuzeichnen und zu sichern versucht. Es wurde bemerkt, dass Wissenschaft analog zur kriminalistischen Spurensicherung verfährt, wenn sie in einem Feld möglichst viele Details wahrzunehmen und aufzuzeichnen sucht. ${ }^{126}$ Das Beschreiben geht dabei in zwei Richtungen: in Richtung Fülle und Anspruch aufVollständigkeit und in Richtung Sicherung und Verdauerung. Beide Motive greifen Hand in Hand.

Wie die wissenschaftliche Praxis des Beschreibens sich auf den Aspektreichtum eines Phänomens richten kann, deutet sich z.B. in Formulierungen zur Konzeption einer Dichten Beschreibung beim Ethnographen Clifford Geertz an. ${ }^{127}$ Er notiert in Bezug auf Bedingungen der Wissenschaftlichkeit der Ethnographie:

»Zunächst einmal muss die Theorie [hier] näher am Boden der Tatsachen bleiben, als dies sonst bei Wissenschaften der Fall ist, die sich eher der imaginativen Abstraktion überlassen können. [...] Darin liegt die erste Bedingung für die Kulturtheorie: sie ist nicht ihr eigener Herr. Da sie von den unmittelbaren Momenten der dichten Beschreibung nicht zu trennen ist, bleibt ihre Möglichkeit sich nach Maßgabe einer inneren Logik zu formen, ziemlich beschränkt. Die Allgemeinheit, die sie möglicherweise erreicht, verdankt sich der Cenauigkeit ihrer Einzelbeschreibungen, nicht dem Höhenflug ihrer Abstraktionen. « ${ }^{128}$

Allgemeine kulturtheoretische Terminologie wird in der dichten Beschreibung eher heuristisch eingesetzt, sie kann nur zu aufschlussreichen Sichtweisen führen, wenn sie »vermöge einer präzisen Charakterisierung der

126 Gabriele Mante: Spuren lesen. Die Relevanz kriminalistischer Methoden für die archäologische Wissenschaft. In: Ulrich Veit/Tobias L. Kienlin/Christoph Kümmel/ Sascha Schmidt (Hrsg.): Spuren und Botschaften. Interpretationen materieller Kultur. New York/München/Berlin 2003, S. 157-172.

127 Dass diese Konzeption in ihrer Haupttendenz ein Beispiel für das Adaequationsparadigma der Hermeneutik ist, haben wir oben ausgeführt (s. Kap. 12). Doch tatsächlich findet sich dieses Paradigma bei Geertz verknüpft mit stark deskriptiven Elementen.

128 Clifford Geertz: Dichte Beschreibung. Beiträge zum Verstehen kultureller Systeme, Frankfurt a.M. 1991 (im Orig. 1973), S. 35. 
Tatsachen $\aleph^{129}$ auf die Beschreibungsebene bezogen bleibt. Wegen der Fülle der Details sind genaue sprachliche Formulierungen und nüchterne Darstellungsformen charakteristisch: »Die Beschreibung liebt die lexikalische Liste, die Nomenklatur, sie akkumuliert und summiert«, bemerkt Klaus Scherpe, der das Genre des Beschreibens als literarische Form untersucht. ${ }^{130}$

Solche Formen dienen zugleich der Gegenstandssicherung: in Formaten wie Listen, Karten, Chroniken und Datenbanken werden Beobachtungen aufgezeichnet und auf Dauer gestellt. Werfen wir mit dem Wissenschaftstheoretiker und Molekularbiologen Hans-Jörg Rheinberger einen Blick auf zwei Manifestationsformen solcher Praktiken: Herbarien und Präparate.

In einigen wissenschaftlichen Disziplinen besteht die Arbeit zu einem großen Teil in der Präparierung von Erkenntnisgegenständen, ja: der Sinn der Wissenschaft besteht hier geradezu darin, Gegenstände auf solche Weisen $\mathrm{zu}$ fixieren und zu bestimmen. Was hier - im Unterschied zu den Auseinandersetzungen um Empirismus und Positivismus - außer Frage steht ist, dass es sich bei diesen Gegenständen nicht um unmittelbare, rohe Fakten handelt. Viel zu groß ist die Anstrengung, ihre Beschaffenheiten dem Lauf der Zeit zu entreißen, als dass hier übersehen werden kann, dass ihre jeweilige Erscheinungsweise durch die Wissenschaften erst hervorgebracht ist. Rheinberger verweist auf den französischen Wissenschaftsphilosophen Gaston Bachelard und schreibt, dieser habe

»eindringlich darauf hingewiesen, dass die modernen Naturwissenschaften [für welche ihm in den zwanziger und dreißiger Jahren des vorigen Jahrhunderts die zeitgenössische Mikrophysik Pate stand] eine ganze >Phänomenotechnik, eine Technik der Erscheinungen - man müsste vielleicht korrekter sagen, eine Technik des In-Erscheinung-Bringens - in Szene setzen. « ${ }^{131}$

Es sind bestimmte Wissenschaften, in denen sich diese Vorgänge am deutlichsten zeigen:

129 Geertz, 1991, S. 40.

130 Klaus R. Scherpe: Beschreiben, Nicht Erzählen! Beispiele zu einer ästhetischen Opposition. In: Zeitschrift Für Germanistik, 2(1996), S. 368-383, hier S. 370.

131 Hans-Jörg Rheinberger: Epistemologica: Präparate. In: Anke von Heesen/Petra Lutz (Hrsg.): Dingwelten. Das Museum als Erkenntnisort., Schriften des deutschen HygieneMuseums Dresden, Köln/Weimar/Wien 2005, S. 65-76, hier S. 66. 
»Die vorwiegend deskriptiven, systematisierenden Wissenschaften lösen in der Regel ihre Gegenstände aus ihrem angestammten Naturzusammenhang heraus und stellen sie in einen anderen hinein. Ein botanischer Garten, eine Gesteinssammlung oder ein Herbarium sind Beispiele für einen solchen Vorgang. ${ }^{132}$

Auch eine Schlüsseltechnologie der modernen Naturwissenschaft, das Mikroskopieren, erfordert eine solche Präparierung der Erkenntnisgegenstände. Durch Verfestigung, Haltbarmachung, Fixierung und Färbung wird das Untersuchungsmaterial überhaupt erst untersuchbar - ein Vorgang, bei dem, wie Rheinberger anmerkt, »die Unterscheidung zwischen Fakt und Artefakt zur epistemologischen Schlüsselfrage wird «. ${ }^{133}$ Auch die Streifenmuster, die die molekularbiologische Elektrophorese bildet, sind chromatographische Präparate, Aufzeichnungen der DNA, die im Material selbst erzeugt werden.

Alle Erkenntnisgegenstände dieser Art unterscheiden sich kategorial von wissenschaftlichen Modellen.

»Das Modell hält sich gleichsam in einem anderen Medium auf, es ist geradezu definiert durch den Übergang vom Gegenstand, den es modelliert, in ein anderes Medium.«Im Unterschied dazu »hat das Präparat gewißermaßen teil an der Materialität des untersuchten Sachverhalts. Es ist, wenn man so will, aus dem gleichen Stoff gemacht wie dieser. Es ist eine Figuration, die diesem Stoff abgerungen ist. $^{134}$

Legt man diesen Gedanken zugrunde, ist leicht zu erkennen, dass auch in anderen Disziplinen präparierte Gegebenheiten eine zentrale Rolle spielen. Der gesicherte archäologische Fund, der Bestand der Quellen in den Geschichtswissenschaften, das Interviewmaterial in der Soziologie, die Protokolle von Beobachtungen und Messungen - all die Formen, in denen solche Daten aufgezeichnet und dargestellt sind. Radikale Anhänger des Deskriptivismus wünschen sich, es würde bei Wissenschaft stets bei solchen Aufzeichnungen bleiben.

\footnotetext{
132 Rheinberger, 2005, S. 65.

133 Rheinberger, 2005, S. 71.

134 Rheinberger, 2005, S. 67.
} 


\section{Wissenschaft und die Ordnung der Dinge: Relationen, Strukturen und die Praktiken des Vergleichens und Typisierens (der taxonomische Ansatz)}

Während im deskriptiven Bild von Wissenschaft die Identifikation, Erfassung und Charakterisierung von Gegenständen im Zentrum steht, verschiebt sich der Blickwinkel im taxonomischen Ansatz der Naturalis Historia auf die Beziehungen zwischen den Dingen und den Ordnungen, die sie bilden. Während im deskriptiven Ansatz die Dinge als einzelne Vorkommnisse, lediglich in ihren Eigenschaften und Verortungen in Raum und Zeit zum Gegenstand werden, geht der taxonomische (von gr. taxis: Ordnung) davon aus, dass die wissenschaftlich erschließbare Welt in sich geordnet ist. Die Frage ist hier, wie die Welt geordnet ist, welche Beziehungen bestehen, welche Unterschiede und welche Gemeinsamkeiten zwischen den Dingen festzustellen sind. Begriffe wie Art, Gattung, Typus, Kriterium und Verwandtschaft bilden die Grundlage dieses Bildes von Wissenschaft und Praktiken wie vergleichen, einordnen und klassifizieren prägen es.

Neben den traditionell naturgeschichtlichen Fächern wie Botanik, Zoologie und Mineralogie entstanden in diesem Paradigma eine Reihe anderer Fächer wie vergleichende Geschichtswissenschaften, vergleichende Kunstgeschichte, vergleichende Rechtswissenschaft, vergleichende Politikwissenschaft, International vergleichende Soziologie und ein Zweig der Linguistik: die Sprachtypologie. Auch viele andere Klassifikationen wie die der Fundstücke der Archäologie oder der Systematik der Bakteriologie stehen in diesem Horizont.

Doch auch dieses Bild von Wissenschaft ist von einigen verwirrenden Bruchlinien durchzogen. Auch hier sind es insbesondere zwei geistesgeschichtliche Strömungen, die mit taxonomischem Denken assoziiert sind, im Grunde aber auf andere Wissenschaftsparadigmen hindeuten. Zum einen ist dies der Ansatz einer Universal-generativen Grammatik, zum anderen die wirkmächtige Strömung des Strukturalismus. Sehen wir uns diese beiden tendenziell anders gearteten Verwandten des taxonomischen Denkens an:

Eine Grundfrage der Sprachwissenschaften: Gibt es unbegrenzt viele unterschiedliche Arten von Sprachen oder handelt es sich um Varianten, die letztlich auf nur eine einzige Sprachform zurückzuführen sind?

Die Suche nach Grundformen aller Sprachen, nach Sprachuniversalien, wurde im 20. Jahrhundert angetrieben durch die Arbeiten des US-amerika- 
nischen Linguisten Noam Chomsky, dessen Transformationsgrammatik auf der Annahme beruht, dem Spracherwerb liege ein "genetisch determiniertes Prinzipiengerüst ${ }^{135}$ zugrunde, dessen Möglichkeiten in verschiedenen Sprachen auf verschiedene Weisen ausgeprägt werden. Der Sprachenvergleich dient hier dazu, hinter den Oberflächenstrukturen der sprachlichen Varianten das Regelgerüst freizulegen, das als Tiefenstruktur ihre Erzeugung bestimmt (Chomsky spricht hier von generativer Syntax).

Mit der Annahme eines »Spracherwerbsmechanismus« zeigt sich aber ganz deutlich, dass wir uns hier nicht im Spektrum der naturgeschichtlichen Ansätze, sondern in demjenigen des Cartesianisch-Galileischen Wissenschaftsbildes bewegen. Während es der taxonomischen Wissenschaftsauffassung darum geht, eine Übersicht über die Gegenstände innerhalb ihrer eigenen Ordnung zu gewinnen, sucht die Cartesianisch-Galileische Wissenschaftsauffassung nach einer Ordnung hinter den Dingen, nach einem Regelsystem, das diese bestimmt und in ihren Grundformen determiniert, wenngleich sie nie unmittelbar, sondern nur in den Erscheinungen hervortritt.

Kommen wir zurück zum taxonomischen Wissenschaftstypus. Die Dominanz des Bildes, das Wissenschaft mit der Suche nach im Verborgenen wirkenden Regelsystemen identifiziert, führte innerhalb des taxonomischen Denkens zu tiefreichenden Verunsicherungen. Sie zeigen sich darin, dass die Operation Vergleichen ${ }^{136}$ (und mit ihr das Ordnen und Klassifizieren) sehr unterschiedlich bewertet wird. Während sie den einen als grundständiges und auch kritisches Verfahren der Wissenschaften gilt, durch das neue Phänomene in Abgrenzung und Beziehung zu bekannten Phänomenen erschlossen werden, gilt sie den anderen als unkritische Angleichung und Rubrizierung von Gegenständen in vorgefertigte Schubladen. Wird das >Schubladensystem ‘ als universale Ordnung verstanden, die allen Phänomenen in einem Bereich zugrunde liegt, so reizt dies zum Widerspruch: werden hier überhaupt Anstrengungen unternommen, dem Gegenstand in seiner Eigenheit gerecht zu werden? Und wird hier nicht aus dem Blick ver-

135 Hadumod Bussman: Lexikon der Sprachwissenschaften. Eintrag >Generative Syntax [Auch: Cenerative Grammatik, (Cenerative) Transformationsgrammatik], Stuttgart 2008, S. 222.

136 So der Titel eines viel beachteten Aufsatzes von Joachim Matthes (1992): The Operation Called `Vergleichen<. In: ders.: Zwischen den Kulturen? Die Sozialwissenschaften vor dem Problem des Kulturvergleichs, (Soziale Welt Sonderband 8), Göttingen 1992, S. 75-102. 


\section{BASISWISSEN 11: Erscheinung und Wirklichkeit - die Suche nach einer verborgenen Ordnung}

Die Idee, dass es hinter den Dingen eine eigene Ordnung gibt, die diese Dinge und ihr Verhalten hervorbringt, diese Idee spielt eine entscheidende, aber kaum beachtete Rolle in der Wissenschaftstheorie. Was ist das für eine Idee?

Eine anschauliche Darstellung findet sich in Martin Hollis Kapitel Die Vernunft aufder Suche nach einer verborgenen Ordnung: Hollis zitiert den Cartesianer Bernard de Fontanelle (1657-1757) mit den Worten, »daß die Natur einem Opernhaus ganz ähnlich ist, in dem man von seinem Standort die Bühne nicht so sieht, wie sie wirklich ist. Bei deren Anlage werden Vorteile ausgenutzt, so daß das ganze Räderwerk und die Bewegungen unsichtbar bleiben«. (Hollis 1995, 45)

Diese Konzeption hatte eine mächtige Vorläuferin: Platons Weltbild, dem gemäß hinter den Phänomenen eine nur näherungsweise erkennbare Ordnung der Ideen steht, die vollkommen ist und an der die Erscheinungen nur teilhaben (methexis). Betrachtet man, wie in der Neuzeit geschehen, diese Ideenordnung als Ordnung mathematischer Formen und interpretiert Mathematik wiederum im Geiste der Beweislehre als mechanische Folgerungstechnik, so kommt es zum Bild des Opernhauses: die ideale, wahre Ordnung wird jetzt zum Mechanismus, der die Erscheinungen allererst hervorbringt.

Von da aus schreibt sich die Idee eines generativen Mechanismus in alle die Wissenschaften, in denen nach zugrundeliegenden universalen Gesetzmäßigkeiten für gegebene Erscheinungen gesucht wird (so z.B. in die generative Grammatik der Sprachwissenschaften, in die evolutionäre Kulturtheorie und auch in der Annahme, dass sich menschliches Ver-

loren, dass jede Zuordnung zu Typen, Klassen, Arten, Epochen, Kulturen ein erkenntnistheoretisch prekärer Akt ist? Die Verunsicherung durch solche Fragen hat sich tief in die empirischen Geschichts- und Kulturwissenschaften eingegraben. Sie führt dort zu so defensiven Wendungen wie etwa, dass »es sich bei Typen um Abstraktionen bzw. mentale Konstrukte, nicht aber 
halten oder politische Prozesse auf einen historischen Mechanismus von Klassenzugehörigkeit zurückführen lässt). Am wirkmächtigsten blieb aber stets die Galileische Deutung dieser Hintergrundslogik: es ist die Mathematik, in der das wahre Buch der Natur geschrieben ist, und Wissenschaft zu treiben bedeutet, herauszufinden, wie die mathematische Struktur der Welt die Erscheinungen hervorbringt.

Schon Aristoteles hatte die Platonische Konzeption mit dem Hinweis auf die darin eingeschriebene Verdopplung der Welt mitsamt einer Kluft (chorismos) zwischen Ideen und Erscheinungen kritisiert und es war gerade diese Konzeption, gegen die sich die deskriptive Wissenschaftsauffassung stets gewandt hatte. Für die Beschreibungslehren ist es reine Metaphysik, hinter dem positiv Gegebenen und seiner Ordnung eine zweite, verborgene, >wahre Ordnung zu postulieren - eine doppelte Ontologie.

$\mathrm{Zu}$ unterscheiden ist diese doppelte Ontologie vom erkenntnistheoretischen Dualismus, bei dem es um den Gegensatz von Subjekt und Objekt, von Geist und Welt, kurz: um die Frage geht, wie die Dinge zu Wissen werden; wie sich Wirklichkeit im menschlichen Geist oder der Sprache abbildet. Während die doppelte Ontologie das Sein selbst verdoppelt (in eine Seite der Erscheinungen und in eine der dahinterliegenden Ordnung), problematisiert der erkenntnistheoretische Dualismus das Verhältnis von Wirklichkeit und ihrer Auffassung - auch eine Art Verdopplung, doch in dieser Verdopplung gibt es keine wahre Ordnung hinter den Dingen, sondern eine problematische Ordnung der Repräsentation der Dinge (in Geist, Subjekt, Sprache). Mehr dazu bei BASISWISSEN 13: Konstruktivismus.

Martin Hollis: Soziales Handeln. Eine Einführung in die Philosophie der Sozialwissenschaften, Berlin 1995.

um reale Objekte oder historische Entitäten handelt« (so zu lesen in einer Einführung zur Prähistorischen Archäologie). ${ }^{137}$

137 Manfred K.H. Eggert: Prähistorische Archäologie. Konzepte und Methoden, Tübingen/Basel 2001, S. 139. 


\section{VERTIEFEND Probleme im Vergleichen}

Die Lage verkompliziert sich dadurch, dass neben den drei genannten eine vierte Deutungsoption ins Spiel kommt: Denn fragt man danach, worauf Gemeinsamkeiten und Unterschiede beruhen, die ein Vergleich zu Tage fördert, gibt es nicht nur die drei Antworten, die wir bisher in den Blick genommen haben. Bisher haben wir neben der (1.) eigentümlich taxonomischen Antwort, dass sich in ihr die Ordnung der Dinge, wie sie nun einmal gegeben ist, zur Darstellung bringt, (2.) die (von diesem Standpunkt betrachtet) extrem defensive Auffassung kennengelernt, dass solche Klassifikationen mentale (oder soziale) Konstrukte sind und die dritte, dass sie generiert ist aus einem verborgenen, universalen Regelwerk der Natur (3.). Nun gibt es aber noch eine vierte Variante: zwei oder mehr Gegenstände können Gemeinsamkeiten aufweisen nicht, weil sie schlicht einander ähnlich sind und auch nicht, weil wir sie als ähnlich ansehen oder weil ein quasi-naturgesetzlicher Mechanismus zugrunde liegt, sondern weil sie in realer Beziehung stehen. Überraschende Gemeinsamkeiten z.B. zwischen Kulturen, Sprachen oder Lebewesen können auch dadurch zustande kommen, dass die eine von der anderen oder beide wechselseitig charakteristische Züge übernommen haben. Adaption und Entlehnung sind Vokabeln, die diese Variante der Auffassung von Gemeinsamkeit ausdrücken.

Es ist dieser Einfluss des einen auf das andere, der in der Suche nach Universalien gerade ausgeschlossen werden soll. Hierher gehört das Stichwort Galton's problem - das eigentlich nicht Galtons Problem war, sondern das des von ihm kritisierten Edward Tylor, der glaubte, aus Daten zu Heiratsinstitutionen aus 350 Kulturen einen evolutionären Trend von maternalen zu paternalen Abstammungslinien ablesen zu können. ${ }^{138}$ Galton hatte eingewandt, dass dieser ,Trend ebenso gut aus gemeinsamen Ursprüngen der Kulturen oder Entlehnungen zwischen den Kulturen zurückgeführt werden könnte - also auf ein historisches Faktum und nicht auf eine verborgene universale Regularität hinweist.

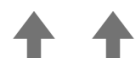

138 Einen guten Überblick gibt Wikipedia im Eintrag: Galton's problem. In: Wikipedia, The Free Encyclopedia, geprüft 12. August 2020. Zur Problematik allgemein: Hartmut Kälble/ Jürgen Schriewer (Hrsg.): Vergleich und Transfer. Komparatistikin den Sozial-, Geschichts- und Kulturwissenschaften, Frankfurt a.M. u.a. 2003. 
Verbunden mit dieser Verunsicherung ist die Verwicklung des taxonomischen Denkens mit einem weiteren geistesgeschichtlichen Paradigma, das die taxonomische Ordnung der Dinge als Ordnungen des Denkens interpretierte und letztlich ins Wissenschaftsparadigma der Kritik führte: der Strukturalismus.

Strukturalismus bezeichnet ein wissenschaftliches und intellektuelles Paradigma, das im 20. Jahrhundert ausgehend von den Sprachwissenschaften auch in der Ethnologie, in der Psychologie, Literaturwissenschaft und Philosophie wirksam wurde. Der Strukturalismus ist ein Spross der naturgeschichtlichen Wissenschaftsauffassung, insofern er Beziehungssysteme zum Gegenstand hat. Allerdings radikalisiert er dieses Bild in einer ganz bestimmten Weise: Es geht hier nicht mehr um Ordnungen, die durch die Eigenschaften der Dinge gebildet werden, sondern um Ordnungen, die die Dinge in ihren wesentlichen Eigenschaften erst hervorbringen und bestimmen. Die Relation wird primär, das Relationierte in Abhängigkeit davon bestimmt.

\section{VERTIEFEND Strukturalismus und die Ordnung der Differenzen}

$\mathrm{Zu}$ beobachten ist dieser Übergang bereits im Ursprung des modernen Strukturalismus, in Ferdinand de Saussures Cours de linguistique générale, ein Werk, das aus Mitschriften dreier Vorlesungen zwischen 1906 und 1911 hervorging. Saussure erläutert dort seine Auffassung, dass Sprache kein Gebilde von in sich positiv bestimmten Elementen, sondern ein System von Relationen sei, so: WWie sich die Laute einer Sprache in ihrer Unterscheidbarkeit $\mathrm{zu}$ anderen Lauten bestimmen, so auch die Bedeutungswerte einer Sprache. Das Wort sheep im Englischen habe einen anderen sprachlichen Wert als das Wort mouton im Französischen, obwohl beide sich auf das gleiche Tier beziehen. Da für Schaf als Speise im Unterschied zum Französischen im Englischen noch ein weiteres Wort existiert, nämlich mutton, verändert sich auch die Funktion des Wortes sheep. Der Inhalt eines Wortes sei deshalb erst »richtig bestimmt nur durch Mitwirkung dessen, was außerhalb seiner vorhanden ist. ${ }^{139}$

139 Ferdinand de Saussure: Grundlagen der allgemeinen Sprachwissenschaft, Berlin 1967 (1906-1911), S. 138. 
So kommt Saussure zu der Auffassung,

»daß es in der Sprache nur Verschiedenheiten gibt. Mehr noch: eine Verschiedenheit setzt im allgemeinen positive Einzelglieder voraus, zwischen denen sie besteht.; in der Sprache aber gibt es nur Verschiedenheiten, ohne positive Einzelglieder. $\ll^{140}$

Der Gedanke, dass die »Sprache ein System ist, dessen Glieder sich alle gegenseitig bedingen «, ${ }^{141}$ hatte vielfältige und weitreichende Wirkungen für die taxonomische Wissenschaftsauffassung im 20. Jahrhundert. Die Ordnung der Dinge erschien nun immer weniger als die der einen kosmologischen Ordnung. ${ }^{142}$ Vielmehr lag es nun nahe anzunehmen, dass es nicht nur unterschiedliche Typen von Sprache, sondern zugleich unterschiedliche Ideensysteme ${ }^{143}$, unterschiedliche Weisen der Welterzeugung ${ }^{144}$ gibt, die in sich als differentielle Systeme bestimmt sind. Die Taxonomien, die sie ausbilden, bilden nicht mehr die Welt oder bestimmte Weltausschnitte $a b$, sondern zeigen sich nun daraufhin geformt - so drückt es der strukturalistische Anthropologe Claude LéviStrauss aus -, dass sie "gut zu denken sind $« .{ }^{145}$ So führte gerade eine Renaissance des Taxonomischen zu dessen fundamentalster Umdeutung: aus der Erforschung der Ordnung der Welt wurde die Erforschung der Ordnungen des Denkens, das die Ordnung der Welt zum Gegenstand hat. Taxonomisches Denken wurde so zu einem Nachdenken und Forschen über unterschiedliche Formen und Möglichkeiten des Denkens und Ordnens. Ein Streit um die Universalität und Relativität kultureller Strukturen brandete auf - Stichwort

140 Saussure, 1967, S. 143.

141 Saussure, 1967, S. 136.

142 Ordnung der Dinge ist der deutschsprachige Titel von Michel Foucaults einschlägiger Monographie Les mots et les choses, Paris 1966.

143 Peter Winch hat Wittgensteins Sprachspieldenken in eine Konzeption von Ideensystemen transformiert (The Idea of a Social Science, London 1958). Vgl. dazu: Werner Kogge: Die Grenzen des Verstehens. Kultur - Differenz - Diskretion, Weilerswist 2002, S. $102-109$.

144 Weisen der Welterzeugung ist der deutschsprachige Titel von Nelson Coodmans Buch Ways of Worldmaking, Indianapolis 1978.

145 Claude Lévi-Strauss: Das Ende des Totemismus, Frankfurt a.M., 1965, S. 116. Vgl. zur Intelligibilität klassifikatorischer Ordnungen auch Claude Lévi-Strauss: Das wilde Denken, Frankfurt a.M. 1973. 
Rationality-Debatte ${ }^{146}$ - und die Frage nach einer zeitgemäßen Ordnung des Seienden (griechisch: Ontologie), die nicht mehr von wesenhaften Eigenschaften der Dinge ausgeht (Substantialismus) beschäftigte seitdem die Gemüter.

Die Problemstellung des Strukturalismus erreichte allerdings die in ihrer Praxis tatsächlich vergleichend und ordnend arbeitenden Wissenschaften nur als punktuelle Verunsicherungen in der Weise, wie sie sich in der oben zitierten Einführung in die prähistorische Archäologie niederschlug. Man folgt der Einsicht, dass Typisieren und Ordnen keine unproblematischen wissenschaftlichen Aktivitäten sind, die sich aus den Eigenschaften der Dinge selbst ergeben, aber es fällt schwer, eine Abgrenzung zu dem am besonderen Gegenstand der Sprache gewonnenen Bild von Ordnung allererst generierender Ordnungen zu gewinnen. Das Wort Konstrukt, das sich in Folge des strukturalistischen und poststrukturalistischen Denkens Bahn brach, wird hier zur Selbstversicherungsformel wissenschaftlicher Reflexivität. Das Thema Konstruktivismus behandeln wir unten nochmal ausführlicher (siehe BASISWISSEN 13: Konstruktivismus - ein Schlagwort, unterschiedliche Bedeutungen).

Hier ist festzuhalten: die Verwirrungen um das Mega-Thema Konstruktivismus sorgten dafür, dass die Frage, wie ein kritisches Herangehen im Typisieren und Ordnen aussieht, häufig in den Hintergrund geriet. Löst man aber das taxonomische Denken von den großen Fragen nach der Beschaffenheit der Welt und der Einheit oder Vielfalt wahrer Weltauffassungen, so kommt ein methodologischer Kern zum Vorschein, der für unsere Fragestellung nach unterschiedlichen Wissenschaftstypen bedeutsam ist:

Schon Aristoteles hatte methodologische Fragen des Ordnens in Taxonomien angeschnitten, etwa in seiner Schrift Über die Teile der Lebewesen, auch Carl von Linné stellt seiner Systema Naturae methodische Überlegungen zu Begründetheit der taxonomischen Begriffe Klasse, Ordnung, Gattung und Art voran. ${ }^{147}$

146 Vgl. dazu Sigrid Frethlöh: Relativismus vs. Universalismus. Zur Kontroverse über Verstehen und Übersetzen in der angelsächsischen Sprachphilosophie: Winch, Wittgenstein, Quine, Aachen1989; Werner Kogge: Die Grenzen des Verstehens. Kultur - Differenz - Diskretion, Weilerswist 2002, Kap.: II.3.2 >Die Debatte um die Rationalität der Kulturen<, S. 109-117.

$147 \mathrm{Vgl}$. zu diesem Textteil in der komplexen Editionsgeschichte von Linnés Systema Naturae: Eintrag »Methodus«. In: Wikipedia, Die freie Enzyklopädie. Bearbeitungsstand: 
Einige für die vergleichenden und klassifizierenden Wissenschaften entscheidende Punkte hat der Historiker Marc Bloch in seinem Text Für eine vergleichende Geschichte der europäischen Gesellschaften (sowie einem Lexikonartikel zum Stichwort Vergleich) ${ }^{148}$ herausgestellt: Einer davon betrifft die Frage der Vergleichseinheiten. In den historischen Wissenschaften, so Bloch, werden häufig unreflektiert politische Einheiten vorausgesetzt, sodass etwa deutsche und französische Städte des Mittelalters miteinander verglichen werden, ohne dass beachtet wird, dass einige dieser Städte in ihrer Einheit von Bistum und Handelsstadt über Grenzen hinweg viel stärkere Gemeinsamkeiten aufweisen als mit anderen Städten der vorausgesetzten politischen Einheit. Dieses Beispiel zeigt, dass das Vergleichen und Klassifizieren nicht einfach als ein Sortieren in vorgefertigte Schubladen hinein betrachtet werden darf, vielmehr als eine Suche nach angemessenen Vergleichseinheiten, die auf Kenntnis und Klugheit beruht. Ein zweiter Punkt Blochs ist, dass das Vergleichen nicht mit einer naiven Suche nach Ähnlichkeiten, die sich allenthalben finden lassen, identifiziert werden darf. Ebenso wichtig wie Gemeinsamkeiten sind im Vergleichen Unterschiede. Gerade da, wo unkritisch »scheinbare Ähnlichkeiten ${ }^{149}$ - »Wieviele Unterschiede verbergen sich nicht allein hinter dem Wort `Adel!! s, schreibt Bloch - angenommen werden, kann der Vergleich Einheiten sprengen und lehren, neue Zusammenhänge zu sehen. Fern davon, das taxonomische Denken als naiv-substantialistisches Weltbild abtun zu können, halten wir fest, dass auch in ihm ein eigenes forscherisches Potential liegt; die Entstehung und Blüte einer Vielzahl komparatistischer Disziplinen lässt sich auch so verstehen.

18. Mai 2014.

148 Beide Texte finden sich abgedruckt in: Marc Bloch: Aus der Werkstatt des Historikers. Zur Theorie und Praxis der Geschichtswissenschaften, Frankfurt a.M. u.a. 2000. >Vergleich (im Orig. 1930); S. 113-121; >Für eine vergleichende Geschichte der europäischen Gesellschaften< (im Orig. 1928), S. 122-159.

149 Bloch, 2000, S. 121. 


\section{Die Rolle der Statistik: Daten, Mengen, Regelmäßigkeiten - und eine Irrfahrt ins Reich der Wahrscheinlichkeit}

Wenden wir uns nun der Statistik zu. Was ist Statistik? Vor allem: Haben wir es hier mit einer neuen Variante von Wissenschaft zu tun? Ist Statistik mehr als das, was wir vom taxonomischen Ansatz schon kennen: Daten nach Kategorien unterteilen und in Rubriken einordnen; typisieren und klassifizieren?

Ein Unterschied fällt ins Auge: beim Erstellen von Statistiken wird gezählt. Quantitative Verhältnisse und Prozentsätze erscheinen geradezu als Wesensmerkmal des Statistischen. Und dabei bleibt es nicht: Statistik ist heute nicht nur der Name für quantitative Datenerhebungen, sondern auch für eine mathematische Disziplin. Diese Mathematik ist es, die in vielen Statistik-Kursen, z.B. in der Psychologie, der Soziologie oder der Epidemiologie gelehrt und gelernt wird. Haben wir es also mit einer Anwendung mathematischer Verfahren auf Gegenstandsbereiche zu tun, ähnlich wie in der Physik? Oder ist der Einsatz solcher Verfahren eher eine Ausweitung der Methoden im sammelnden und ordnenden Wissenschaftsparadigma der Naturalis historiae?

Blicken wir auf gegenwärtige Debatten in diesem Feld, so fällt zweierlei auf: Erstens, dass das Erheben, Speichern und Verarbeiten von Daten mit steiler Konjunktur zugenommen hat; es sieht aus, als wäre statistisches Wissen auf ungebremstem Vormarsch. Zweitens aber wird Kritik an Standardverfahren der Statistik immer deutlicher vernehmbar: »Vorsicht Statistik! «150 heißt ein aktueller Titel eines Wissenschaftsmagazins, Das Einmaleins der Skepsis ein Buchtitel ${ }^{151}$, Significance Tests as Socery ein wissenschaftlicher Artikel. ${ }^{152}$ Vom »Fluch des P-Werts « liest man, von »statistischen Ritualen«, "mindless statistics« und "null science $« .{ }^{153}$ Ein Resumee zu einer breit angelegten Studie zu Statistik im Forschungsprozess lautet:

150 Spektrum der Wissenschaft. Physik, Mathematik, Technik, Spezial: Vorsicht Statistik! Vom Gesetz der großen Zahlen bis zu Klimarekorden, Heft 3(2017).

151 Gerd Gigerenzer: Das Einmaleins der Skepsis. Über den richtigen Umgang mit Zahlen und Risiken, München/Berlin 2015.

152 Charles Lambdin: >Significance tests as sorcery: Science is empirical - significance tests are not. In: Theory \& Psychology 22, 1 (2012), S. 67-90.

153 Uwe Saint-Mont: Statistik im Forschungsprozess. Eine Philosophie der Statistik als Baustein einer integrativen Wissenschaftstheorie, Heidelberg u.a. 2011, S. 93. 
»Im großen und ganzen stehen Naturwissenschaftler der >offiziellen Statistik« recht reserviert gegenüber [...] In den Sozialwissenschaften inklusive der Medizin wurden jedoch im Fahrwasser des Erfolgs quantitativer Methoden auch Hypothesentests und einige andere statistische Verfahren zum de facto Standard. Es sollte jedoch nicht verwundern, dass die Einsichten, welche man mithilfe der [...] >kochbuchartigen Schulstatistikı gewonnen hat, eher dürftig sind. [Man] verwendet [...] zwar fleißig ihre Begriffe und berechnet darüber hinaus emsig $p$-Werte und andere Statistiken, betrachtet dieses jedoch nicht ganz zu unrecht als lästige Pflichtübung. Statistik nach strengen Regeln betrieben hört sich wissenschaftlich an, beeindruckt mit exakten Zahlen, schwer verständlichen Argumenten und macht Arbeiten vor allem publikationsfähig. Primär aus diesen Gründen wird sie wohl von vielen Wissenschaftlern benutzt, nicht weil man ihren intrinsischen Forschungswert schätzte. ${ }^{154}$

Was ist hier schiefgelaufen? Zumindest ein Teil von Statistik scheint eher die Funktion $\mathrm{zu}$ haben, wissenschaftsförmige Effekte $\mathrm{zu}$ simulieren als wissenschaftliche Erkenntnisse zu produzieren. Und doch ist klar, dass so wichtige wissenschaftliche Vorhaben wie z.B. Klimamodelle, Bevölkerungsprognosen oder medizinische Studien auf Statistiken angewiesen sind. Die Situation - in sich so widersprüchlich - gibt zu vermuten, dass hier ein Fall von Selbstmissverständnis in den Wissenschaften vorliegt, eine Art Kategorienfehler in der Anlage von Studien, der durch unpassende Erwartungen erzeugt wird.

Sehen wir uns die Entstehung der aktuellen Situation an: Zunächst lässt sich feststellen, dass das, was wir heute Statistik nennen, aus der Kreuzung zweier unterschiedlicher Quellen hervorgegangen ist und sich mit der Zeit in mehrere, sehr verschiedenartige Felder ausdifferenziert hat. Die eine dieser beiden Quellen ist die sich in der Neuzeit ausprägende staatswissenschaftliche Statistik, die im Sammeln und Verarbeiten staatsrelevanter Daten besteht: Bevölkerungszahlen, Geburten, Todesfälle, Heiraten, Suizide, Körpergrößen von Rekruten - eine Vielzahl solcher Daten wurden erhoben und mussten dann auch geordnet, ausgewertet und dargestellt werden.

Diese Geschichte der Verwaltungspraktiken durch Daten verband sich nun im 19. Jahrhundert mit einer ganz anderen Entwicklung, nämlich der der Wahrscheinlichkeitstheorie oder Probabilistik. Diese wiederum hatte 
ihre Quelle in der mathematischen Behandlung von Glücksspielen und so nimmt es kaum Wunder, dass das Wort Statistik heute, neben seiner staatspolitischen Bedeutung, auch einen Zweig der Mathematik bezeichnet. ${ }^{155}$

Die gegenwärtige Rolle der Statistik wird aber erst verständlich, wenn wir ein drittes Moment in Rechnung stellen: nämlich das Entstehen einer Wissenschaft vom Sozialen. Zu Beginn des 19. Jahrhunderts formierten sich Anstrengungen, aus dem Wissen von der Gesellschaft eine veritable Gesellschaftswissenschaft zu formen, eine Physique Sociale sollte entstehen - Vorläufer dessen, was sich schließlich als 'Sociologie etablierte. Der Begründer der Physique Sociale war nun aber ein Statistiker. Adolphe Quetelet, zuvor Mathematikdozent und Direktor eines astronomischen Observatoriums (was für das Folgende nicht unwesentlich ist), bekleidete seit 1841 das Amt des Präsidenten der statistischen Zentralkommission Belgiens. Sehen wir uns an, wie Quetelet das Neuartige seines wissenschaftlichen Ansatzes darstellt:

Er fragt: „Erfolgen die moralischen und intellektuellen Handlungen des Menschen nach bestimmten Gesetzen? ${ }^{156}$ Und gibt als methodische Leitlinie an:

»Vor allem müssen wir vom einzelnen Menschen abstrahieren und dürfen ihn nurmehr als einen Bruchteil der ganzen Gattung betrachten. Indem wir ihn seiner Individualität entkleiden, beseitigen wir alles, was nur zufällig ist; die individuellen Besonderheiten, die wenig oder keinen Einfluß auf die Masse haben, verschwinden dann von selbst und lassen uns zu allgemeinen Ergebnissen gelangen. $\ll^{157}$

An dieser Stelle nun bietet Quetelet eine Analogie dar, die recht deutlich macht, welche Art von Wissen dieser Typ von Statistik hervorbringt. Er schreibt:

155 Zur Begriffsgeschichte und Diskursgeschichte vgl. Eintrag sStatistik in: Historisches Wörterbuch der Philosophie, Bd. 10, S. 39750-39768 (v. Petra Cehring).

156 Adolphe Quételet: Soziale Physik oder Abhandlung über die Entwicklung der Fähigkeiten des Menschen; n. d. Ausg. letzter Hand (1869) [im Orig. 1835] übers. v. Valentine Dorn u. eingel. v. Heinrich Waentig, 1. Bd., Jena 1914, S. 103.

157 Quételet, 1914, S. $103 f$. 
»So würde, um die Art unseres Verfahrens durch ein Beispiel sinnfällig zu machen, derjenige, welcher einen kleinen Abschnitt einer auf einer Fläche gezogenen sehr großen Kreislinie zu nahe prüfen würde, in diesem Bruchteil nichts weiter sehen, als eine bestimmte Menge materieller Punkte, die mehr oder weniger bizarr, mehr oder weniger willkürlich, mag die Linie im übrigen auch noch so sorgfältig gezogen sein, wie von ungefähr vereinigt sind. Aus größerer Entfernung würde sein Auge eine größere Anzahl Punkte überblicken, die er bereits regelmäßig auf einen Bogen von bestimmter Ausdehnung verteilt sehen würde; noch weiter zurücktretend, würde er bald keinen von ihnen mehr einzeln sehen, aber er würde das Cesetz begreifen, nach dem sie im allgemeinen angeordnet sind, und die Natur der gezogenen Kreislinie erkennen. $\ll^{158}$

Sehen wir uns das Erkenntnisparadigma an, das in dieser Analogie zum Ausdruck kommt: Die regelmäßige Form erscheint erst dann, wenn eine große Zahl von Elementen gleichzeitig in den Blick genommen wird. Dass dies hier durch Entfernung geschieht, ist nur der Analogie geschuldet. Entscheidend ist die große Zahl. Während das einzelne Element sich scheinbar regellos verhält, werden mit Blick auf eine große Zahl gleichartiger Elemente Regelmäßigkeiten sichtbar. In diesen Regelmäßigkeiten sieht Quetelet soziale Gesetze ausgedrückt. Doch um was für einen Begriff von Gesetz handelt es sich hier?

Quetelets erstes Beispiel sind Kriminalstatistiken aus französischen Gerichten. Die frappierend regelmäßige Anzahl der Morde und die gleiche Verteilung der dazu verwendeten Mittel offenbaren, so Quetelet, Gesetzmäßigkeiten der Gesellschaft. Doch wie drückt sich diese Gesetzmäßigkeit aus?

Die Analogie zur Kreislinie aus Punkten kann uns hier auf die richtige Spur bringen: Quetelet sucht weder - in der Tradition Euklids - nach einer Konstruktionsregel für Kreise, noch - in der Tradition Aristoteles' - nach prinzipiellen Bestimmungen von Kreisförmigkeit, vielmehr ist die Kreisform hier selbst das gesuchte Gesetz. Für ihn bedeutet Wissenschaft: in einer unübersichtlichen Mannigfaltigkeit die »Ordnung im Gange der Natur ${ }^{159}$ sichtbar zu machen. Wissenschaftliche Erkenntnis heißt hier also: die Wahrnehmung gestalthafter Ordnung in einer großen Zahl individueller Elemente. Und weil es bei dieser Form von Wissenschaft um Ordnungsgestalten geht, kann es auch nicht verwundern, dass Quetelet die Frage, ob 
Abb. 3: Verteilung von Verbrechensarten.

\begin{tabular}{|c|c|c|c|c|c|c|}
\hline & 1826 & 1827 & 1828 & 1829 & 1830 & 1831 \\
\hline Morde im allgemeinen. . . & 241 & 234 & 227 & 230 & 205 & 266 \\
\hline mittels Gewehr und Pistole. . & 56 & 64 & 60 & 61 & 57 & 88 \\
\hline $\begin{array}{c}\text { Säbel, Degen, Stilett, } \\
\text { Dolch usw. }\end{array}$ & 15 & 7 & 8 & 6 & 12 & 30 \\
\hline Messer . . . . . . & 39 & 40 & 34 & 46 & 44 & 34 \\
\hline Stock, Rohr usw. . . & 23 & 28 & 31 & 24 & 12 & 21 \\
\hline $\begin{array}{l}\text { Steine } \\
\text { schneidender, stechender } \\
\text { und zerschmetternder }\end{array}$ & 20 & 20 & 21 & 21 & 11 & 9 \\
\hline Instrumente . . . . & 35 & 40 & 42 & 45 & 46 & 49 \\
\hline $\begin{array}{l}\text { Erdrosselungen } \\
\text { durch in die Tiefe stürzen und }\end{array}$ & 2 & 5 & 2 & 2 & 2 & 4 \\
\hline ertränken . . . . . . & 6 & 16 & 6 & 1 & 4 & 3 \\
\hline durch Fuß- und Fauststöße. & 28 & 12 & 21 & 25 & 17 & 26 \\
\hline durch Feuer . . . . . . & 28 & 1 & 21 & 1 & 17 & 26 \\
\hline auf unbekannte Art und Weise & 17 & 1 & 2 & 1 & 2 & 2 \\
\hline
\end{tabular}

Quelle: Adolphe Quételet: Soziale Physik, S. 106.

die Statistik »als eine Kunst oder eine Wissenschaft anzusehen ${ }^{160}$ ist, mit Verweis auf die Botanik beantwortet, die sich durch ihre, über das bloße Sammeln und Beschreiben hinausgehende "tiefgründige Klassifikation « ${ }^{161}$ zur Wissenschaft erhob.

Gesetzmäßigkeit als Ordnungsgestalt: unschwer ist zu erkennen, dass wir es hier wieder mit dem Gegensatz zu tun haben, den wir im vorletzten Abschnitt als den zwischen einer beweisenden und einer deskriptiven Physik kennengelernt haben. Für die Deskriptivisten war entscheidend, jegliche nicht phänomenal auftretenden Kräfte als metaphysische Annahme zurückzuweisen. In diesem Sinne ist Quetelet zunächst reiner Deskriptivist. Er schreibt:

"Die Statistik beschäftigt sich mit einem Staate während eines bestimmten Zeitabschnittes; sie sammelt die auf das Leben dieses Staates bezüglichen Elemente, macht sie vergleichbar und stellt sie so zusammen, wie es für die

160 Quételet, 1914, S. 111.

161 Quételet, 1914, S. 112. 


\section{BASISWISSEN 12: Kausalität und Korrelation}

Die Problematik des Unterschiedes von Korrelation und Kausalität tritt beim Übergang von darstellender zu erklärender Statistik auf. Bereits bei Quetelet findet sich der Gedanke, dass durch Vergleich verschiedener Zahlenreihen sich verschiedene Ursachen für Phänomene erschließen lassen müssten. Beobachtet man z.B., dass die mittlere Lebensdauer an unterschiedlichen Orten unterschiedlich ist, so lässt sich danach fragen, welche Faktoren und Einflüsse diese Unterschiedlichkeit hervorbringen. Klima, Wohlstand, Ernährung, Städtebau: Der Vergleich der Daten zur Lebensdauer in Hinblick auf Unterschiede in diesen Faktoren könnte, so der Gedanke, Ursachen der Unterschiede in der Lebensdauer offenbaren. Doch schon Quetelet deutet an, welche Schwierigkeit in diesem Unterfangen liegt: »bis jetzt kennt man nur die Resultate verschiedener Kräfte, welche man nicht nur im einzelnen nicht messen, sondern nicht einmal vollständig aufzählen könnte.« (Quételet, 1914, S. 164)

Die Frage ist aber, ob im genuin statistischen Modell der Erkenntnis ein solcher Begriff von Ursache überhaupt eine Rolle spielen kann. Heinrich Waentig, ein deutscher Nationalökonom, der die Einleitung zu Quetelets Werk von 1914 verfasste, zieht es vor, nicht von Ursachen, sondern von Umständen zu sprechen. In der statistischen Wahrscheinlichkeitsberechnung werde nämlich der Ausdruck Ursache

»ohne irgend eine Bezugnahme auf eine vermutliche Kraft angewendet, die imstande wäre, ein gegebenes Resultat vermöge einer von ihr unzertrennlichen Tätigkeit hervorzubringen. Er bezeichnet nur die Veranlassung für die mehr oder weniger häufige Wiederholung eines Resultates und kann ebensogut in der Entfernung eines Hindernisses wie in einer direkten Handlung bestehen.«(Quételet, 1914, S. 12)

Erkenntnis aller Tatsachen, die sie uns enthüllen können, am vorteilhaftesten ist. ${ }^{162}$

162 Quételet, 1914, S. 112. 
Leider ist das Wort Umstand aus der Mode gekommen und man spricht stattdessen von Korrelationen. Der Unterschied zwischen Korrelation und Kausalität wird gerne an sinnfälligen Beispielen demonstriert, wie dem der statistisch auffälligen Korrelation zwischen Storchenpopulation und Geburtenrate: weniger Störche - weniger Geburten. Wer darin keinen Kausalzusammenhang vermuten möchte, der kann immerhin nach gemeinsamen Umständen suchen - wie etwa Urbanisierung, Industrialisierung etc.

Folgende Abbildung stammt aus einer Sammlung absurder Korrelationen, deren Korrelationskoeffizient hoch ist, ohne dass ein Zusammenhang vermutet werden könnte. Die Entwicklung nicht-kommerzieller Weltraummissionen korrespondiert hier beeindruckend mit der Zahl der Doktorats-Abschlüsse im Fach Soziologie (aus Tyler Vigen: Spurious Correlations. Correlation does not equal causation, New York 2015, S. 61).

Korrelation bezeichnet eine symmetrische, Kausalität eine asymmetrische Beziehung. Die Datenreihen, die miteinander korreliert werden, sind prinzipiell gleichwertig, erst die Deutung der einen als die Ursache für die andere macht daraus eine Kausalbeziehung. Und diese Deutung erfolgt extern, sie kann nicht selbst statistisch begründet werden.

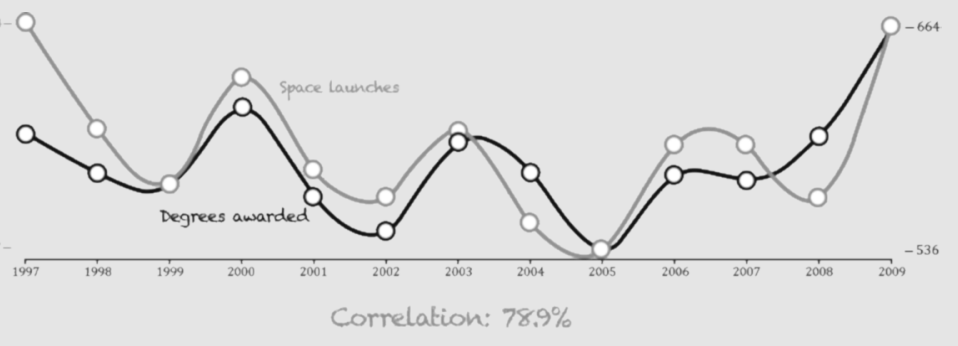

Das entspricht dem Bild, mit dem Quetelet ursprünglich das statistische Erkennen charakterisiert: In den Punktmengen sehen wir Ordnungszusammenhänge, jeder weitere Punkt, jede Hinzufügung von Daten verdeutlicht das Bild eines Zusammenhangs. Die Daten stehen in Beziehung zueinander, sie sind korreliert. In diesem Ordnungszusammenhang allerdings die einen Daten zu Ursachen der anderen zu erklären - dies ist ein bedeutender Schritt. 
Machen wir uns den Übergang von einer deskriptiven zu einer erklärenden Statistik an einem Beispiel klar. Noch einmal Quetelet: »Jeder soziale Zustand setzt also eine gewisse Zahl und eine gewisse Ordnung von Verbrechen voraus, die eine notwendige Folge seiner Organisation sind. ${ }^{163}$ Die Textstelle klingt zirkulär, in der Terminologie von Umständen liegen alle Daten auf der gleichen Ebene: die Häufigkeit von Verbrechen gilt z.B. als ein Umstand für ein prekäres soziales Milieu und ein prekäres soziales Milieu als ein Umstand für die Häufigkeit von Verbrechen. In einem schwachen Sinn kann man auch hier davon sprechen, dass das eine die Ursache des anderen ist. Doch die Beziehung ist symmetrisch und ergibt als Ganzes ein Bild, das sich konzeptuell fassen und durch Daten begründen lässt.

Verwendet man nun aber einen starken Begriff von Ursache, sodass z.B. das soziale Milieu als Ursache für eine Zahl von Verbrechen gedacht wird, so fügt man die Daten in ein asymmetrisches Verhältnis zueinander: die einen bezeichnen die Ursachen, die anderen die Wirkungen. Nun stellt sich eine ganz andere und neue Frage, die im deskriptiv-naturgeschichtlichen Paradigma überhaupt nicht auftaucht, oder aber strikt abgelehnt wird: welche Regel, welcher Mechanismus liegt der Bewirkung des Effekts aus den Ursachen zugrunde?

Das frühe 20. Jahrhundert ist nun die Epoche, in der die neue Sichtweise sich etablierte und mathematisch ausformuliert wurde. Nun geht es nicht mehr um eine Menge von Phänomenen (ob sie nun Punkte am Himmel, Körpergrößen oder Morde waren), sondern um Anzahlen von Experimenten bzw. Beobachtungen und den sich daraus ergebenden Daten.

Symptomatisch für den Übergang ist der neue Gebrauch des Begriffs Population. So liest man:

»Der Begriff Population ist nicht nur auf lebende oder auch nur materielle Dinge beschränkt. Wenn eine Beobachtung, wie beispielsweise eine einfache Messung, unbegrenzt oft wiederholt wird, so ist die Gesamtheit dieser Ergebnisse die Population der Messungen. $\aleph^{164}$

163 Quételet, 1914, S. 107.

164 Ronald A. Fisher/Dora Lucka: Statistische Methoden für die Wissenschaft, Edinburgh [u.a.] 1956, S. 2. 
Die wichtigste Frage, für die Statistik nun zuständig wird, ist, wie viele Beobachtungen notwendig sind, um einen hinreichenden Beleg für eine allgemeine Regel zu erhalten; oder umgekehrt: wie aussagekräftig (»signifikant«) eine bestimmte Datenmenge für eine bestimmte Regelannahme ist. Nullhypothese, P-Wert und Signifikanztest sind die Begriffe, die das Feld der Statistik von nun an beherrschen. Sie haben ihre Quelle in der mathematischen Wahrscheinlichkeitstheorie und finden nun ihre Anwendung in einem bestimmten Typ von >Experiment‘, nämlich dem Prüfexperiment.

Die Geschichte der mathematischen Wahrscheinlichkeitstheorie ist gut erforscht. In einer Reihe von Studien lässt sich nachlesen, wie sich von Pascal, Leibniz und Bernoulli (Jakob) bis zu Laplace und Bayes im 17. und 18. Jahrhundert eine elaborierte mathematische Wahrscheinlichkeitstheorie entwickelte. ${ }^{165}$ Im 19. Jahrhundert nun verbindet sich diese Theorie mit der Praxis der staatlichen Statistik und damit mit der Erhebung und Sammlung großer Mengen empirischer Daten. Von diesem Zeitpunkt an entstand eine Dynamik, in der es immer häufiger so aussah, als ob es gerade Statistik wäre, was Wissenschaft ausmacht - bis nun, in jüngster Zeit, die Rolle von Statistik tiefgreifend fragwürdig wurde.

\section{$\checkmark$ VERTIEFEND Der (Irr-)Weg der Statistik}

Um uns deutlich zu machen, was hier passiert ist und welche Rolle wir der Statistik in den Wissenschaften zuzuschreiben haben, schauen wir uns systematisch einige entscheidende Schritte auf diesem Weg an.

Gehen wir aus von dem einfachsten Fall, den wir kennen gelernt haben: die Kriminalstatistiken Quetelets - wie oben abgebildet. Solche Statistiken fixieren schlichte Daten: Jahr für Jahr wird die Anzahl der Fälle notiert. Übertrüge man die Zahlen in die Form eines Liniendiagramms, so ließe sich eine Linie auftragen, deren nur leichte Schwankungen nach oben und unten die Regelmäßigkeit bezeugt, die Quetelet so imponierte.

Etwas anders verhält es sich schon mit den Körpergrößentabellen, die wir ebenfalls bei Quetelet finden. (Abb. 5) Die Zahlen, die sich in der zwei-

165 G. Gigerenzer/Z. G. Swijtink/T. Porter/L. Daston/J. Beatty/L. Krüger (Hrsg.): Das Reich des Zufalls: Wissen zwischen Wahrscheinlichkeiten, Häufigkeiten und Unschärfen. Heidelberg 1999, S. 19. 
Abb. 5: Größenverteilung von Rekruten.

\begin{tabular}{|c|c|c|c|c|c|c|}
\hline \multicolumn{3}{|c|}{$\begin{array}{c}\text { Größenmaße nach } \\
\text { Metern }\end{array}$} & \multirow{4}{*}{$\begin{array}{c}\text { Zahl der Gezählten } \\
\text { nach dem Größen- } \\
\text { unterschied von } \\
0,0255 \mathrm{~m} \\
\\
\\
4 \\
1\end{array}$} & \multicolumn{2}{|c|}{$\begin{array}{l}\text { Verhältnis der Größe } \\
\text { von } 1000 \text { gemessenen } \\
\text { Eingeschriebenen }\end{array}$} & \multirow[t]{2}{*}{$\begin{array}{c}\text { Unterschied } \\
\text { zwischen den } \\
\text { beobachteten u. } \\
\text { berechneten Werten }\end{array}$} \\
\hline & & & & beobachtet & gemessen & \\
\hline \multicolumn{3}{|c|}{1,397 und darunter } & & \multirow{6}{*}{1} & \multirow{6}{*}{2} & \multirow{6}{*}{-1} \\
\hline 1,422 & " & “ & & & & \\
\hline 1,448 & “ & “ & 3 & & & \\
\hline 1,473 & $"$ & “ & 7 & & & \\
\hline 1,499 & “ & “ & 6 & & & \\
\hline 1,524 & $"$ & “ & 10 & & & \\
\hline 1,549 & $"$ & “ & 15 & 1 & 3 & -2 \\
\hline 1,575 & $"$ & “ & 50 & 2 & 9 & -7 \\
\hline 1,600 & $"$ & “ & 526 & 20 & 21 & -1 \\
\hline 1,626 & “ & “ & 1237 & 48 & 42 & +6 \\
\hline 1,651 & $"$ & “ & 1947 & 75 & 72 & +3 \\
\hline 1,676 & $"$ & “ & 3019 & 117 & 107 & +10 \\
\hline 1,702 & “ & “ & 3475 & 134 & 137 & -3 \\
\hline 1,727 & “ & $"$ & 4054 & 157 & 153 & +4 \\
\hline 1,753 & “ & “ & 3631 & 140 & 146 & -6 \\
\hline 1,778 & $"$ & $"$ & 3133 & 121 & 121 & 0 \\
\hline 1,803 & $"$ & $“$ & 2075 & 80 & 86 & -6 \\
\hline 1,829 & $"$ & $"$ & 1485 & 57 & 53 & +4 \\
\hline 1,854 & “ & “ & 680 & 26 & 28 & -3 \\
\hline 1,880 & “ & $"$ & 343 & 13 & 13 & 0 \\
\hline 1,905 & “ & $"$ & 118 & 5 & 5 & 0 \\
\hline 1,930 & " & “ & 42 & 2 & 2 & 0 \\
\hline 1,956 & “ & “ & 9 & & & \\
\hline 1,981 & “ & “ & 6 & 1 & 0 & +1 \\
\hline 2,007 & " & $“$ & 2 & & & \\
\hline \multicolumn{3}{|c|}{ Zusammen } & 25878 & 1000 & 1000 & $\begin{array}{l}-28 \\
-28\end{array}$ \\
\hline
\end{tabular}

Quelle: Quételet: Soziale Physik, S. 145.

ten Kolumne dieser Tabelle finden (die weiteren können wir zunächst außer Acht lassen), sind schon keine Anzahlen von Gegenständen und Ereignissen in der Welt mehr, sondern Zahlen, die sich auf Zahlen beziehen: Man sortiert die gemessenen Körpermaße in Gruppen und schaut sich dann an, wie viele Messungen sich in jeder Gruppe jeweils finden. Das ist die Zahl in der zweiten Spalte. Natürlich lässt sich an dieser Darstellung das empirische Phänomen noch erkennen: wir können uns vorstellen, dass die 25878 Rekruten nach ihrer Körpergröße in Gruppen aufgeteilt und sodann die Gruppen der Größe 
der Gruppe nach aufgestellt würden. Abgesehen von praktischen Schwierigkeiten ist dies denkbar - und doch wird hier schon kenntlich, dass im Interesse nicht mehr an der Größe der Rekruten, sondern an der Größe der Gruppen (gebildet nach Größen der Rekruten) ein spezielles, theoretisches Interesse durchscheint.

Dieses theoretische Interesse sieht nun wiederum sehr schlicht und einfach aus, wenn man diese Daten - wie es Quetelet auch tat - in einer Kurve darstellt. (Abb. 6)

Abb. 6: Gausssche Darstellung.

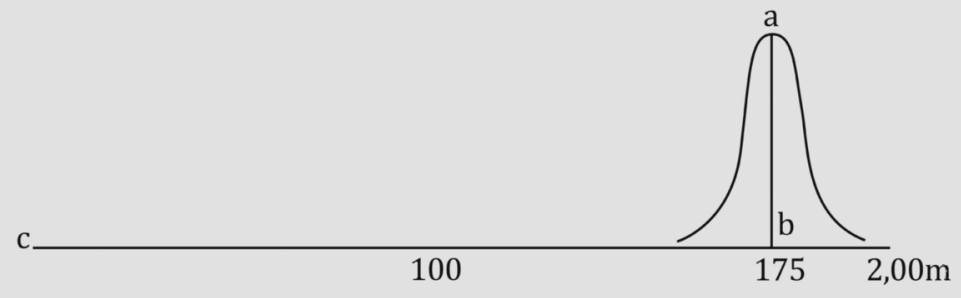

Quelle: Quetelet: Soziale Physik, Figur 1, S. 146.

Quetelet verwendet hier die Darstellungsform der Gaussschen Normalverteilung. Sie macht sichtbar, welche Werte am häufigsten auftreten und welche Abweichungen von der häufigsten Form in welcher Zahl vorgefunden werden.

Die Frage nach der Häufigkeitsverteilung ist nun der Punkt, an dem sich die beiden Traditionsstränge, die staatliche Statistik und die Wahrscheinlichkeitstheorie, getroffen haben. Wie es der staatlichen Statistik um die Häufigkeiten sozialer Phänomene ging, so den Wahrscheinlichkeitstheoretikern um die Häufigkeiten von Ergebnissen. Für beide ergab es sich, dass die gesuchte Regelmäßigkeit in der großen Zahl liegt: für die einen in der großen Menge sozialer Gegebenheiten, für die anderen in der großen Menge der Ereignisse (z.B. der Ziehungen von Kugeln). Jeweils stabilisiert sich der Wert des Gesamten mit der steigenden Zahl der Daten.

Was nun kann eine Wissenschaft an der Verteilung von Häufigkeiten interessieren? Dass diese Frage im Glücksspiel, im Versicherungswesen und in der Risikoabschätzung von Belang sind, liegt auf der Hand. Aber was hat dies mit Wissenschaft zu tun? 
Hier nun tritt das Thema der Ursachenforschung auf den Plan, mit ihrer gänzlich neuen Fragestellung in diesem Feld! Ursachenforschung bedeutet ja (auf die schlichteste Formel gebracht) zu fragen, unter welchen Bedingungen A auftritt und ob A ausbleibt, wenn eine bestimmte Bedingung nicht gegeben ist.

Wie hier, im Feld der Ursachenforschung, sich das Problem der Statistik weiterentwickelte, machen wir uns an einem Beispiel klar, das Ronald A. Fisher, einer der Gründungsväter der modernen Statistik, in seiner einführenden Darstellung benutzt. (Abb. 7)

$A b b .7$

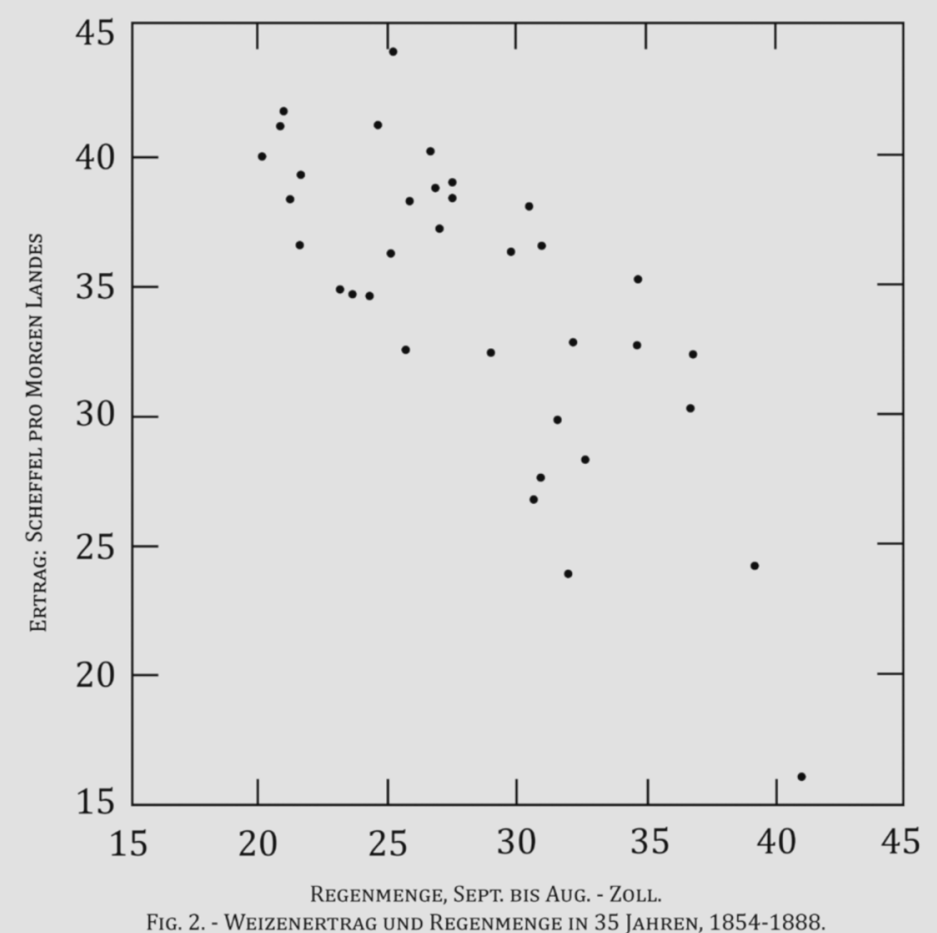

Quelle: Fisher: Statistische Methoden, S. 31.

Diese Darstellung zeigt ein Korrelations-Diagramm von Regenmengen und Ernteerträgen. Und auch hier gilt wie schon oben: den Punkten im Diagramm entsprechen keine unmittelbaren empirischen Gegebenheiten. Un- 
mittelbare Daten aufzuzeichnen, sähe in diesem Fall so aus, dass wir Jahr für Jahr die Regenmenge und Jahr für Jahr den Ernteertrag notieren. Diese Notate könnten als Punkte jeweils in ein Koordinatensystem eingetragen und zu Linien verknüpft werden. Die beiden Linien könnten sodann miteinander verglichen werden und man könnte nach Übereinstimmung in den Kurven suchen. Eine solche Darstellung stünde genau auf der Grenze zwischen Quetelets Ordnungserkenntnis in Punktmengen und einer ursachenbezogenen Sichtweise. Allerdings: Wie sich schon am Beispiel von Geburtenrate und Storchpopulation zeigte, können solche Korrelationen nur indirekt kausal oder sogar rein zufällig sein.

Fishers Punktmenge ist tatsächlich keine, in der man empirische Ordnungen dargestellt findet. Jeder einzelne dieser Punkte ist schon die Darstellung einer Verhältnisgröße. Er stellt weder den Ernteertrag noch die Regenmenge dar, sondern stets schon das Verhältnis von Ernteertrag und Regenmenge. Dieses Verhältnis ist erschlossen, nicht gegeben. In einem strengen Sinne haben wir es bei den Punkten daher nicht mehr mit Daten zu tun, vielmehr mit Resultaten von Operationen mit Daten. Das Suggestive besteht nun darin, dass die Punkte immer noch wie Daten aussehen. Es scheint so, als ob die Verknüpfung von Regenmenge und Ernteertrag eine empirische Tatsache ist. Die Suggestion kommt zustande, weil man dem Punkt nicht ansieht, dass er seinen Charakter wesentlich verändert hat. Es sieht so aus, als ob jeder Punkt eine reale Gegebenheit anzeigt und als ob alle Punkte zusammen eine Regelmäßigkeit in der Wirklichkeit anzeigten. Tatsächlich aber zeigen sie das Ergebnis einer In-Beziehung-Setzung an: Wenn wir den Ernteertrag zur Regenmenge in Beziehung setzen, dann erscheint das (hier sichtbare) Resultat.

Dieses Resultat kann aber aus unterschiedlichen Gründen eine Ordnung aufweisen. Zum einen ganz zufällig: In der Korrelation vieler empirischer Verläufe werden immer wieder zufällig ähnliche Verläufe und damit Gestalttendenzen in der Punktmenge auftreten (siehe Abb. in BASISWISSEN 12). Zum anderen, weil die >korrelierten Daten gar nicht unabhängig voneinander sind, sondern einem gemeinsamen Ursachenzusammenhang angehören, der aber nicht durchschaut wird (z.B., dass bei häufigem Regen die Bauern weniger Unkraut jäten o.ä.). Außerdem ist hier offen, ob nicht andere Faktoren, die nicht bedacht werden, mit dem Ernteertrag viel stärker in Beziehung stehen als die Regenmenge. Die Korrelationswerte kommen also durch eine Operation zustande, die auf der Annahme beruht, dass es eine bedeutende ursächliche Beziehung zwischen Ernteertrag und Regenmenge gibt. 
Entsprechend vorsichtig drückt sich Fisher an dieser Stelle auch aus:

Es »kann ein Punkt-Diagramm Assoziationen anregen, die bis dahin nicht vermutet worden waren, oder, was ebenso wichtig ist, die Abwesenheit von Assoziationen darstellen, die bis dahin zuversichtlich vorausgesagt worden waren. Der Wert der Punkt-Diagramme besteht darin, dass sie eine einfache Übersicht über die bisher gesammelten Erfahrungen und dem Ceist Anregungen geben, die experimentellen Untersuchungen zugänglich sind..166

Lesen wir genau, was Fisher hier schreibt: die Punkte im Diagramm geben Anregungen für Experimente. Statistik in diesem Sinne wäre ein Instrumentarium innerhalb experimenteller Forschung. Als heuristischer Einsatz kann sie der experimentellen Laborforschung Hinweise geben, aber sie ist als solche nicht geeignet, experimentelle Ergebnisse zu beurteilen.

Doch genau dieses Verhältnis zwischen mathematischer Datenbehandlung und experimenteller Forschung kehrt sich in der modernen Statistik um. Es scheint nun so, als ob mathematische Operationen mit Daten dazu geeignet wären, empirische Annahmen zu validieren, das heißt: darüber zu entscheiden, welche empirische Annahme in welchem Maße gerechtfertigt ist. Und damit auch: die Gültigkeit von Annahmen im Sinne des Grades von Wahrscheinlichkeit zu beweisen.

Am deutlichsten zeigt sich diese Aufladung des Anspruchs am sogenannten P-Wert, der im Zentrum der modernen Statistik - und der Debatte über sie - steht. Fisher hatte diesen Wert als ein Maß für die Abweichung von der Standard-Verteilung eingeführt. Graphisch betrachtet handelt es sich sozusagen um die Fläche des Kurvenendes der Häufigkeitsverteilung. (s. Abb. 8)

Es sind mehrere Aufstufungen, mit denen aus Daten ein P-Wert erzeugt wird. Im ersten Schritt werden - wie soeben gesehen - zwei Datensätze korreliert und zu einem vereinigt. Im zweiten Schritt wird diese resultierende Datenmenge nun daraufhin betrachtet, ob sich in ihr eine regelhafte (Un-) Gleichverteilung findet, sodass ein Regelzusammenhang erkennbar wird (z.B. je weniger Regen, desto mehr Ernte). Dargestellt wird dies, indem eine Linie in das Punktdiagramm eingezeichnet wird, wie beispielsweise in Abb. 9.

166 Ronald A. Fisher: Statistische Methoden für die Wissenschaft, Edinburg/London 1956 (12. neu bearb. u. erw. Aufl.) (im Orig. 1925), S. 31f. 
Abb. 8: Darstellung des p-Werts.

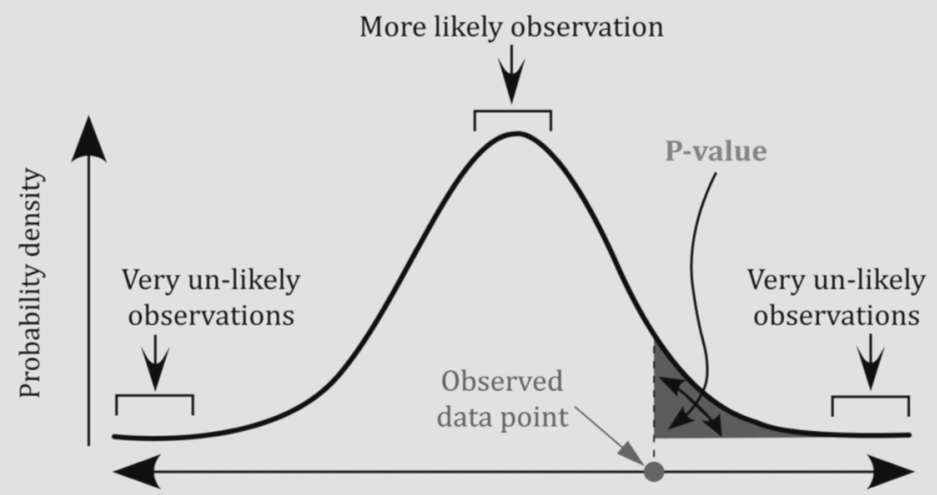

Set of possible results

A p-value (shaded green area) is the probability of an observed (or more extreme) result assuming that the null hypothesis is true.

Quelle: Wikipedia

Abb. 9: Linien-Darstellung von Korrelationen.

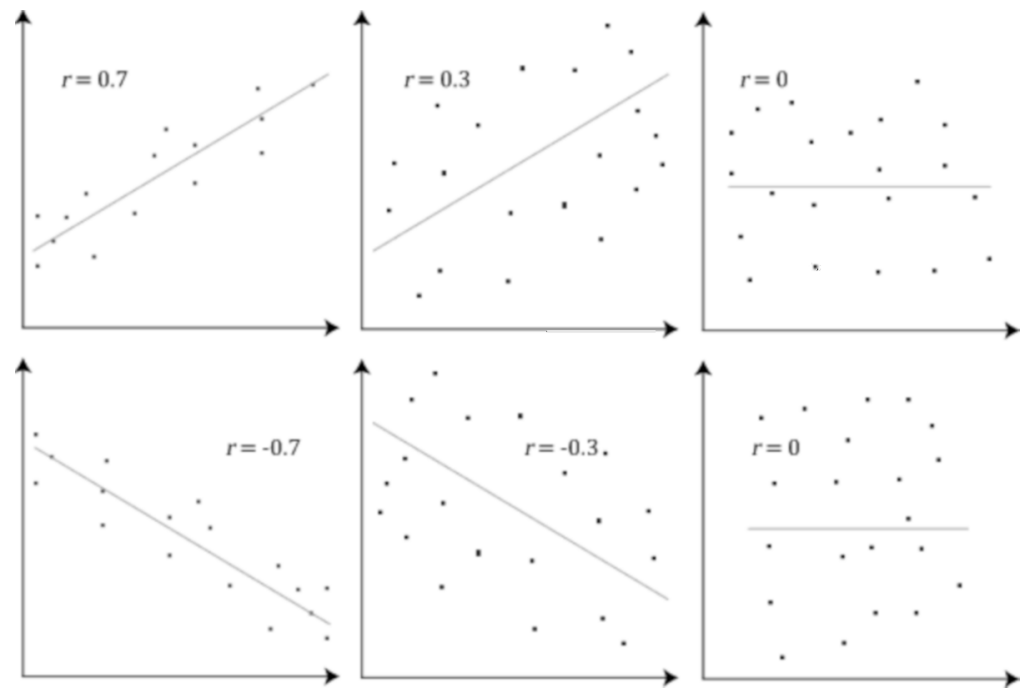

Quelle: Wikipedia 
Im dritten Schritt wird diese resultierende Regelannahme, die aufgrund von Daten gewonnen wurden, die aus einer Beziehungsannahme stammen (so kompliziert müssen wir das sagen!), in der Weise näher bestimmt, dass das Maß, in dem die einzelnen Daten (Punkte) der ermittelten Regel entsprechen, berechnet wird. Damit wird erschlossen, wie gut die einzelnen Daten zu der Regelmäßigkeit passen, die sich aus ihnen ergeben hat. Es wird also die Streubreite der Daten bestimmt. Im nächsten Schritt wird nun diese Streubreite verglichen mit der Streubreite von Daten, die schon aufgrund einer zufälligen Verteilung - oder aufgrund von Messfehlertoleranzen - zu erwarten gewesen wäre. Warum man dies tut, ist klar: Man möchte ein Maß für die Besonderheit der angenommenen Korrelation an die Hand bekommen, ein Maß, mit dem sich zeigen lässt, dass diese angenommene Korrelation den Bereich der zufälligen Streuung von Daten übersteigt. Dazu dürfen Werte, die außerhalb der normalen Abweichung liegen, nur relativ selten auftreten. Weil man diese relative Regelmäßigkeit nur im Vergleich erkennen kann, kehrt man die gesamte gedankliche Versuchsanordnung um: Man geht von der Annahme aus, dass sich in den zueinander in Beziehung gesetzten Größen gerade keine spezifische Korrelation findet - dass die abweichenden Werte also nur dem Zufall geschuldet sind (Nullhypothese) - und vergleicht die aus den Daten gewonnenen Abweichungswerte mit diesen zufallsbedingten: der P-Wert bemisst nun die Größe des Unterschiedes zwischen diesen beiden Abweichungssummen.

Die Debatte um den P-Wert dreht sich nun unter anderem um die Frage, wie groß dieser Unterschied sein muss, damit das Ergebnis signifikant ist. ${ }^{167}$ Doch abgesehen von solchen Fragen haben wie es hier bei diesem Vorgehen mit einigen wesentlich tiefer liegenden Problemen zu tun. Woher nämlich kennen wir denn die zzufällige Wahrscheinlichkeitsverteilung? In unserem Beispiel: Woher wissen wir denn, in welcher Streuung die Ernteerträge schwanken - abgesehen von Unterschieden in der Regenmenge? Wir müssten langfristige Messreihen zur Verfügung haben, in denen die Regenmenge konstant gehalten werden könnte. Damit ist klar, dass wir eine experimentelle Versuchsanordnung benötigen, die es erlaubt, Faktoren probeweise anund abzuschalten. Die Situation wird dadurch erschwert, dass wir ja auch aus langfristigen Messreihen nicht ersehen können, ob sie einer nur zufälli-

167 Vgl. Ronald L. Wasserstein/Nicole A. Lazar: >The ASA Statement on $p$-Values: Context, Process, and Purpose. In: The American Statistician, 2 (2016), S. 129-133. 
gen Streuung unterliegen - oder ob nicht vielmehr andere kausale Faktoren, die in ungewöhnlicher Weise auftreten (z.B. Schwankungen in der Bienenpopulation), eine ungewöhnliche Verteilung der Werte hervorrief.

Damit zeigt sich auch das Grundproblem der Anwendung der mathematischen Verfahren in der Statistik: Diese Verfahren sind aus Spielsituationen gewonnen, in denen die möglichen Resultate durch die geschlossene Struktur der Spielanlage bestimmt sind. Stellen wir uns vor, wie wir von einer Spielsituation wie dem Würfelspiel zu einer Problemstellung gelangen, wie sie sich in der Soziologie, der Medizin oder in den Agrarwissenschaften darstellt. Dazu müssten wir von einem Würfel ausgehen, der nicht nur zufällig und mit gleicher Wahrscheinlichkeit verschiedene Resultate liefert, sondern von einem, der unterschiedlichsten kausalen Einflüssen ausgesetzt ist, die jeweils die Tendenz der Ergebnisse beeinflussen; der sich also, in Abhängigkeit von vielen, selbst veränderlichen, teils womöglich unbekannten, teils interdependenten Faktoren immer wieder anders verhält. Regelmäßigkeiten wären zu beobachten, aber jede weitergehende Erklärung des Würfelverhaltens würde voraussetzen, dass das Bedingungsgefüge dieses Verhaltens im $\mathrm{Zu}$ sammenspiel seiner konstanteren und variableren Faktoren verstanden wäre.

Die an limitierten Spielsituationen gewonnene Mathematik ist somit einer bestimmten Idee von wissenschaftlicher Forschung entgegengesetzt: Während es in der - emphatisch aufgefassten - Forschung gerade darum geht, noch unerkannte oder unzureichend verstandene Faktoren aufzudecken, in ihrer Wirksamkeit und in ihrem Zusammenspiel theoretisch oder modellhaft zu erfassen, fragt dieser Typ von Statistik - gleichsam mechanisch - die Rolle von Einzelfaktoren ab. Man glaubte, auf ein Verständnis der Wirkungszusammenhänge verzichten zu können, weil ja - so schien es - sich an den Daten selbst Regelmäßigkeiten ablesen und das Maß der Regelmäßigkeiten bestimmen ließ. Doch dass in diesem Prozedere an mehreren Stellen quasi-theoretische Annahmen in Gebrauch genommen werden - erstens schon bei der Wahl der gemessenen Größen, zweitens bei der Wahl der untersuchten Korrelation und, drittens, bei der Bestimmung der Vergleichsebene - dass diese Statistik also nicht theoriefrei, sondern latent hochgradig theoretisch ist und dabei auf schwachen Beinen steht, das wurde übersehen. So absurde Ergebnisse, wie sie die P-Wert-geleitete Forschung produziert (indem z.B. eine signifikante Korrelation zwischen politischer Gesinnung und physiologischer Fähigkeit, 
Grauschattierungen wahrnehmen zu können, festgestellt wird). ${ }^{168}$ haben ihren Grund in einer Verfahrensweise, in der man meint, aus Daten Schlüsse auf Regeln ziehen zu können, ohne dazu irgendein Verständnis des Regelzusammenhangs entwickeln zu müssen. Das sogenannte P-Hacking ist die Endstufe einer Entwicklung, in der sich ,Wissenschaft‘ von Intelligibilität löst. ${ }^{169}$

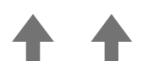

Unbenommen von der tiefliegenden Problematik probabilistischer Verfahren bleibt aber der Wert der Statistik im Allgemeinen. Geht es darum, Regelmäßigkeiten der Erscheinungen zu beobachten und aufgrund dieser Beobachtungen Prognosen anzustellen, so kann dieses Vorgehen einer kausalanalytischem auch überlegen sein. Steven Toulmin erläutert dies am Beispiel der - so von ihm angenommenen - Diskrepanz zwischen babylonischer und griechischer Astronomie. Während erstere aufgrund ihrer arithmetischen Kompetenzen »ein bedeutendes Vorhersagevermögen « ${ }^{170}$ ausbildeten, entwickelten zweitere durch »den Gebrauch der spekulativen Phantasie« eine »theoretische Basis«, die »zu einer Deutung der Himmelsbewegungen kommt « ${ }^{171}$, aber in Sachen Prognostik hinter ersterer zurückbleibt.

Ganz analog geht es bei den Clustering-Ansätzen in Big Data Analysen darum, potenziell relevante Muster zu erkennen, um Prognosen anstellen zu können. ${ }^{172}$ Bleibt dieser Ansatz innerhalb seiner Grenzen, dann hat er einen bedeutsamen praktischen Wert. Statistik zeigt sich dann als ein Mittel, Unterschiede und Gemeinsamkeiten in großen Datenmengen zu detektieren. Sind die Datenmengen klein, genügt das Gedächtnis oder einfache visuelle Darstellung, um solche Verhältnisse sichtbar und einschätzbar zu machen. Mit dem Anwachsen der Datenmenge verlieren wir diese Möglichkeit aber sehr schnell und es zeigt sich, wie sich die mathematische Statistik als ein Instrumentarium der Forschung bewährt: Wie das Teleskop und das

168 Regina Nuzzo: Fehlerschätzung. Der Fluch des P-Wertes. In: Spektrum Spezial 3 (2017) (zunächst in Heft 9 (2014)), S. 32-36, hier S. 32.

169 Vgl. Nuzzo, 2014, S. 32-36.

170 Stephen Toulmin: Voraussicht und Verstehen. Ein Versuch über die Ziele der Wissenschaft, Frankfurt a.M. 1968, S. 36.

171 Toulmin, 1968, S. 36.

172 Vgl. Harald Binder/Maria Blettner: Big data in medical science-a biostatistical view. In: Deutsches Ärzteblatt International 112, 9 (2015), S. 137-142. 
Mikroskop die Bereiche des Sehr-Entfernten und des Sehr-Kleinen zugänglich machen, so erschließt die mathematische Statistik den Bereich des SehrVielen, der großen Mengen.

Anders gesagt: Bleibt die Statistik in ihrem Selbstverständnis im Paradigma der Naturalis Historia, dann ist sie ein wertvolles Instrumentarium. Gibt sie aber vor, an wirklichem Experiment und sorgfältiger Interpretation vorbei Beweiskraft für Thesen bieten zu können, dann führt sie in die Irre und suggeriert eine Leistung, die sie nicht erbringen kann. 
